Aus dem zoologischen Institut der Universität Kiel.

Ueber die

Nahrung von Thieren aus der

\title{
Kieler Bucht.
}

\section{Inaugural-Dissertation}

zur Erlangung der Doktorwürde

der philosophischen Fakultät

der Königl. Christian-Albrechts-Universität \%u Kiel

vorgelegt

vous

\section{Ernst Rauschenplat}

aus Cuxlraven.

Opponenten:

Herr Dr. mecl. Grolwahl,

" cand. pluil. Lesclake.

- . med. Tiedemann.

$$
\text { Kiel. }
$$

Druck von Schuidt \& Klaunig. 1901. 

Ueber die

Nahrung von Thieren aus der

\section{Kieler Bucht.}

\section{Inaugural-Dissertation}

\section{zur Erlangung der Doktorwürde}

der philosophischen Fakultät

der Königl. Christian-Albrechts-Universität zu Kiel

vorgelegt

voll

\section{Ernst Rauschenplat}

aus Cuxhaven.

Opponenten:

Herr Dr. med. Grotwahl,

- cand. phil. Lesclike,

n $\quad$ med. Tiedemann.

Kiel.

Diuck von Schmidt \& Klaunig.

1901. 
Nr. $1 \mathrm{~s}$

Rektoratsjalı 19001901.

Zum Druck genehmigt:

Dr. L. Weber,

d. Z. Dekan. 


\section{Meinen lieben Eltern}

in Dankbarkeit 



\section{Einleitung.}

Die Nahrung der für den Menschen nützlichen Meeresthiere ist vielfach untersucht worden und deshalb in Allgemeinen bekannt. So finden sich zum Beispiel in den Werken von Kröyer, Günther, Möbius und Heincke, Cunningham, Mc'lntosh Zusammenfassungen der Resultate von Untersuchungen über die Nahrung der Nutzfische. Bezüglich der niederen Thiere dagegen, die den Nutzthieren zur Nahrung dienen, finden sich in der Litteratur 1 ur zerstreute Angaben in dieser Hinsicht. Daher habe ich die gemeinsten Arten der Wirbellosen sowie einige besonders häufige kleine Fische der Kieler Fölrde auf ihre Nahrungsweise untersucht, und die eiuschlägige Litteratur nach Möglichkeit zusammengestellt.

Die nachstehende Uebcrsicht giebt die Arten an, welche ich selbst untersuclit habe und ausserdem in Parenthese diejenigen, über welche nur nach Litteraturangaben Znsammenstellungen gemacht sind. Die Anzahl der mntersuchten Exemplare habe ich hinter dem Speziesnamen angegeben, damit jeder sich ein Urtheil bilden kann, wie weit meine Schlüsse berechtigt sind.

\section{Coelenterata.}

Aurelia alurita L. . . . . . . etwa 20

Scyphostoma . . . . . . . . 15

Gonothyraea Lovenii Allman. . . etwa 10

Cordylophora lacustris Allman. . etwa 10 (Actinia).

\section{Echinodermata.}

Asteracanthion rubens L. . . . etwa 20

Ophioglypha albida Forb. . . . . 42

\section{Vermes.}

Priapulus caudatus Lamarck. . . . 16

Halicryptus spinulosus v. Sieb. . . 10

Pectinaria belgica Pallas. . . . . 14

Terebellides Stroemii Sars. . . . . 11

Polydora ciliata Müller. . . . einige

Spirorbis nautiloides Lamarck. . etwa 10

Amphitrite Johnstonii Malmgren.. . 7

Flabelligera affinis M. Sars. . . . 9

Nephthys . . . . . . . . . 15

Nereis diversicolor Müller. . . . . 20

Nereis pelagica L. . . . . . . . 2
Harmothoe imbricata L. . . . . 13

Lepidonotus squamatus L. . . . 12

Arenticola marina L. . . . . . etwa 20

\section{Crinstacea.}

Balanus crenatus Brugière . . . 13

Balanus improvisus Darwin. . . . 18

Gammarus locusta L. . . . . . . 38

Amathilla Sabinei Leach. . . . . 11

Amphithoe podoceroides Ratlıke. . 6

Orchestia litorea Montagu. . . . . 10

Idothea tricuspidata Desm.. . . . 34

Jaera marina Fabr. . . . . . . 5

Cuma Rathkci Kröyer. . . . . . 30

Mysis inermis Rathke. . . . . . 6

Mysis flexinosa Müller. . . . . . 17

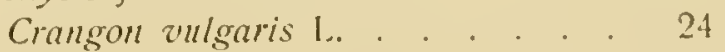

Lcander adspersus Rathkc. . . . . 26

Carcimus maenas L. . . . . . etwa 20

\section{Mollusca.}

Rissoa octona L. . . . . . . . 34

Cerithinm reticulatum da Costa . . 16 
Litorina litorea $\mathrm{L}$.

24

(Hydrobia ulvae) Pennant.

Acera bullata Müller.

(Aeolis).

Mytilus edulis L. . . . . . . 30

Cyprina islandica L. . . . . . . 22

Astarte borealis Chemnitz. . . . . 12

Mya arenaria L. . . . . . . . 16

Mya truncata L. . . . . . . . . . 9

Cardium edule L. . . . . . . . 12

Cardium fasciatum Montagu.. . . . 5

Tellina baltica L. . . . . . . . . 25

Scrobicularia piperata Gmelin . . . 6

\section{Tinnicata.}

Ascidia canina O. F. Müller. . . 22

Cynthia grossularia van Ben. . . . 30

Cynthia rustica L. . . . . . . . 9

Pisces.

Gobius Ruthensparri Euphrasėı. . . 19

Gasterosteus pungitius L. . . . . . 12

Spinachia v'ulgaris Flem. . . . . . 11

Nerophis ophidion L. . . . . . . 11

Siphonostoma typhle L. . . . . . 21

Pleuronectes platessa (jung) L. . . . 32

Pleuronectes flesus (jung) L. . . . . 28

\section{Methodik.}

Zur Ermittelung der Nahrung und Ernährungsweise stehen vier Wege offen:

1. die Beobaclitung in der Natur,

2. die Beobaclitung im Aquarium,

3. Fütterungsversuche,

4. Darmuntersuchungen.

Die Beobachtung in der Natur ist bei Wasserthieren schwerer als bei Landthieren möglich. Die meisten leben in Tiefen, in die das Auge nicht zu dringen vermag und die wenigen am Strande lebenden Thiere sind zu klein, als dass man ihre fressende Thätigkeit mit Erfolg beobachten könnte. Trotzdem ist die Beobachtung in der Natur unerlässlich, der Inhalt des Schleppnetzes liefert oft wichtige Anhaltspunkte. Lokales Vorkommen, Häıfigkeit, Bodenverhältnisse lassen sich daraus erkenıen und gestatten oft Schlüsse auf die Rolle, die die betreffenden Thiere als Nahrungsthiere und als Konsumenten spielen. Zu der Beobachtung in der Natur gehören auch die Reusenversuche, die der Fürst von Monaco zu wissenschaftlichen Zwecken verwerthet hat. $1 m$ Sommer 1899 stellte Herr Dr. med. Buerkel 1) in der Kieler Bucht Reusen-

1) Emit Buerkel: Biologische Studien üher die Fauna der Kieler Föhrde (158 Reusenversuche) hiel und Leipzig 1900.

Der Unterzeichnele benutzt die Gelegenheit, über die Veröffentlichung des Hern Dr. Buerkel einige Worte der Aufklärung hier cinzufügen, weił die Untersuchungen dazu in dem hiesigen zoologischen Institut ausgeführt sind. Die Aufgabe, die ich ihn gestellt hatte, bestand darin, zunächst durch eine grössere Anzahl von Reusenversuchen festzustellen, welche Meeresthiere der Kieles Bucht sich durch frischen oder faulen köder, durch Glühlampen oder glänzende Gegenstände anlocken lassen und in welcher Menge die einzelnen Arten in verschiedenen Reusen und auf verschiedenen Gebieten angetroffen werden. Ausserdem sollten bei Thieren, die sich antocken liessen, durch Aquarium-Versuche Sitz und Stärke der Sinneswahmehmungen näher untersucht werden. Die Untersuchungen des Hern Dr. Buerkel waren über das Stadiun der Vorversuche noch nicht wesenttich hinausgekommen, als er die Arbeit abbrechen musste, um nach Deutsch-Siidwestafrika sich zu begeben. Leider hat Dr. Buerkel gegen meinen ausdricktichen Wunsch die Arbeit in der vorliegenden Form (Biologische Studien 1900) veröffentlicht.

Wenn nus die ganz einwandfreien Reusenversuche in Betracht gezogen wären, wenn danı der Verf. sich der Miile unterzogen hätte, das Ganze meinen Vorsclalägen entsprechend umzuarbeiten, vieles Ueberfliissige oder gar Unrichtige fortzulassen und dafür die Originatbefunde mitzutheilen, so wäre immerhin brauchbares Materiat für weitere Arbeiten in der einmal eingeschlagenen Richtung gegeben worden. Da aber Dr. Buerkel die in unvollkommener Weise ansgeführten Vorversuche mit den methodisch einwandfreien späteren Versuchen zusammengeworien hat und da er auch nur von 20 der 149 Reusen das Protokolf selhst (in Anlage 6) mittheilt, alle andern Werthe aber nur in umgerechneter, nicht kontrolisbarer Form wiedergiebt, so inuss ich die Verantwortung für diese Schrift entschieden ablehnen

Auf einen groben Fehter hatte ich den Verf. schon aufmerksan gemacht, als er mir das Manuskript vortegte. Buerkel halte sich nicht die verhăltnissmässig geringe Mühe gemacht, die freilebenden Nematoden, die sich auf dem Köder eingelunden hatten, zu zählen. Wenı er sich damit hegnight hătte, anzugeben, dass meist sehr viele Nematoden, oft mehrere Hundert, auf dem Köder solcher Reusen, die in der Seegras-Region ausgelegt waren, sich finden, wälurend die nicht mit köder versehenen frei von 
versuche an, um die Aasfresser der Kieler Bucht zu ermitteln. Die Reusen waren mit frischem oder faulem Fleisch versehen und wurden durchschnittlich drei Tage nach der Zeit des Auslegens wieder aufgenommen. Es war von vornherein anzunehmen, dass nicht alle Thiere, die sich in den Reusen fanden, von dem Köder angelockt wären, sondern dass manche durch Strömungen oder infolge schlechten Sehvermögens hineingerathen sein könnten. Um dieses klarzustellen, wurden einige Reusen ohne Köder gelassen; andere wurden mit hellen Scherben versehen, um zu beobachten, ob diese Anziehungskraft ausübten.

Für die freundliche Einladung zur Theilnahne an den Fahrten sage ich Hern Dr. Buerkel an dieser Stelle verbindlichen Dank. Einige Beobachtungen, die ich dabei machte, sowie einige Ergebnisse der Reusenversuche werde ich bei der Einzelbesprechung der Thiere erwähnen. Ich selbst habe keinc Reusemversuche angestellt.

Die Beobachtung im Aquarium soll dazu dienen, uns über Thiere, deren Lebensweise unserer Beobachtung in der Natur nicht zugänglich ist, Aufklärung zu geben. Es liegt auf der Hand, dass die Lebensbedingungen nicht immer den natürlichen gleichgemacht werden können. Wasserdruck und Beleuchtung, von der Wasserhöhe abhängend, Bewegung des Wassers und Gehalt an organischer Substanz sind mehr oder minder verschieden. Immerhin latten die meisten Thiere gut in den Aquarien aus und wir haben kemen Grund daran zu zweifeln, dass sie eine Lebensweise führen, die derjenigen in der Natur ähnlich ist. Bei kleineren Thieren kann der Akt der Nahrungsanfnahme meist nicht beobachtet werden, bei grösseren dagegen kann man sehr interessante Studien machen. Besonders ist die Beobachtung der allgemeinen Lebensweise, der Ortsbewegung und manches Andere mehr von Bedeutung; sie giebt den Vorstellungen von der Ernährungsweise bestimmte Richtungen und illustrirt die Ergebnisse der Darmnntersuchungen. In zoologischen lnstitut in Kiel befinden sich mehrere Seeaquarien, in denen ich Beobachtungen gemacht habe. Bei der Einzelbesprechung werde ich mich wiederholt auf sie berufen.

Durch Fütterungsversuche wollte ich festzustellen suchen, ob die Thiere unter Nahrungssortcn, die ihnen in gleichem Masse zugänglich sind, auswählen, und ob sie, falls eine Auswahl getroffen wird, durch Hunger gezwungen werden können, eine für gewöhnlich von ihnen verschmähte Nahrung zu fressen. Ich liess die zum Versuch bestimmten Thiere hmugern und bot ihnen dann zwei verschiedene Nahrungssorten, zum Beispiel Seegrasstücke und Miesmuschelfleisch an. Besonders bei Gammarus locusta und Idothea tricuspidata erzielte ich interessante Resultate, die scheinbar in Widerspruch zu den Ergebnissen der Darmuntersuchungen standen. Es ist jedoch wohl zu berücksichtigen, dass die Lebensbedingungen bei diesen Versuchen sehr von den watürlichen abweichen, und man darf sich daher nicht ausschliesslich auf solche Experimente beschränken.

Weitaus die exakteste Methode ist die der Darmuntersuchnngen, denn sie giebt uns Rechenschaft darüber, was ein Thier unter natürlichen Lebensbedingungen gefressen hat. Un Darmuntersuchnngen mit Erfolg anstellen zu können, ist es nothwendig, die Thiere sogleich nach dem Fang zu töten, weil sonst die Verdauung fortdauert und den Darminhalt unkemutlich macht. Ich habe fast immer 70 prozentigen Alkohol benutzt, Quallen habe ich auch in schwacher Formollösung getötet. Bei manchen Thieren hat sich auch der 70 prozentige Alkohol als zu schwach erwiesen. Viele Crustaceen, insbesondere die Decapoden, lebten noch lange, und oft habe ich bei der Untersuchung den Magen leer gefunden, und zwar nicht in Folge fortdatternder Verdaunng, sondern weil die Krebse den Mageninhalt wieder ausstiessen,

Nematoden waren, so wäre das in sler Ordnung gewesen. Un nun aber cine Verschiedenlseit in der Anlockung durch Irisclnen und durch faulen Köder herauszurechnen, hat er die Menge der nicht durch Zählung festgestellen Nematoden gleicli $x$ gesetzt und $x$ mit dem Quotienten aus der 7alıl der Fänge, in denen sich Oncholaimen fanden, und der Gesammlzalıl der Untersuchungstage inultiplizirt. Wenn ilso Oncholainus in einer + Tage lang ausgestellten Reuse unit faulem Köder konstatirt war, sn waren nach Buerkel täglich 0,25 x gefangen worden, während, weun in einer nur 3 Tage lang ausgestelten Reuse mit Jrisclem Köder Nematoden gefunden waren, der Werh $0,33 \mathrm{x}$ von Buerkel erhalten wude. Aus dieser rein zufäligen Verschiedenheit der Untersuchungshage schliessen zu wollen, dass fuischer Köder inelır Oncholaimen anlockt als fauler, ist wie ich Herrn Dr. Buserkel schon uror seiner Veröffentlichung gesagt habe - falsch, denn es komm vor allem anf den verschiedenen Werth von $x$ selbst an, und der kann nur durch Zählung festgesleltı werden. Ich befïrchte, dass auch mancher der anderen Schlisse von Bueskel bei näherer Prilung der Linterstichungs-Profokolle, deren Zustellung mir Dr. Buerkel seil einem Jahte versprochen hal, sich als Irrthimer erweisen werden. 
sobald sie in Alkohol gesetzt wurden; manchmal fand ich ihn noch zwischen den Mundwerkzeugen. Wiederausstossen der Nahrung in Alkohol habe ich auch bei Halicryptus spinulosus und Priapulus caudatus beobachtet, doch handelte es sich bei diesen Würmern immer nur um kleinere Portionen des Darminhaltes. Vermuthlich ist auch bei anderen Thieren, deren Darm leer war, der Grund für diese Erscheinung in dem Ausbrechen des Darminhaltes zu suchen. Man könnte solche Thiere in einem feinen Seidenbeutel oder in besonderen Gefässen isolirt konserviren und den Rückstand nach Herausnahme des Thieres untersuchen; doch ist zu berücksichtigen, dass oft an der Körperoberfläche Fremdkörper haften, die möglicherweise im Alkohol abiallen. Die Methode der Darmuntersuchungen krankt noch an anderen Uebelı. Abgeselıen davon, dass die Freilegung der verdauenden Kavitäten bei manchen kleinen Thieren bedeutenden Schwierigkeiten begegnet, und dass viele Bestandtheile des Darminhaltes garnicht oder nur ungenau bestimmt werden können, sind es im wesentlichen zwei Punkte, die schwer ins Gewicht fallen. Erstens findet man oft bei räuberischen Thieren ausser dem eigentlichen eigenen Darminhalt auch noclı den der gefressenen Thiere, wodurch die Deutung erschwert wird. Zweitens kann thierische Nahrung nur schwer nachgewiesen werden, wenn keine festen Bestandtheile, wie Krustaceenpanzer, Chätopodenborsten oder Molluskenschalen gefunden werden. Die nacktell thierischen Zellen verfallen der Verdauung viel leichter, als die allseitig mit einer Membran umschlossenen pflanzlichen. Hierdurch wird man leicht zu Trugschlüssen verleitet. Aber trotz aller dieser Mängel halte ich die Darmuntersuchungen, begleitet von Beobachtungen und Versuchen, für die geeignetste Methode und habe sie auch vorwiegend beiolgt. In vielen Fällen habe ich mir Dauerpräparate angefertigt, um sie bei weiteren Untersuchungen zum Vergleich mit dem Darminhalt von Thieren heranziehen zu können, die an anderen Stellen nnd zu anderer Zeit gefangen wurden.

\section{Ueber die Nahrung, die den hier in Betracht kommenden Thieren zur Verfügung steht.}

Die Nahrung der Thiere zerfällt in pllanzliclıe und thierische. Doch ist es rathsam, gleich zwei Nahrungsquellen abzusondern, das Plankton und den Detritus. Beide sind ein Gemisch thierischer und pilanzlicher Bestandtheile. Das Plankton setzt sich aus kleinen und kleinsten lebenden Organismen zusammen, und unter Detritus versteht man bekanntlich die abgestorbenen, zerfallenden Pflanzen und Thiere. Sowohl beim Plankton als auch beim Detritus kommt es daher nicht auf eine Gegenüberstellung der vegetabilischen und animalischen Bestandtheile an, sondern vielmehr auf die Würdigung ihres Gesammtnährwerthes. Ich unterscheide demnach vier grosse Nahrungsquellen, nämlich
1. die pflanzliche Nahrung,
2. die thierische Nahrung,
3. das Plankton,
4. den Detritus.

Die pilanzliche Nahrung sondere ich wiederum in grosspflanzliche und kleinpflanzliche, mit der Unterscheidung, dass die grosspilanzliche, um aufgenommen werden zu können, erst zerkleinert werden muss, während die kleinpflanzliche Kost in Form ganzer Organismen aufgenommen werden kann. Demgemäss rechne ich zur grosspilanzlichen Nahrung das Seegras und die vielzelligen Algen, zur kleinpflanzlichen die festsitzenden und am Boden lebenden Diatomeen, die pennaten Formen. Die freisclıwimmenden, cyklischen Diatomeen gehören, ebenso wie die Peridineen, dem Plankton an. Jedoch ist der Unterschied 'zwischen Uier- und Planktondiatomeen nicht streng durchzuführen, da viele pennate Formen im Plankton, und manche cyklische am Boden vorkommen. Karste ${ }^{1}$ ) zählt 15 im Plankton lebende pennate Formen aul, und Herr Dr. Lohmann theilte mir mit, dass er in einem Wasservolumen von 38 I, das an einem 
Novembertag des Jahres 1899 an der Oberlläche der Föhrde geschöpft worden war, 68000 Exemplare von Cocconeis gefunden hat, einer Diatomee, die sonst epiphytisch auf Seegras und Algen lebt.

\section{Grosspflanzliche Nahrung.}

Zur grosspilanzlichen Nalırung rechne ich, wie schon erwähnt, das Scegras und die mehrzelligen Algen. Pollenkörner, Algensporen, Protococcoideen (Merismopedia) und eine andere kleine Alge (Rhizoclonium?) lasse ich unberücksichtigt, weil ich sie nur vereinzelt fand, und weil ich nicht entscheiden konnte, ob sie dem Plankton oder der Bodenflora angehörten; das Vorkommen der Pollenkörner war sicher rein zufällig, denn es handelte sich um solche von Coniferen. - Die grosspilanzliche Nahrung findet sich in lebendem Zustande nur in den Küstenzonen, und ihre Menge nimmt mit wachsender Tiefe ab. "Nur in seichtem Wasser ist der Pflanzenstreifen dicht, während nach dem tiefen Wasser hin die Vegetation bald spärlicher und immer spärlicher wird 1)." In der Kieler Bucht gestaltet sich der Pflanzenwuchs bekanntlich derartig, dass dic Ufer der ganzen Föhrde, abgesehen von dem innersten Theil von einem unterseeischen Seegrasgürtel umfasst sind. Während dieser im inneren Theil der Föhrde, oft mit Algen und Enteromorphen vermischt, nach der Mitte zu in die Region des Mud übergeht, ist im äusseren Theil noch eine Zone eingeschaltet, nämlich die der Roth- und Braunalgen. In den Regionen der lebenden Pflanzen stösst man auf ein reiches Thierleben. Zwar sind es, wie wir weiter unten sehen werden, nur wenig Thierarten, die sich von lebender grosspflanzlicher Kost nähren, aber sie treten in so grosser Individuenzahl auf, dass sie zu den gemeinsten Thieren der Kieler Bucht gehören. Indirekt haben die lebenden Gewebspflanzen, wie auch Brandt ?) betont, für die Ernährungsverhältnisse Bedeutung, indem sie den Diatomeen zur Ansatzstelle dienen. Diese werden zusammen mit dem auf der Oberiläche der Pflanzen haftenden Detritus von manchen Schnecken abgeweidet. Andere Thiere, wie Ascidien, Schwämme und junge Muscheln setzen sich an den Pflanzen fest, um die im Wasser suspendirten organischen Bestandtheile aulzunehmen, wozu vielleicht die durch Wellen und Strömungen verursachten Bewegungen der Pflanzen förderlich sein mögen.

Viel bedeutender als die lebenden Pilanzen sind für die Ernährung der Thiere die abgestorbenen und zerfallenen Gewebspflanzen. Durch Wellenschlag und durch den Sogstrom gelangen diese in das tiefere Wasser und bilden hier den Hauptbestandtheil des [Detritus. Andererseits werden auch grosse Mengen von Seegras, die durch Wellenschlag entwurzelt oder abgerissen werden, an den Strand gespült und dienen hier zwei Arten von Flohkrebsen, die das Wasserleben mit dauerndem Aufenthalt auf dem Lande vertauscht haben, zur Nahrung. Endlich ist bei der grosspilanzlichen Nahrung auch noch das Holz der Pfähle zu erwähnen, das von einem lsopoden Limnoria lignorum, gefressen wird.

\section{Die kleinpflanzliche Nahrung.}

Was die festsitzenden oder am Grunde lebenden Diatomeen anbetrifft, so glaube ich auch ihnen eine grosse Bedeutung als Thiernahrung beilegen zu dürfen. Hensen ") erkennt den Diatomeen uur sehr geringen Nährwerth zu. Zwar hat er dabei in erster Linie die Plankton-Diatomeen im Auge, aber ich erwähnte schon, dass die Unterschiede zwischen Grund- und Plankton-Diatomeen sich sehr verwischen. Wie sich pennate Formen in Plankton finden, so kommen auch cyklische am Grunde vor. Coscinodiscus und eine dickwandige Melosira, die ich nicht bestimmen konnte, habe ich im Darm von nanchen Schnecken ebenso häufig geiunden wic im Darm von Planktonzehrern, und zwar mit Zellinhalt. Darum thut man gut, die Diatomeen auf ihren Gesammtnährwerth zu prüfen. Brandt ${ }^{4}$ ) hat Untersuchungen über den Nährwerth der Diatomeen angestellt, und ist zu dem Ergebniss gekommen, dass die Diatomeen in der That grossen Nährwerth besitzen. Ein von Brandt angestellter Vergleich zwischen der chemischen Zusammensetzung

1) Karl Brandt: Ueher den Stoffwechsel im Meere. Wissenschafliche Meeresuntersuch ungen, herausgegeben von der Konmission zur Untersuchung der deutschen Meere. Abth. Kiel. Nene Folge. Bd. IV p. 11 (223).

2) Karl Brandt: Beitråge zur Kenntniss der chemischen Zusammensetzung des Planktons. Wiss. Meeresunters. Neue Folge. Bd. III Heft 2, p. 45 (3).

3) Victor Hensen: Ueber die Bestimmung des Planktons oder des Im Meere treibenden Materials an Pflanzen und Thieren.

5. Bericht der Kommission zur Untersuchung der dentschen Meere. Berlin 1887.

4) Karl Brandt: Beitrăge zur Kenntniss der chemischen Zusammensetzung des Planktons, I. c. p. 89 (47). 
der aschefreien Diatomeensubstanz mit der aschefreien Trockensubstanz von Futterpflanzen zeigt, dass der Nährwerth der Diatomeen im Allgemeinen von Futterpflanzen nicht erreicht wird.

\begin{tabular}{llll|c|c|c}
\hline & & & Eiweiss & Fett & Kohlehydrate \\
\hline Futterwicke, sehr gut. & & & & & & \\
\hline
\end{tabular}

"Maı darf allerdings nicht ausser acht lassen, dass mehr als die Hälfte der ganzen Diatomeentrockensubstanz aus der für die Ernährung werthlosen Kieselsäure besteht. Die Kieselsäureschalen der Planktondiatomeen sind aber recht dünn im Vergleich zu denen der Uferdiatomeen. Trotzdem werden die letzteren viel gefressen. Auch Planktondiatomeen findet man häufig im Darm von Ascidien und anderen Küstenthieren, sowie im Darm von echten Planktonthieren, wie Salpen u. s. w. (Brandt 1).

Ferner führe iclı hier einige Angaben und Citate an, die ich der Karstenschen Diatomeenarbeit entnehme. Karsten erwähnt zunächst selber, dass manche Grunddiatomeenbestände regelmässig von Amöben bewohnt seien, die sich ausschliesslich von den betreffenden Diatomeen nähren dürften, wenigstens habe er nie andere Gebilde von ilırem Körper umschlossen gefunden. Ferner bemerkte Karsten den Schaden, den wenige Exemplare von Corbula gibba anrichteten; er schildert, wie diese Muscheln mit dem eingesaugten Wasserstrom alle ihnen erreichbaren Diatomeen aufnähmen. Die Untersuchung des Kothes ergab dann, dass die Schalen mehr oder weniger ausgenutzt waren. Von Apstein und von Zacharias sind Schalen von Melosira im Darminhalt von einigen Cladoceren und Copepoden nachgewiesen worden. Lohmann giebt an, dass Appendicularien, Naviculaceen, Coscinodiscen und Peridineen als Nahrung aufnähmen. Auch Murray stellt fest, dass die Copepoden und andere kleine Kruster von Diatomeen leben. Im Darm von jungen Fischen hat Murray ebenfalls Diatomeen gefunden, lässt es aber fraglich, ob als direkte Nahrung oder als Nahrung niederer gefressener Thiere. Nur bei jungen Clupeiden ist er davon überzeugt, dass es sich um direkte Aufnahme handelt, weil die Schalen alle vollständig und gut erhalten waren.

Ergänzt werden diese Angaben durch eine Mittheilung von Meyer und Möbius $\left.{ }^{\circ}\right)$. Die beiden Forscher sahen Litorinen die Glaswände des Aquariums abweiden, deren Belag zum grossen Theil von Diatomeen gebildet wird, Lotsy") hat den Darminhalt von Ostrea, Mytilus und Mya untersucht und gefunden, dass die Hälfte desselben aus Diatomeen besteht. Auch durch Fütterungsversuche ist er zu dem Ergebniss gelangt, dass die genannten Muscheln thatsächlich Kieselalgen aufnehmen und verwerthen. Deby ${ }^{4}$ ) fand im Darm von Mytilus 37 Arten Diatomeen. Frenzel ${ }^{5}$ ) fand Diatomeen häufig im Darm von Fischen etc., misst ilnen aber wie Hensen nur untergeordnete Bedeutung als Nahrung bei. Frenzel

1) K. Brandt: Beiträge zur Kenntriss der chemisclien Zusammensetzung des Planktons. 1. c. p. 89 (47).

2) H. A. Meyer und K. Möbius: Die Prosobranchiata und Lamellibranchiata der Kieler Bucht. Leipzig 1872, p. 13.

3) J.P. Lotsy: The Food Supply of the Adult Oyster, Soft Clam, Clam and Mussel. in Johns Hopkins University Circulars Vol. Xll, Nr. 106.

4) Referat aus Archiv für Naturgeschichte, 42. Jahrgang, 2. Band. (Die mir nicht zugängliche Originalarbeit findet sich in Procès-verbal de la Socièté malacologique de Belgique 111, p. 202. Berlin 1897.

5oh. Frenzel: Die Diatomeen und ihr Schicksal, in: Naturwissenschaftliche Wochenschrift. X11. Bd., Nr. 14. 
stützt seine Annahme darauf, dass er im Koth der ebenerwähnten Thiere „völlig unversehrte Diatomeenschalen" bemerkte. Da Frenzel über die Besclaffenheit des Zellinhaltes nichts angiebt, so scheint mir seine Annahme in Hinblick auf die oben citirten Resultate von Brandt's chemischen Untersuchungen nicht gerechtfertigt. Ich selbst konnte bei einigen Schnecken reiuen Diatomeenfrass feststellen und in vielen Thieren fand ich eine grosse Menge Kieselalgen. Bei der Besprechung der betreffenden Thiere werde ich darauf hinweisen.

\section{Die thierische Nahrung.}

Der pflanzlichen Nahrung steht die thierische gegenüber. Man kann diese nicht in derselben Weise eintheilen wie jene. Während die hier in Betracht kommenden Pflanzen in Folge ihrer durchgehend gleichartigen Lebensweise ziemlich einheitlich geartet sind, treten in Thierreiche tiefgehende Unterschiede auf, die dazu zwingen, auch bei dieser Betrachtung dem Gang des Systems zu folgen. Auch macht sich bei der thierischen Nahrung noch ein Unterschied geltend, der bei der vegetabilischen zurücktritt, das ist der zwischen toter und lebender Substanz.

Infusorien und andere Protozoen finden sich in grosser Menge in den Küstenregionen, auf und zwischen Pflanzen lebend; in Folge des Fehlens von Hartgebilden habe ich sie jedoch nie bei der Untersuchung des Darmes hölıerer Thiere nachweisen kömmen. Nur Foraminiferen fand ich ganz vereinzelt. Tintinnen, die ich oft im Darm von Planktonzehrern antraf, lasse ich hier ausser acht.

Die Schwämme schützt ihr Nadelskelett nicht vor räuberischen Angriffen, zu wiederholten Malen konnte ich konstatiren, dass sie als Nahrung gedient hatten. Pagenstecher') schreibt: „Ehlers scheinen weiche Schwämme den Raubannelliden ein beliebtes Futter zu sein," und gerade bei Nereis pelagica fand ich Spongienfrass. Keller") giebt dagegen an: "Es ist auffallend, wie (zum Beispiel) Seeschwämme von Fischen und Raubmollusken gemieden werden," und führt dies auf einen widerlichen Geruch zurück. Bei unserer Amorphina panicea habe ich mich nicht von einem widerlichen Geruch überzeugen können, auch fand ich im Darm einer Litorina grosse Schwammstücke, die nach der Form der Nadeln zu Amorphina gehörten. Man darf jedoch keinegswegs aus dem Vorhandensein einzelner Spongiennadelı im Darm auf Spongienfrass schliessen. Die Nadeln sind in unendlicher Menge im Wasser vertheilt. Wie etwa die Schmetterlingsschuppen im Sonmer im Staube, findet man die Schwammspicula im Wasser. Trifft man sie deshalb im Darm vereinzelt oder in spärliclıer Menge, so kann nan sie, da ilınen zudem noch jeglicher Nährwerth mangelt, bei der Beurtheilung des Darminhaltes ruhig bei Seite lassen. Man könnte annehmen, dass die Schwammnadelı, ebenso wie Sandkömchen, die ich fast immer antraf, aufgenommen würden, um bei der Zerkleinerung grösserer Nahrungsbestandtheile mitzuwirken. Ich habe jedoch nicht den geringsten Anhaltspunkt für diese Vermuthung gefunden. - Die Medusen enthalten kaum $2^{n}$ o organischer Substanz, und ich habe auch nicht feststellen können, dass sie eine wesentliche Rolle als Thiernahrung spielen, ausgenommen für die Hyperinen, die an ihnen schmarotzen und sie ausfressen. Im Aquarim fiel, wie Herr Dr. Vanhoeffen mir mittheilte, ein junger Cyclopterns Quallen an, und Brandt3) erwähnt, dass dieser Fisch sie gerne frässe. Möbius und Heincket) berichten ferner, dass die Makrelen Medusen fressen, vermuthen aber, dass es diesen Fischen weniger un die Quallen, als um die Hyperinen zu thun sei. Interessant ist die Mittheilung des Japaners Kishinouye"), dass zwei Quallen der Gattung Rhopima in Japan und in China ein wohlschmeckendes Gericht liefern und anch als Fischköder benutzt werden.

Unter den Stachelhäutern dient nach Möbius und Heincke') Ophioglypha vielen Nutzfischen, besonders den Plattfischen zur Nahrung. Im Darm der von mir untersuchten Thiere habe ich nie Reste von Echinodermen gefunden. Asteracanthion rubens soll nach Marshalli) giftig sein. Marshal! beruft sich

1) Alexander Pagenstecher: Allgemeine Zoologie oder Grundgesetze des thierischen Bans und Lebens. IV'. Buch. Berlin 1877. p. 87.

$\Rightarrow$ Conrad Keller: Das Leben des Meeres. Leipzig 1895. p. 47.

3) Karl Brandt: Beitrăge zur Kenntniss der chemischen Zusammensetzung des Planhton. I. C. p. f6 (t).

1) K. Möbius und Fr. Heincke: Die Fische der Ostsee, in: 4. Rericht der Kommission zur Untersuchung der dentscluen Meere. Kiel 1883. p. 216.

5) K. Kislifunuye: Edible Medusae, in: Zoolog. Jalurbicher, Abth. System. 12. Band, p. 215.

b.) l. c.

万W Whliam Marshall: Die deutschen Meere und ilne Bewohner, p. 161. 
auf zwei Franzosen, Brounié und Durandeau. Diese fütterten Hunde mit Seesternen und beobachteten, dass die Hunde heftig erkrankten und einige von ihnen starben.

Reiches Nährmaterial liefern die Würmer. Die Bedeutung der Nemertinen und der gemeinen kleinen freilebenden Nematoden (Oncholaimus) als Nahrung habe ich nicht ermitteln können, da ihnen nennenswerthe Hartgebilde fehlen. Turbellarien und Gephyreen sind zu spärlich, als dass sie eine bedeutende Rolle in dieser Hinsicht spielen könnten. Ueberaus wichtig sind dagegen die Chätopoden. Fischen, Krebsen und Individuen der eigenen Gattungen und Arten fallen sie zum Opfer. Jedoch ist aucl hier wieder Vorsicht geboten, da die unlöslichen Chitinborsten, ähnlich wie die Kieselnadeln der Schwämme, weit im Wasser verbreitet sind und oft als nẹbensächliche Bestandtheile in den Darm von Thieren gelangen.

Die Krebse bilden die Hauptnahrung der meisten von mir untersuchten kleineren Fische. Bei der Einzelbesprechung werde ich eingehender darauf zurückkommen.

Muscheln und Schnecken sind durch ihre Schalen gegen viele Angriffe geschützt, für viele Fische bilden sie jedoch einen Hauptbestandtheil der Nahrung. Auch anderen Thieren fallen sie zur Beute, in erster Linie dem Seestern, der sich hauptsächlich von ihnen nährt. Die Muscheln haben wahrscheinlich auch nach ihrem Tode noch eine grosse Bedeutung als Thiernahrung. In Folge der Zersetzung der Adduktoren klaffen die Spalten auseinander und der Weichkörper wird allen möglichen Thieren zugänglich. Im Aquarium beobachtete ich, wie eine Litorina in einer Miesmuschel, die geöffnet ausgenommen und dann wieder in den Behälter geworfen worden war, die Reste der Schliessmuskeln verzehrte. Nacktschnecken, anscheinend von der Gattung Doris, fand ich im Darm einer jungen Platessa vereinzelt, im Darm einer andern in grösserer Zahl.

Dass auch die Ascidien eine Bedeutung als Nährmaterial besitzen, schreibt Lang. ${ }^{1}$ ) "Gewisse Fische.... zerzupfen die Ascidien, um sich von ihren Eingeweiden zu ernähren. Lacaze-Duthiers hat beobachtet, wie Ascidien der Gattung Molgula, deren Mantel sich mit Sand bedeckt, von einem Tag zum andern massenhaft von Krabben, vornehmlich Cancer maenas, zerstückelt und verzehrt wurden, sodass nur die leeren Mantelhüllen übrig blieben."

Auf Fischreste bin ich bei meinen Darmuntersuchungen nie gestossen, doch ist es bekannt, dass Fischlaich, junge Exemplare und kleine Arten den grösseren Fischen zur Nahrung dienen. Möbius und Heincke ${ }^{2}$ ) berichten übereinstimmend mit Benecke ${ }^{3}$ ) dass die beiden hier vorkommenden Lophobranchier, Nerophis und Siphonostoma von grösseren Raubfischen nicht nur nicht gefressen, sondern sogar absichtlich gemieden werden. Im Aquarium sah ich, wie eine grosse lebende Seenadel am Kopfende von einem Carcinus gepackt worden war und langsam verzehrt wurde; bei einem Fütterungsversuch konnte ich beobachten, wie ein junges Siphonostomum von einer Idothea angefallen und gefressen wurde; im Aquarium gestorbene Schlangennadeln sollen von Asteracanthion verspeist worden sein.

\section{Das Plankton.}

Die Erkenntniss, dass das Plankton eine Nahrungsquelle von ganz hervorragender Bedeutung ist, ist verhältnissmässig neu. Möbius ${ }^{4}$ ) führt noch in einer Arbeit aus dem Jahre 1871 als Hauptnahrung für Muscheln die "Modertheilchen der toten Pflanzen“, sowie die organischen Reste an, die die grossen Ströme in das Meer tragen, ohne das Plankton zu berücksichtigen. Erst durch Hensen und Brandt ist das Plankton zu voller Würdigung als Nährmaterial gelangt. Freilich lässt Ernst Voges in seiner 1888 erschienenen Bearbeitung der dritten Auflage des oben citirten Schleidenschen Werkes das Plankton auch noch ausser acht. Brandti) hat das Plankton chemisch auf seinen Nährwerth untersucht und ist zu dem Ergebniss gekommen, dass derselbe zwar nach den Jahreszeiten sehr schwankt, aber durchgehend recht hoch ist. Am niedrigsten ist er in den Frühlingsmonaten, weil dann die Diatomeen mit ihren unverdaulichen Kieselschalen den Hauptbestandtheil des Planktons bilden.

\footnotetext{
1) Arnold Lang: Ueber den Einfluss der festsitzenden Lebensweise auf die Thiere. Jena 1888 , p. 109.

) 1. c. p. 247.

3) Berthold Benecke: Fische, Fischerei und Fischzucht in Ost- und Westpreussen. Königsberg 1881.

4) K. Möbius. Das Thierleben am Boden der deutschen Ost- und Nordsee. Berlin 1871.

5) Karl Brandt. Beiträge zur Kenntniss der chemischen Zusammensetzung des Planktons. 1. c.
} 


\begin{tabular}{r|r|r|r|r}
\hline \hline Fangzeil & Eiweiss & Felt & Kohlehydrate & Asche \\
\hline 3. 10.92. & 21,84 & 2,12 & 66,10 & 9,94 \\
13. 10.92. & 20,24 & 2,26 & 68,95 & 8,55 \\
15. 11. 92. & 21,01 & 3,21 & 60,07 & 15,71 \\
14. 2.93. & 20,41 & 4,35 & 45,50 & 29,68 \\
15. 3.93. & 13,45 & 2,58 & 23,60 & 60,08 \\
2. 4. 93. & 15,56 & 4,24 & 18,79 & 61,41 \\
5. 5. 93. & 26,54 & 1,58 & 23,07 & 38,77 \\
28. 8. 93. & 33,56 & 8,70 & 38,31 & 19,11 \\
28. 9. 93. & 21,29 & 3,20 & 39,30 & 36,14
\end{tabular}

Ein Vergleich des Herbst- und Winterplanktons mit einigen Futterstoffen ergiebt nach Brandt:

\begin{tabular}{l|c|c|c|c}
\hline & Eiweiss & Fetl & Kohlehydrate & Asche \\
\hline Planklon . . & $20,2 \quad 21,8$ & $2,1-3,2$ & $60,0 \quad 68,9$ & $8,5 \quad 15,7$ \\
Feltweide. . & 20,6 & 4,5 & 64,6 & 10,1 \\
Lupine . . . & 20,6 & 2,6 & 72,0 & 4,6
\end{tabular}

Die meisten von mir untersuchten Planktonzehrer sind festsitzende oder zum wenigsten keine freischwimmenden Thiere. Die Muscheln, die, wie wir sehen werden, in der Kieler Föhrde das Haupt. kontigent der Planktonfresser stellen, leben am Boden im Mud oder Sand, oder auch an Pfählen und anderen im Wasser befindlichen Gegenständen. Besonders von den am Grunde lebenden Muscheln kann man nicht erwarten, dass sie reines Plankton in sich aufnehmen. Schiffsschrauben, Fischernetze, grössere Thiere, vielleiclıt auch Wellen und Strömungen rühren den lockeren Mudboden beständig auf und vermengen das Plankton mit Bestandtheilen des Bodens. An den Pfählen spielen sich ähnliche Vorgänge ab. Die sich an ihnen brechenden Wellen reissen kleine Pflanzenstückchen und Holztheilchen los nnd spülen die zwischen den Muschelklumpen sich sammelnden Sandkörnchen und Detritustheilchen ab; dadurch wird das umgebende Wasser in ähnlicher Weise verunreinigt wie am Grunde. Es fragt sich mun, ob diese Beimengungen für die Ernährung werthlos sind, oder ob auch sie Bedeutung haben. Abgesehen von Sandkörnchen, die zweifellos werthlos sind, bestehen diese Beimengungen fast immer aus einer feinen braunen unkenntlichen Masse, in der sich nicht selten organische Reste, vornehmlich pflanzlicher Natur, vorfinden. Diese braune unkenntliche Masse stellt ohne Zweifel einen schon stark in Zersetzung begriffenen Detritus dar. Lotsy ${ }^{1}$ ) spricht diesem eine wesentliche Bedentung als Nahrung ab, da sich bei der Untersuchung des Kothes von Ostrea, Mytilus und Mya ergab, dass der Detritus scheinbar nnverändert war, „The decaying organic matter was apparently unaltered". Nun habe ich aber bei Thieren, die sich ganz bestimmt von Detritus nähren, wie die Gephyreen und andere Würmer, auch keinen sichtbaren Unterschied in der Beschaffenlıeit des Darminhaltes im vorderen und hinteren Theil wahrnehmen können. Deswegen theile ich die Ansicht von Frenzel’2), dass der Detritus eine gute Nahrung ist. Die Bestandtheile wie Cellulose, sind schon "gelockert und der Verdauung leichter zugänglich". Bestärkt werde ich in meiner Ansicht durch den Unstand, dass die meisten Muschelı nicht auf dem relativ detritusfreien Sandboden, sondern auf Mudgrund leben.

\section{Der Detritus.}

Dass der Detritus thatsächlich eine reiche Nahrungsquelle ist, geht schon daraus hervor, dass sich eine ganze Reihe von Thieren, wie ich schon andeutete und unten weiter ausführen werde, ausschliesslich

1) 1. c.

2) Joh. Frenzel: Zur Biologie von Dreissensia polymorpha Pallas. in Archiv flir die gesammte Physiologie Bd. 67 , p. 187. 
von ihm nährt. Der Detritus bedeckt den Grund der Föhrde mit einer mehr oder weniger dicken Schicht und wird von abgestorbenen, in Zerfall begriffenen pflanzlichen und thierischen Organismen gebildet. Am stärksten ist diese Schicht in der Mitte der Föhrde, und zwar aus zwei Gründen. Der Boden senkt sich gegen die Mitte zu und ist hier durchweg an tiefsten. So ist hier die Wasserhöhe und mit ihr der Reichthum an Organismen am grössten. "Indem nun die mikroskopischen Organismen tot gleich einem Regen zu Boden sinken, liefern sie organische Substanz" (Pagenstecher ${ }^{1}$ ). Die Mudfresser können darum, wie $\mathrm{Brandt^{2 } )}$ erwähnt, zu Planktonzehrern werden, indem sie die zu Boden gesunkenen Planktonorganismen fressen. Zweitens werden die abgestorbenen Organismen der Küstengebiete allmählich nach dem tieferen Wasser hingeführt, und zwar weniger, wie Möbius:) diese Erscheinung darzustellen gesucht hat, in Folge des Druckes nachfolgender Partien, als vielmehr durch den landabwärtswirkenden Sogstrom. Im Detritus prävaliren stets die vegetabilischen Bestandtheile, weil sie widerstandsfähiger sind als die thierischen. Dieselben Ursachen, die eine Verunreinigung des Planktons am Grunde bewirken, verhindern auch, dass sich der Detritus ganz rein ablagern kann. Wir finden ihn immer stark mit Sand durchsetzt, und er wird auch so von den Detritusfressern aufgenommen.

\section{Ueber die Nahrung der von mir untersuchten Arten.}

Nach demselben Prinzip, nach dem wir die Nahrung eingetheilt haben, können wir auch die Konsumentell eintheilen in:
1. Grossplanzenfresser,
2. Kleinpflanzenfresser,
3. Thierfresser,
4. Planktonzehrer,
5. Detrituszeh'rer.

Die Thierfresser zerlege ich wieder in Räuber und Aasfresser, will jedoch gleich bemerkell, dass diese Eintheilung mehr theoretischer Natur ist, denn ich habe kein Thier gefunden, von dem ich mit Bestimmtheit angeben könnte, dass es ein typischer Aasfresser sei; die Versuche von Buerkel scheinen mir nicht einwandfrei, und ilıre Ergebnisse werden theilweise durch die meiner Untersuchungen und Versuche zweideutig. Auch die Unterschiede zwischen. den grösseren Gruppen, wie Pflanzenfresser und Fleischfresser, oder Detritus- und Planktonzehrer sind nicht streng durchzuführen. Die meisten Thiere sind onmivor, das heisst, sie nehmen alles, wessen sie habhaft werden können. Immerhin lässt sich meist eine Hauptnahrung erkennen, und ich will deshalb die Eintheilung auch beibehalten, jedoch mit der Einschräıkung, dass ich vor die Bezeichnungen "Pflanzenfresser" u.s. w. das Wörtchen "vorwiegend" setze.

\section{Thiere, die sich vorzugsweise von grosspflanzlicher Kost nähren.}

Wie schon erwähnt, sind es nur wenig Thierarten, die hierher gehören, die aber zu den gemeinsten der Kieler Bucht zählen. Unter den von mir untersuchten Thieren sind folgende Spezies als Grosspflanzenfresser zu bezeichnen:

\section{Idothea tricuspidata Desm. | Amphithoe podoceroides Rathke. \\ Jaera marina L. \\ Gammarus locusta L. \\ Amathilla Sabinei Leach.

\author{
Orchestia litorea L. \\ Litorina litorea $\mathrm{L}$. \\ Acera bullata Müller.
}

Von 34 untersuchten Exemplaren des Idothea tricuspidata hatten 29 den Darm hauptsächlich mit Seegras-, Ulven- und Florideenstücken, sowie mit fadenförmigen Algen gefüllt, entweder nur mit einer oder aber auch mit mehreren der genannten Pflanzensorten. Bei vier Thieren war der Darm leer, und im

1) Alex. Pagenstecher: Ueber die Thiere der Tiefsee, Berlin 1879.

2) Karl Brandt: Beilräge zur Kenntniss der chemischen Zusammensetzung des Planklons. 1. c. p. 45 (3).

Karl Möbius: Wo kommt die Nahrung für die Tiefseethiere her? in Zeitschrift für wissenschaftliche Zoologie. Band 21, p. 294. 
Darm eines einzigen fand ich statt der Pflanzen feine braune unkenntliche Masse; in geringerer Menge fand ich diese ïbrigens im Darm fast sämmtlicher untersuchten Thiere. Ob es sich dabei un Detritus oder um Verdaunugsprodukte handeit, muss ich unentschieden lassen. Der Zellinlialt der gefressenen Pflanzenstücke war nur seiten noclı gut erhalten, meist war er dentfich zersetzt und brauı gefärbt, oder auch die Zellen waren leer. Im Darm sämmtlicher Thiere, die überhaupt Darminhalt besassen, fand ich anch Diatomeen in wechselnder Menge. Immer waren es Grundformen, die vermuthlich auf den gefressenen Pflanzenstücken gesessen haben. Nur in einem Exemplar, das ich an 19. Juni $1899 \mathrm{im}$ Seegras bei Mönkeberg gefangen habe (Tab. Nr. 8) fand ich eine Unmenge von Synedren, die in langen regelnässigen Zügen das Präparat durchzogen. Zweifellos war cin ganzer Diatomeenrasen gefressen worden. Im übrigen waren es meist Synedra und Cocconeis, Rhabdonema, Rhoicosphenia, Grammatophora, Naviculaceen, Coscinodiscus und andere, die meist durcheinander im Darm vorkamen. Die Schalen waren gewöhulich leer, nur bei Rhoicosphenia und Grammatophora waren die Chromatophoren fast immer erlalten. - Thierische Reste habe ich nur in sieben Fällen gefunden, in fünf von ihnen waren es Bruchstücke von Krebspanzerı, die jedoch so zertrümmert waren, dass ich sie nicht näher bestimmen konnte. Ein Thier, dasselbe, das den Diatomeenrasen gefressen hatte, hatte mehrere Ostracoden im Darm und im Darm von fünf Exemplaren fand ich Eizellen. Das spärliche Vorhandensein animalischer Bestandtheile muss befremden, denn sowolıf durch Versuche als auch durch gefegentliche Beobachtungen konnte ich mich davon überzeugen, dass Idothea animalische Kost keineswegs verschmäht. So zum Beispiel habe ich eine $11 \mathrm{~mm}$ lange Idothea mit einer $35 \mathrm{~mm}$ langen Seenadel (Siphonostoma typhle) anfangs in einer flachen Schale, dann in einem breiten Becherglase zusammen gebraclit. Sofort setzte sich die Assel am Fisch fest, und liess ihn trotz der kräftigen Abschüttelungsversuche seines Opfers nicht los. Die Bewegungen der Seenadel wurden immer schwächer und schwächer und schliesslich lag sie regunungsios, vermuthlich tot, an Boden des Gefässes. Am anderı Morgen war der Fisch an der Bauchseite stark angefressen. - In einer Reuse, die Buerkel in der Strander Bucht ausgelegt hatte, und die als Köder faules Fischffeisch enthieit, fanden sich nach $3 \times 24$ Stunden eine sehr grosse Menge Idotheen und einige Exemplare von Gobius niger. Eines der letzteren war tot, und ebenfalls an der Bauchseite stark angefressen. Auf ähnliche Beobachtungen mag es zurückzuführen sein, dass sich in der einschlägigen Litteratur verschiedentlich Angaben finden, die diesem Isopoden rein animalische Kost zusprechen, so zun Beispiel, wie Karl Matzhoff') erwähut, bei Desmarest und Lamarck. Die gegentheilige Ansicht, die unter Anderen Möbius²) ausgesprochen hat, dass nämlich Idothea rein pflanzliche Nahrung wählt, stützt sich wohl ausschliesslich auf Darmuntersuchungen und auf gefegentliche Beobachtungen im Aquarium. Hier sieht man die Assein meist auf den Seegrasblättern sitzen und kriechen, und gelegentlich auch davon fressen. Wie ich schon in der Methodik hervorgehoben habe, zerfallen thierische Bestandtheile viel schneller als pflanzliche; darauf wird sich das spärliche Vorhandensein thierischer Nahrung im Darm der Idotheen wohl in erster Linie zurückführen lassell. Nach Matzhoff nlässt sich das Ueberwiegen der pflanzlichen Bestandtheile .... auch ohne Schwierigkeit aus dem Ueberwiegen der Pflanzen an ihren Aufenthaltsorten .... erklären." Małzhoff erhielt Geseliscilaften von Idotheen wochenlang sowohl bei rein vegetabilischer als auch bei rein animalischer Nahrung lebend und beim besten Wohlbefinden. „Die Thiere nahmen alle Arten lebender und toter, ja verwesender Kost an. Fütterte man die Thiere mit Stücken frisch zerstückelter Genossen, so stürzten sie sich über die noch zuckenden Theile her und begannen an ihnen zu fressen, wobei nur die grösseren Chitinbestandtheile übrig gelassen wurden." "Dass Idothea vor keiner irgendwie brauchbaren Kost zurückscheut, geht auch darans hervor, dass sie sogar Netze annagt. Das haben bereits Desmarest und Ronx erwähnt und konnten mir Fischer des Kieler Hafens bestätigen." Spence Bate und Westwood") citiren aus Dalyells "Powers of Creation: "this creature feeds voraciously, seizing and carrying off prey in its fore limbs. It also devours the smailer crustacea and mussels very readily." Die vereinzelten Planktonorganismen, dic ich in cinigen Thieren - in Nr. 8 zwei dornige Cysten und in Nr. 13 einen Tintinnus - halte ich für zufällige Be-

1) Karl Matzhoff: Ueber die Färbung von Idothea tricuspidala Desm. Inaug. Diss. Kiel. Jena 1882. p. 28.

*) Karl Möbius: Die wirbellosen Thiere der Ostsee. In 1. Jahresbericht der Kommission zur Untersuchung der deulschen Meere. Berlin 1873. p. 97 pp.

3) Spence Bate and Westwood: A listory of the British sessile-eyed Crustacea. London 1863. p. 382. 
Idothea tricuspidata Desm.

\begin{tabular}{|c|c|c|c|c|c|c|c|c|c|c|}
\hline Nr. & $\begin{array}{c}\text { Länge } \\
\text { in } \\
\text { min }\end{array}$ & $\begin{array}{c}\text { Fang- } \\
\text { zeit }\end{array}$ & Fangort & Diatomeen & Peridineen & Gewebspflanzen & Tintinnen & Metazoen & Sonstiges & $\begin{array}{l}\text { Bemer- } \\
\text { kungen }\end{array}$ \\
\hline 11. 2. & ? & 11.1 & $\begin{array}{l}\text { Lebendes } \\
\text { Seegras, } \\
\text { Bellevue }\end{array}$ & $\begin{array}{l}\text { Grundformen, vor- } \\
\text { wiegend Cocconeis }\end{array}$ & $=$ & $\begin{array}{c}\text { viel Seegrasstücke, } \\
\text { Fadenalgen }\end{array}$ & & - & & - \\
\hline 3. & 15 & $\begin{array}{r}17.6 . \\
1900 \\
\end{array}$ & $\begin{array}{c}\begin{array}{c}\text { Seegras, } \\
\text { Wiker Bucht }\end{array} \\
\end{array}$ & $\begin{array}{l}\text { Synedren } \\
\text { und andere }\end{array}$ & - & $\begin{array}{l}\text { Seegrasstücke und } \\
\text { besond. Fadenalgen }\end{array}$ & - & & $\ldots$ & \\
\hline 4. & 15 & , & ". & $\begin{array}{l}\text { Synedren } \\
\text { und andere }\end{array}$ & - & - & - & - & $\begin{array}{l}\text { viel unkennt- } \\
\text { liche Masse } \\
\end{array}$ & -3 \\
\hline 5. & 14 & " & " & - & - & - & 一 & 一 & - & Darm leer \\
\hline 6. & 13 & $"$ & " & $\begin{array}{l}\text { Synedren } \\
\text { und andere }\end{array}$ & - & $\begin{array}{l}\text { vereinzelte Seegras- } \\
\text { und Algenstuicke }\end{array}$ & - & $\ldots$ & $\begin{array}{l}\text { viel unkennt- } \\
\text { liche Masse } \\
\end{array}$ & - \\
\hline 7. & 9 & $"$ & $"$ & wenig & - & $\begin{array}{c}\text { Seegrasstijcke } \\
\text { (und Fadenalgen) } \\
\text { vereinzelt }\end{array}$ & - & - & - & - \\
\hline 8. & 25 & $\begin{array}{l}19.6 . \\
1899\end{array}$ & $\begin{array}{c}\text { Seegras } \\
\text { bei } \\
\text { Mönkeberg }\end{array}$ & $\begin{array}{c}\text { sehr viele Grund- } \\
\text { formen, vorwiegend } \\
\text { Synedren }\end{array}$ & - & $\begin{array}{l}\text { Seegrasstücke } \\
\text { und Fadenalgen }\end{array}$ & - & $\begin{array}{c}\text { Ostracoden und } \\
\text { grosse Crustaceen- } \\
\text { reste }\end{array}$ & $\begin{array}{l}2 \text { dornige } \\
\text { Cysten }\end{array}$ & \begin{tabular}{|c} 
Synedren \\
in langen \\
Ziigen \\
\end{tabular} \\
\hline 9. & $?$ &. & ." & - & - & - & - & - & $\ldots$ & Darm leer \\
\hline 10. & $?$ & " & " & Grundformen & - & $\begin{array}{c}\text { Seegrasstücke, } \\
\text { Fadenalgen }\end{array}$ & - & Crustaceenreste & $=$ & - \\
\hline 11. & 16 & $\begin{array}{c}18.6 . \\
1900\end{array}$ & $\begin{array}{l}\text { Seegras } \\
\text { bei } \\
\text { Möltenort }\end{array}$ & $\begin{array}{c}\text { Grundformen } \\
\text { vorwiegend, } \\
\text { Synedren sehr viel }\end{array}$ & - & $\begin{array}{l}\text { Ulven } \\
\text { und Fadenalgen }\end{array}$ & $\overline{-}$ & - & - & - \\
\hline 12. & 12 & $"$ & $"$ & - & & - & - & - & - & Darm lees \\
\hline 13. & 12 & ", & " & $\begin{array}{l}\text { Grundformen, } \\
\text { vorwiegend } \\
\text { Synedren }\end{array}$ & - & $\begin{array}{c}\text { Ulven- und Seegras- } \\
\text { stücke, } \\
\text { Faderalgen }\end{array}$ & $\frac{1 \mathrm{~T}}{\text { ventricosus }}$ & & & . \\
\hline 1. 11. 15. & 15 & $"$ & ", & $\begin{array}{l}\text { Grundformen, } \\
\text { vorwiegend } \\
\text { Synedren }\end{array}$ & - & $\begin{array}{c}\text { Ulven- und Seegras- } \\
\text { stücke, } \\
\text { Fadenalgen }\end{array}$ & - & - & & - \\
\hline 16. & 15 & $"$ & $"$ & $\begin{array}{l}\text { Grundformen, } \\
\text { vorwiegend } \\
\text { Synedren }\end{array}$ & - & fast nur Fadenalgen & - & - & - & - \\
\hline 7. 11. 18. & $\begin{array}{l}14 \\
13\end{array}$ & $\begin{array}{l}23.7 \\
1900\end{array}$ & $\begin{array}{c}\text { Florideen } \\
\text { und Seegras, } \\
\text { Strander } \\
\text { Bucht }\end{array}$ & $\begin{array}{l}\text { Grundformen, } \\
\text { vorwiegend } \\
\text { Synedren }\end{array}$ & - & Florideenstücke & + & - & 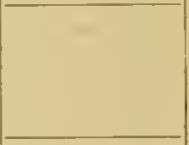 & - \\
\hline 9. 11. 20. & 15 & " & $"$ & $\begin{array}{l}\text { Grundformen, } \\
\text { vorwiegend } \\
\text { Synedren }\end{array}$ & - & $\begin{array}{c}\text { Florideenstïcke, } \\
\text { grosse } \\
\text { Seegrasstücke }\end{array}$ & - & - & & - \\
\hline 21. & $?$ & $\begin{array}{l}21.2 . \\
1899\end{array}$ & $"$ & $\begin{array}{c}\text { Synedren und } \\
\text { andere } \\
\text { Grundformen }\end{array}$ & 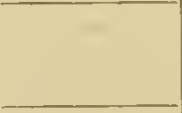 & $\begin{array}{c}\text { Florideentriebe und } \\
\text {-stücke, Fadenalgen, } \\
\text { Seegrasstïcke } \\
\end{array}$ & $\ldots$ & - & - & - \\
\hline 22. -24 & $?$ & $\begin{array}{l}5.8 . \\
1899\end{array}$ & $\begin{array}{c}\text { treibendes } \\
\text { Seegras, } \\
\text { Strander } \\
\text { Buclit }\end{array}$ & vorhanden & $\begin{array}{l}\text { Dinophysis, } \\
\text { Prorocentron } \\
\text { vereinzelt }\end{array}$ & Seegrasstìcke & $\begin{array}{c}\mathrm{T} . \\
\text { ventricosus } \\
\text { vereinzelt }\end{array}$ & $\begin{array}{c}\text { grosse } \\
\text { Crustaceenreste, } \\
\text { Eizellen }\end{array}$ & 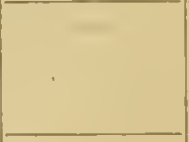 & (n) \\
\hline 5. แ. 26. & $?$ & $"$ & $\overline{1}$ & vorhanden & $\begin{array}{c}\text { Dinophysis, } \\
\text { Prorocentron } \\
\text { vereinzelt } \\
\end{array}$ & Seegrasstüicke & $\begin{array}{c}\text { T. } \\
\text { ventricosus } \\
\text { vereinzelt }\end{array}$ & Eizellen & - & $\cdots$ \\
\hline 27. 30 & $?$ & $\begin{array}{r}6.12 . \\
1899 \\
\end{array}$ & Kleverberg & Grundformen & 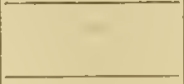 & $\begin{array}{l}\text { Seegrasstiicke, } \\
\text { Algentriebe }\end{array}$ & - & - & - & - \\
\hline 31 & 20 & $\begin{array}{c}28.10 \\
1899\end{array}$ & $\begin{array}{c}\begin{array}{c}\text { Ftorideen } \\
\text { bei } \\
\text { Boje Bülk A }\end{array} \\
\end{array}$ & $\begin{array}{l}\text { Cocconeis } \\
\text { und andere } \\
\text { Grundiormen }\end{array}$ & & Seegrasstücke & & - & & - \\
\hline 2.11 .33$. & $\begin{array}{l}15 \\
10\end{array}$ & " & $"$ & Grundformen & - & $\begin{array}{l}\text { Seegras- } \\
\text { und vorwiegend } \\
\text { Algensticke }\end{array}$ & & $\ldots$ & . & - \\
\hline 34. & 11 & $\begin{array}{c}23.7 . \\
1900\end{array}$ & $\begin{array}{l}\text { Strander } \\
\text { Grasberg }\end{array}$ & 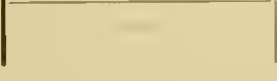 & - & - & - & $\underline{-}$ & - & - \\
\hline
\end{tabular}


standtheile. In den Exemplaren Nr. 22-26 jedoch fanden sich Planktonorganismen in grösscrer Zahl. Ich habe diese Asseln, die an treibendem Seegras sassen, mit cinem Oberilächennetz in der Strander Bucht gefangen. Vermuthlich werden die Peridineen, Tintinnen und Eizellen von den Idotheen erst in dem Netz anfgenommen worden sein. Sandkörnchen, die ich verschiedentlich fand, lasse ich unberüchsichtigt.

Von Jaera marina habe ich nur fünf Exemplare untersucht. In einem einzigen Thier fand ich kleine Crustaceenreste, in den anderen vier nur Seegras- mnd Algenstücke mit Grunddiatomcen, vornehmlich Synedra. Danach scheint Jaera eine ähnliche omnivore Lebensweise zu füliren wie ldothea. Sye ${ }^{1}$ ) schreibt: „Ihre Nahrung besteht meist aus pflanzlichen Stoffen, die sie am Meeresboden antreffen, doch verschmähen sie auch thierische Nahrung nicht, selbst tote Exemplare der eigenen Art werden nicht verschont".

Jaera marina Fabr.

\begin{tabular}{|c|c|c|c|c|c|c|c|c|}
\hline Nr. & $\begin{array}{l}\text { Länge } \\
\text { in } \\
\mathrm{mm}\end{array}$ & Fangzeit & Fangort & Diatomeen & Gew'ebspflanzen & Metazoen & $\begin{array}{c}\text { Unkenntlicise } \\
\text { Masse }\end{array}$ & Sand \\
\hline 1. 11. 2 & $\begin{array}{l}\text { ca. } 5 \\
\text { ca. } 6\end{array}$ & $\begin{array}{l}17.9 \\
1900\end{array}$ & $\begin{array}{c}\begin{array}{c}\text { Strand } \\
\text { bei } \\
\text { Heikendorf }\end{array} \\
\end{array}$ & $\begin{array}{l}\text { Synedren 11. and. } \\
\text { in spärlicher Menge }\end{array}$ & $\begin{array}{l}\text { Algen- } \\
\text { und Seegrasstïcke }\end{array}$ & & viel & vorhanden \\
\hline 3. & ca. 8 & " & " & $\begin{array}{l}\text { Synedren } 1 . \text { and. } \\
\text { in spärlicher Menge }\end{array}$ & $\begin{array}{c}\text { Algen- } \\
\text { und Seegrasstiicke }\end{array}$ & $\begin{array}{c}\text { kleine } \\
\text { Crustaceenstilcke }\end{array}$ & tiel & vorhandell \\
\hline 4. & ca. 8 & " & ." & $\begin{array}{c}\text { Synedren } \\
\text { in spärlicher Menge }\end{array}$ & $\begin{array}{c}\text { sehr viel Seegras- } \\
\text { und vorwiegend } \\
\text { Algenstücke }\end{array}$ & - & $?$ & wenig \\
\hline 5. & ca. 11 & " & $"$ & $\begin{array}{c}\text { Synedren } \\
\text { in spärlicher Menge }\end{array}$ & $\begin{array}{l}\text { sehr viel } \\
\text { Algensticke }\end{array}$ & - & $?$ & wenig \\
\hline
\end{tabular}

Der Idothea ähnlich im Vorkommen und Ernährungsweise ist Gammarus locusta, der gemeinste Flohkrebs der Kieler Föhrde (Tabelle siehe S. 19 13. 20). Ich habe 38 Thiere untersucht und in allen nuit Ausnahme von 7, deren Darm entweder leer oder spärlich oder mit unkemntlicher Masse gefüllt war, Seegrasund Algenstücke gefunden. Diatomeen waren nicht so regelmässig wie bei Idothea naclizuweisen; andererseits fand ich sie im Darm einiger Thiere, in denen nur spärliche Pflanzenstücke vorhanden waren, in grosser Menge. Vermuthlich werden sie von den betreffenden Thieren abgeweidet worden sein, wobei dann einzelıe Stücke der als Unterlage dienenden Pflanzen mit abgerissen sein mögen. Thierisclie Reste liabe ich auch bei Gammarns nur spärlich gefunden. Abgesehen von vereinzelten Schwammnadelu und einer Chätopodenborste, die sicherlich keine Bedeutung gehabt haben, stiess ich wiederholt auf zertrümmerte kleine oder grössere Crustaceenreste, die keine Deutung mehr zuliessen. Dass sie nicht etwa bei der Präparation der Thiere in das Präparat gekommen sein konnten, sah ich daraus, dass sie stets leer und ohne Pigment waren. Von Planktonorganismen habe ich im Darm eines Thieres (Nr. 1) Bruchstücke von mehreren Ceratien (C. tripos) gefunden; besonders auffallend ist das Vorkommen verschiedemer Organismen des Süsswasserplanktons im Darm der letzten 10 Thiere, die aus dem Kaiser Willelm-Kanal vou kı 89,5 stammen, und dort zwischen Muscheln, Schnecken und Balaniden gelebt haben. Die Protococcoideen, die sich vereinzelt in Darm einiger dieser Thiere fanden, waren leer, ebenso verschicdene der Rotatorien. Ob die Organismen als lebende Planktonwesen oder als tote Bestandtheile des zwischen den Muscheln sich ansammelnden Detritus aufgenommen worden sind, lässt sich schwer cutscheiden. Mehrere Pollentörner, von Coniferen stammend, und einige Stücke prosenchymatösen Holz-(?) gewebes werden wohl ncbensåchliche Bestandtheile gewesen sein. Auch vou der Ernährungsweise dieses Krehses geben die Darmuntcrsuchungen allein kein richtiges Bild. Zwar sieht man im Aquarim Gammarus auch oft Pflanzen fressen und Hensen ²)

1) Christ. Georg Sye: Beiträge zur Anatomie und llistologie von Jaera marina. lnang.-Dissert. Kiel. Kiel 1887, p. 8.

i) 1. c. p. 101 . 
schreibt, dass Gammarus und andere Amphipoden in Gemeinschaft mit /dothea in seinem Versuchsaquarium grossen Schaden unter den Roth- und Braunalgen angerichtet haben. Aber man kann auch beobachten, wie Gammarus mit grosser Begierde nach den Miesmuschelstückchen fahndet, die als Futter in die Aquarien geworfen werden.

Bei Fütterungsversuchen erwies sich Gammarus als ein gefrässiger Räuber. So liess ich eimmal zwei Exemplare, 23 beziehungsweise $15 \mathrm{~mm}$ lang, 22 Stunden hungern und setzte dann eine etwa $40 \mathrm{~mm}$ lange Capitella capitata in das Gefäss, in dem sich die Krebse befanden. Sofort stürzten sich diese auf den Wurm und hatten ihn in kaum einer halben Stunde bis auf geringe Reste verzehrt. Ein anderes Mal brachte ich zwei mittelgrosse Gammarus, ohne sie vorher in filtrirtem Wasser hungern zu lassen, in ein Gefäss, in dem sich eine ca. $25 \mathrm{~mm}$ lange Mysis flexuosa befand. Auch diese fiel den Flohkrebsen nach kurzer Jagd zum Opfer und war bald verzehrt. Wenn ich den Krebsen gleichzeitig Seegras und animalische Nahrung anbot, wurde meistens ersteres vorgezogen.

Auch Amathilla Sabinei (Tabelle siehe S. 21) rechne jch zu den Thieren, die sich vorwiegend von grosspflanzlicher Kost nähren. Freilich habe ich im Darm zweier Individuen keine Pflanzenstücke gefunden, aber in beiden Fällen war der Darm auch nur spärlich gefüllt. In den übrigen untersuchten Thieren waren grössere Pflanzenstücke in kleinerer oder grösserer Menge vorhanden. Diatomeen waren immer vorhanden und unter ihnen prävalirten gewöhnlich Synedren und die schon erwähnten, nicht genau zu bestimmenden Melosiraketten. Von thierischen Bestandtheilen des Darminhaltes sind zu erwähnen: Spongiennadeln, die ich in jedem Thier vereinzelt, in einem etwas zahlreicher fanden, in einem Darm vereinzelte zerbrochene Chätopodenborsten, in drei Exemplaren vereinzelte leere Eizellen und schliesslich in einem Thier eine Halacaride; ein Thier hatte auch einen Tintinnus ventricosus aufgenommen.

Von Amphithö̈ podoceroides habe ich nur sechs Exemplare untersucht, von denen ich fünf am 6. November 1899 am Kleverberg und eins am 23. Juli 1900 am Strander Grasberg gefangen hatte. Sie hatten sämmtlich grosse Algenstücke - zum Theil mit Diatomeen — im Darm. Animalische Bestandtheile sind mir nicht aufgefallen.

Amphithoë podoceroides Rathke.

\begin{tabular}{c|c|c|c|c}
\hline \hline Nr. & $\begin{array}{c}\text { Länge } \\
\text { in } \\
\text { mm }\end{array}$ & Fangzeit & Fangort & Darminhalt \\
\hline 1.- -5. & $?$ & 6.11 .1899 & Kleverberg & Algenstücke, besonders junge Triebe \\
6. & J2 & 23. 7.1900 & $\begin{array}{c}\text { Strander } \\
\text { Grasberg }\end{array}$ & grosse Florideenstiicke mit Diatomeen
\end{tabular}

Ebensowenig habe ich thierische Reste im Darm von Orchestia litorea (Tabelle sielıe S. 22) bemerkt, sondern nur grössere oder kleinere Pflanzenstücke mit spärlichen Diatomeen. Orchestia hat, wie schon erwähnt, das Wasserleben aufgegeben und hält sich in dem an den Strand gespülten Seegras auf. Doch soll dieser Krebs, ebenso wie der verwandte Talitrus, nicht ausschliesslich auf pflanzliche Nahrung angewiesen sein und thierische Nahrung keineswegs verschmähen. Spence Bate und Westwood ${ }^{1}$ ) schreiben darüber - in erster Linie freilich von Talitrus - wie folgt: „..... they come out to feed upon any carrion left by the retiring tide. Offal which would otherwise decompose and infect the air is thus by their assistance often rapidly removed. They are not very daintly feeders. We have seen them enjoyiny their repast upon a common earthworm; drowned puppies and other mammals afford a luxury to thousands; and, when they can get nothing else, they are content to feed upon each other".

l) 1. c. p. 21 . 
E. Rauschenplat, Ueber die Nahrung von Thieren aus der Kieler Bucht.

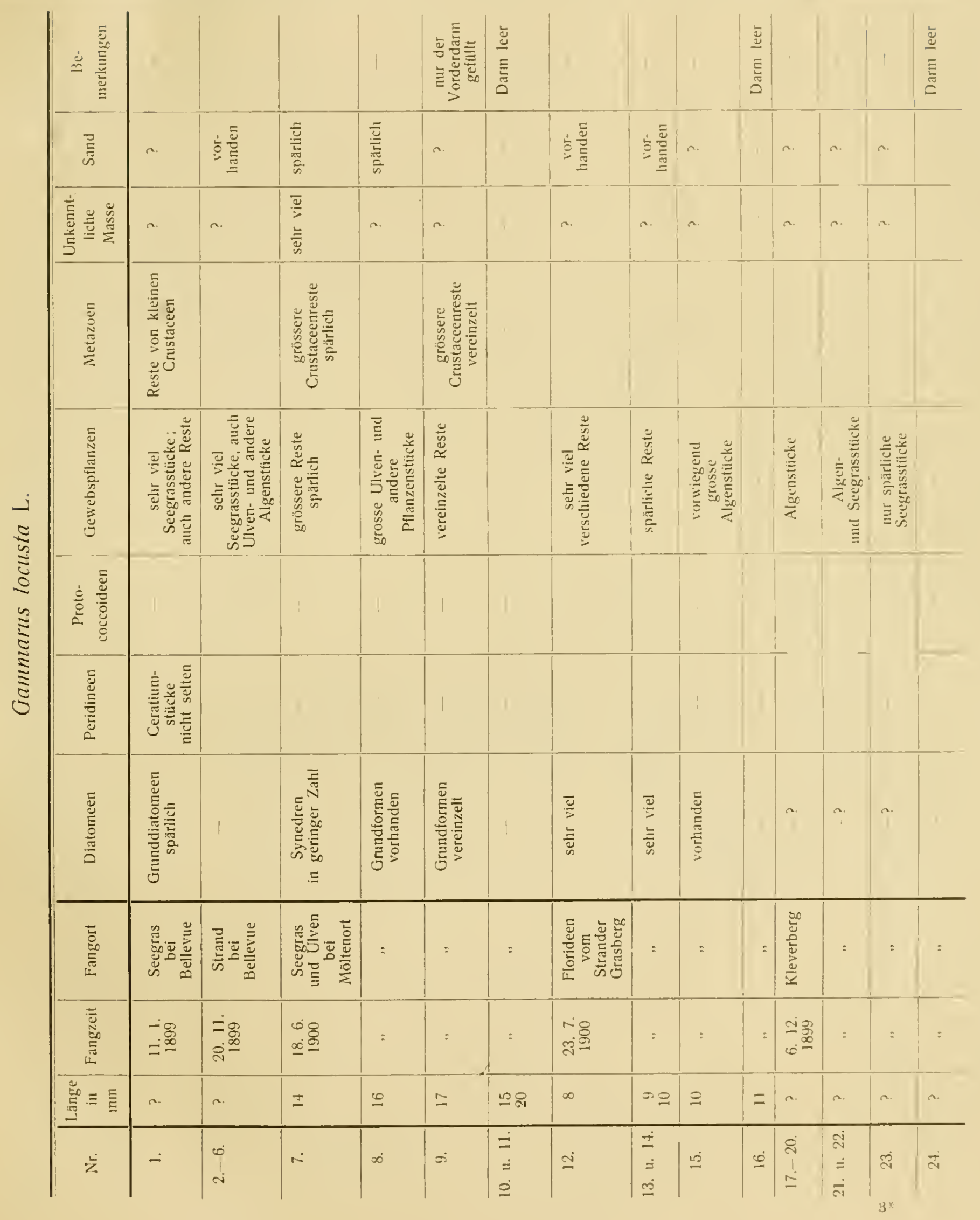


E. Rauschenplat, Ueber die Nahrung von Thieren aus der Kieler Bucht.

\begin{tabular}{|c|c|c|c|c|c|c|c|c|c|c|c|c|c|}
\hline 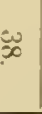 & $\stackrel{\sim}{\sim}$ & $\ddot{~}$ & $\stackrel{\omega}{M}$ & $\dddot{m}$ & $\underset{\omega}{\omega}$ & $\stackrel{\mathscr{N}}{\mathrm{N}}$ & ن̈ & $\dddot{\%}$ & ש: & $\begin{array}{l}= \\
= \\
\infty\end{array}$ & $\tilde{\infty}$ & $\stackrel{v}{0}$ & z \\
\hline$\vec{v}$ & $\vec{r}$ & $\mp$ & $\mp$ & क & $\vec{r}$ & $\vec{\omega}$ & $\mp$ & $\mp$ & . & $v$ & $v$ & $v$ & 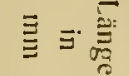 \\
\hline 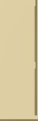 & $=$ & $=$ & : & $=$ & $=$ & $=$ & $=$ & : & $\overline{5}$ & $=$ & : & $\begin{array}{l}\vec{\infty} \overline{0} \\
\vec{c}\end{array}$ & 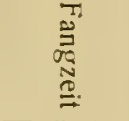 \\
\hline & : & & $=$ & : & $=$ & $=$ & : & & 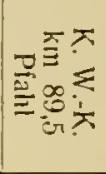 & $=$ & : & 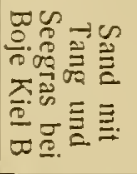 & 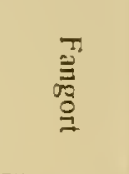 \\
\hline & 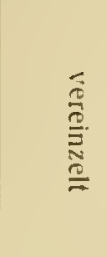 & 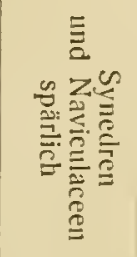 & $v$ & 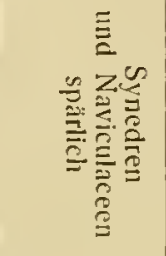 & & 衰 & 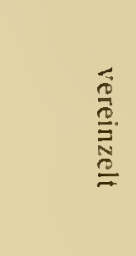 & & & 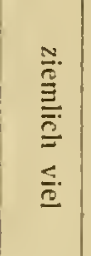 & 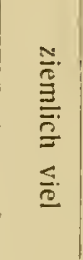 & & 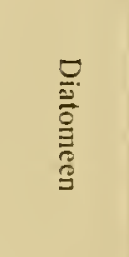 \\
\hline 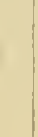 & & & $f$ & & & 1 & 1 & 1 & & 1 & 1 & 1 & 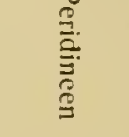 \\
\hline 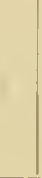 & 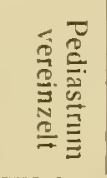 & 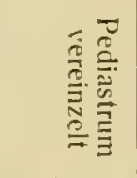 & ] & 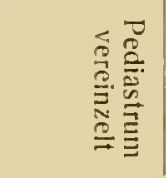 & & & & & & 1 & 1 & & 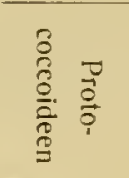 \\
\hline & 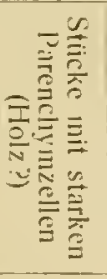 & 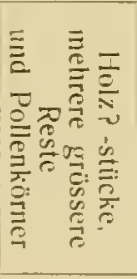 & 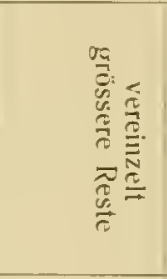 & 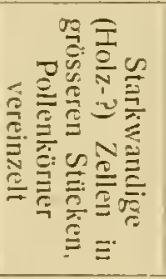 & & 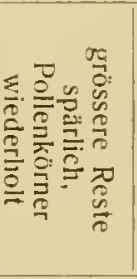 & 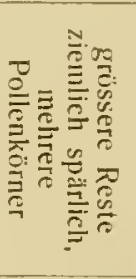 & 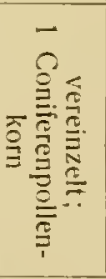 & 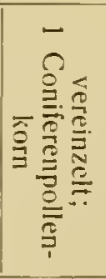 & 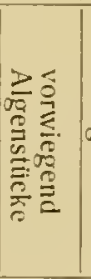 & 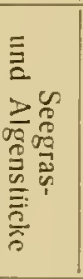 & 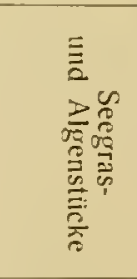 & 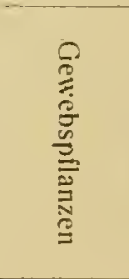 \\
\hline & 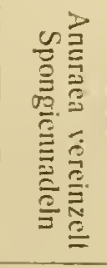 & 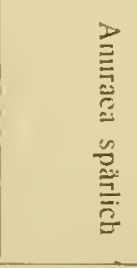 & 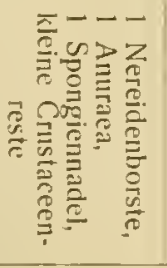 & 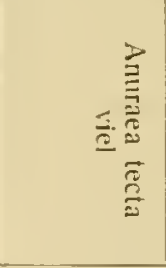 & & 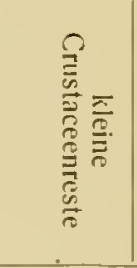 & 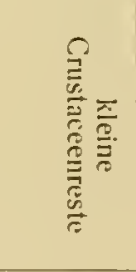 & 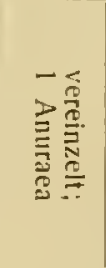 & 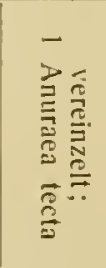 & & & & 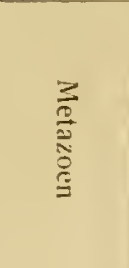 \\
\hline 点 & 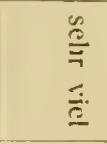 & 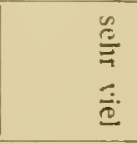 & 咅. & 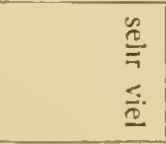 & & 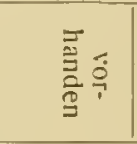 & 可 & 䓂 & 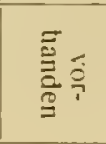 & $v$ & $\omega$ & $v$ & 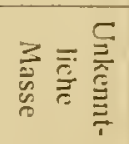 \\
\hline$v$ & 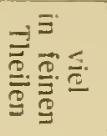 & $v$ & 充. & $v$ & I & 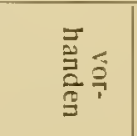 & 产 & 产 & 产 & $v$ & $v$ & $v$ & $\stackrel{\mathscr{Z}}{\Xi}$ \\
\hline & & & & & 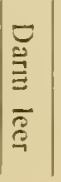 & & & 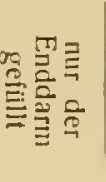 & 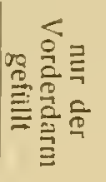 & & & f & 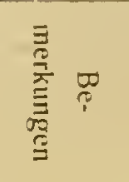 \\
\hline
\end{tabular}




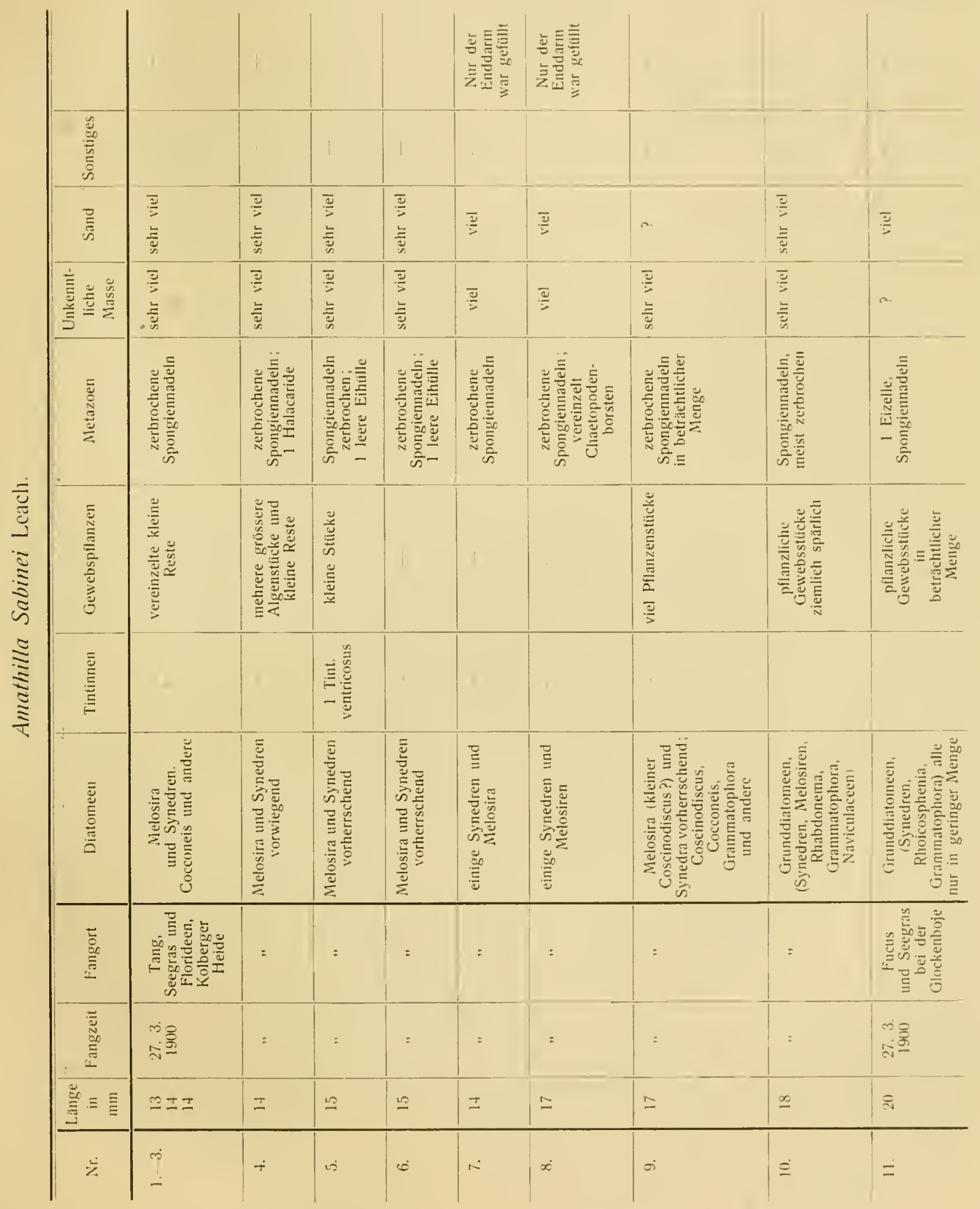


Orchestia litorea Montagu.

\begin{tabular}{|c|c|c|c|c|c|c|}
\hline Nr. & $\begin{array}{l}\text { Lãnge } \\
\text { in } \\
\text { min }\end{array}$ & Fangzeit & Fangort & Diatomeen & Gewebspflanzen & Sand \\
\hline $1 .-5$. & $\begin{array}{l}10 \\
12 \\
12 \\
15 \\
15 \\
\end{array}$ & 10.7. 1899 & $\begin{array}{c}\text { Strand } \\
\text { bei } \\
\text { Bellevue } \\
\end{array}$ & vereinzelt Cocconeis & $\begin{array}{l}\text { grosse Stücke von } \\
\text { Seegras } \\
\text { und vereinzelt von } \\
\text { anderen Pflanzen }\end{array}$ & wenig \\
\hline 6. & 10 & 17. 9.1900 & $\begin{array}{l}\text { Strand } \\
\text { bei } \\
\text { Bellevut }\end{array}$ & $\begin{array}{l}\text { Cocconeis, } \\
\text { 2. noch auf den } \\
\text { Seegrasstiucken } \\
\text { sitzend }\end{array}$ & grosse Seegrasstücke & $?$ \\
\hline 7. & 11 & " & , & Cocconeis spärlich & $\begin{array}{c}\text { grosse Seegrasstủcke } \\
\text { (die Zellen z. T. mit } \\
\text { frischem fnhalt) }\end{array}$ & ? \\
\hline 8. & 12 & , & $"$ & $\begin{array}{c}\text { vereinzelte leere } \\
\text { Schalen }\end{array}$ & Seegrasstücke & wenig \\
\hline 9. & 12 & ." & . & - & $\begin{array}{c}\text { kleine, stark zersetzte } \\
\text { Seegrasstiicke }\end{array}$ & sehr wenig \\
\hline 10. & 9 & ", & " & $\begin{array}{l}\text { wenig leere } \\
\text { Schalen }\end{array}$ & $\begin{array}{c}\text { kleine, stark zersetzte } \\
\text { Seegrasstïcke }\end{array}$ & wenig \\
\hline
\end{tabular}

Die Nahrung von Litorina litorea besteht nach Meyer und Möbins') aus pflanzlichen und thierischen Stoffen. Die Ergebnisse meiner Untersuchungen und Beobachtungen stimmen vollkommen damit überein. Im Darminhalt überwogen die vegetabilischen Bestandtheile immer. Es ist dabei wohl in Betracht zu ziehen, dass an den Stellen, wo ich die meisten Thiere gefangen habe, pflanzliche Organismen prävaliren, und ferner, dass die Litorinen infolge ihrer geringen Ortsbewegungsfähigkeit nicht sehr zur Verfolgung anderer Thiere geeignet sind. Von 24 Exemplaren, die ich auf ihren Darminhalt untersucht habe, hatten 22 grössere und kleinere Pflanzenstücke gefressen. Das eine der beiden Thiere, deren Darminhalt frei von Pflanzenstücken war, (Nr. 2) stammte aus der Region des lebenden Seegrases in der Wiker Bucht, das andere (Nr. 24) von einem Pfahl bei Bellevue. Im letzteren Fall ist der Mangel an vegetabilischen Nahrungsbestandtheilen nicht überraschend, denn an den Pfählen treten die pflanzlichen Organismen gegen die thierischen zurück, und diese letzteren sind zum grossen Theil den Schnecken wohl zugänglich, da sie festsitzen und keine ausreichenden Schutzvorrichtungen besitzen. In England werden die Strandschnecken nacl Meyer und Möbius') in die Austernparks gesetzt, um die Algen, die die Verschlammung nnd Versandung der Bänke verursachen, zu vertilgen. Im Darm sämmtlicher untersuchten Thiere habe ich sehr viel Diatomeen gefunden. Nur in einem Fall (Nr. 22) habe ich im Protokoll keine verzeichnet; ich glaube jedoch, dass es versehentlich unterblieben ist. Im Aquarium sieht man die Litorina oft an den Wänden kriechen und die Ueberzüge von mikroskopischen Pflanzen und Thieren abweiden, die Spuren ihrer Radulaarbeit als Zeichnung zurücklassend (Meyer und Möbius\%). Von thierischen Bestandtheilen fand ich in zwei Exemplaren (Nr. 8 und 18) eine Cyprislarve von Balanus, in drei anderen (Nr. 2, 19 und 20) einen Tintinuus ventricosus. Vermuthlich sind diese Organismen in totem Zustande aufgenommen worden. Vereinzelte Spongiennadeln habe ich nur in einem Fall notirt, doch steht es ansser Zweifel, dass sie ebenso wie Sand und Detritus auch im Darm anderer Thiere vorhanden waren. Besonders bemerkenswerth sind die Exemplare Nr. 16 und 17. Bei itmen habe ich richtigen Spongienfrass konstatiren können. Die Nadeln waren zum grossen Theil noch durch Gewebe mit einander verbunden und in so grosser Menge vorhanden, dass schon aus diesem Grunde die Möglichkeit einer zufälligen Aufnahme ausgeschlossen ist. 
Litorina litorea L.

\begin{tabular}{|c|c|c|c|c|c|c|c|c|c|}
\hline Nr. & $\begin{array}{c}\text { Höle } \\
\text { in } \\
\text { mm }\end{array}$ & Fangzeit & Fangort & Diatomeen & Tintinnen & Gewebsplancen & Metazoen & $\begin{array}{c}\text { Untiennt- } \\
\text { liche } \\
\text { Masse }\end{array}$ & Sand \\
\hline 1. & $?$ & 11.1 & $\begin{array}{l}\text { Seegras } \\
\text { bei } \\
\text { Bellevue }\end{array}$ & $\begin{array}{l}\text { Selir viel Cocconeis, } \\
\text { daneben auch } \\
\text { Naviculaceen, Synedren } \\
\text { und Rhoicosphenia } \\
\end{array}$ & - & $\begin{array}{l}\text { mehrere } \\
\text { Gewebstheile }\end{array}$ & & $?$ & ziemlich viel \\
\hline 2. & $?$ & $\begin{array}{l}6.7 \\
1899\end{array}$ & $\begin{array}{l}\text { Seegras in der } \\
\text { Wiker Bucht }\end{array}$ & $\begin{array}{l}\text { sehr viel } \\
\text { Grunddiatomeen } \\
\end{array}$ & $\begin{array}{l}1 \text { Tint. } \\
\text { ventricosus } \\
\end{array}$ & - & & ? & $?$ \\
\hline 3. เ1. 4 & $\begin{array}{l}17 \\
19\end{array}$ & $\begin{array}{l}17.8 \\
1900\end{array}$ & $"$ & $\begin{array}{l}\text { sehr viel } \\
\text { Grunddiatomeen, } \\
\text { vorhesrschend } \\
\text { Cocconeis }\end{array}$ & - & $\begin{array}{l}\text { vereinzelte } \\
\text { Seegrasstucke }\end{array}$ & & viel & $?$ \\
\hline 5. & 20 & ," & " & $\begin{array}{c}\text { sehr viel } \\
\text { Grunddiatomeen, } \\
\text { rorherrschend } \\
\text { Cocconeis }\end{array}$ & - & $\begin{array}{l}\text { grössere Seegras- } \\
\text { und Algenstiicke }\end{array}$ & & viel & ? \\
\hline 6. & 22 & " & " & $\begin{array}{l}\text { sehr viel } \\
\text { Grunddiatomeen, } \\
\text { rorherrschend } \\
\text { Synedren } \\
\end{array}$ & - & $\begin{array}{l}\text { grössere Seegras- } \\
\text { und Algenstiicke }\end{array}$ & & vitel & $?$ \\
\hline 7. & 22 & " & $"$ & $\begin{array}{c}\text { Grunddiatomeen } \\
\text { spärlich }\end{array}$ & - & $\begin{array}{c}\text { grosse } \\
\text { Seegrasstuicke }\end{array}$ & & ? & $?$ \\
\hline 8. & $?$ & $\begin{array}{r}24.7 \\
1899\end{array}$ & $\begin{array}{l}\text { Florideen } \\
\text { bei Boje C }\end{array}$ & $\begin{array}{c}\text { Grunddiatomeen } \\
\text { viel }\end{array}$ & $\cdots$ & $\begin{array}{c}\text { grosse Algenstïcke } \\
\text { und -fäden }\end{array}$ & $\begin{array}{l}\text { 1 Balanidenlarve } \\
\text { (Cyprisstadium) }\end{array}$ & ? & ziemlich wenig \\
\hline 9. & 16 & $\begin{array}{l}23.7 \\
1900\end{array}$ & $\begin{array}{l}\text { Florideen } \\
\text { anl } \\
\text { Strander } \\
\text { Grasberg } \\
\end{array}$ & $\begin{array}{l}\text { Sehr viel lange } \\
\text { Synedren, } \\
\text { daneben andere } \\
\text { Diatomeen }\end{array}$ & - & $\begin{array}{l}\text { viel } \\
\text { Florideenstiicke }\end{array}$ & - & $?$ & ? \\
\hline 10. 11. 11. & $\begin{array}{l}13 \\
15\end{array}$ & " & $"$ & $\begin{array}{c}\text { wie die vorige, } \\
\text { doch überwiegen die } \\
\text { Synedren nicht so sehr }\end{array}$ & - & $\begin{array}{l}\text { selur viel } \\
\text { Florideenstiocke }\end{array}$ & & $?$ & ziemlich viel \\
\hline 12. แ1. 13. & $\begin{array}{l}15 \\
17 \\
\end{array}$ & $"$ & " & wie die vorigen & - & $\begin{array}{l}\text { viel } \\
\text { Florideenstuicke }\end{array}$ & - & ? & $?$ \\
\hline 14. & $?$ & $\begin{array}{l}21.2 . \\
1899\end{array}$ & Kleverberg & $\begin{array}{c}\text { Rhabdonema, Gramma- } \\
\text { tophora, Rhoicosphenia, } \\
\text { Synedra u. a. }\end{array}$ & 一 & Algenstücke & - & $?$ & wenig \\
\hline 15. & $?$ & ", & $"$ & wie die vorige & - & $\begin{array}{l}\text { Algenstijcke und } \\
\text {-triebe }\end{array}$ & - & viel & wenig \\
\hline 16. แ1. 17. & $?$ & $\begin{array}{c}28.10 \\
1899\end{array}$ & $\begin{array}{l}\text { Florideen } \\
\text { zw. Heulboje } \\
\text { und Builk A } \\
\end{array}$ & $\begin{array}{l}\text { Grunddiatomeen } \\
\text { vorhanden }\end{array}$ & - & Florideenstïcke & $\begin{array}{c}\text { Stiicke von } \\
\text { Amorphina panicea }\end{array}$ & ? & ? \\
\hline 18. & 22 & $\begin{array}{l}2.6 . \\
1900\end{array}$ & $\begin{array}{c}\text { Sand mit } \\
\text { Florideen } \\
\text { Stoller Grund }\end{array}$ & $\begin{array}{l}\text { Grunddiatomeen } \\
\text { selır viel }\end{array}$ & $\begin{array}{l}1 \text { Tint. } \\
\text { ventricosus }\end{array}$ & $\begin{array}{l}\text { Pflanzenreste } \\
\text { spärlich }\end{array}$ & $\begin{array}{c}1 \text { Balanidenlarve } \\
\text { (Cyprisstadium) } \\
\text { Spongicunadeln } \\
\text { vereinzelt }\end{array}$ & ? & $\begin{array}{l}\text { grosse } \\
\text { Körnchen }\end{array}$ \\
\hline 19. 11. 20. & 18 & . & $"$ & $\begin{array}{l}\text { Grunddiatomeen viel, } \\
\text { Synedra vorherrschend }\end{array}$ & $\begin{array}{c}1 \text { Tint. } \\
\text { ventricosus } \\
\text { (nur in 19) } \\
\end{array}$ & wie die vorige & - & viel & ziemlich wenig \\
\hline 21. & 23 & $"$ & ", & wie die vorigen & - & wie die vorigen & - & viel & $\begin{array}{l}\text { ziemlich wenig, } \\
\text { aber grosse } \\
\text { Körnclien }\end{array}$ \\
\hline 22. & 17 & $\begin{array}{l}9.6 \\
1900\end{array}$ & $\begin{array}{l}\text { K. W.-K. } \\
\text { Knoop } \\
\text { Dredge }\end{array}$ & - ? & $\ldots$ & $\begin{array}{l}\text { grossere Algenfäden } \\
\text { und Pllanzenstiicke }\end{array}$ & & selır viel & viel \\
\hline 23. & 13 & $"$ & ", & $\begin{array}{l}\text { ziemlich viel } \\
\text { Grunddiatomeen }\end{array}$ & - & $\begin{array}{c}\text { grössere } \\
\text { Pflanzenstücke }\end{array}$ & 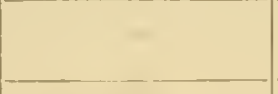 & Sehr viel & viel \\
\hline 24. & $?$ & $\begin{array}{l}11.2 . \\
1899\end{array}$ & $\mid \begin{array}{c}\text { Pfalil } \\
\text { hei Bellerue }\end{array}$ & $\begin{array}{l}\text { sehr viel } \\
\text { Grunddiatomeen }\end{array}$ & 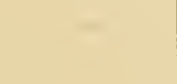 & $=$ & -3 & ? & $?$ \\
\hline
\end{tabular}


Meyer und Möbius sahen Strandschnecken Fleisch von Säugethieren fressen, und im Aquarium habe ich beobachtet, wie eine Litorina die Schliessmuskelreste einer klaffenden, ausgenommenen Miesmuschel verzehrte. Fütterungsversuche, die ich wiederholt mit Litorina angestellt habe, sind mir stets misslungen. Die Schnecken blieben, selbst in ganz reinen Gefässen und in filtrirtem Wasser tagelang an den Glaswänden, ohne die ihnen dargebotene Nahrung zu beachten. Es ist bekannt, dass manclie Schnecken monate- und jahrelang ohne Nahrung leben können. Krukenberg ${ }^{1}$ ) erwähnt, dass Heliciden jahrelang, in Schächtelcheı verpackt, an Leben geblieben sind, und dass andere Schnecken (?), die im britischen Museum mit dem Gehăuse an einer Unterlage festgeklebt waren, nach Jahren davongekrochen sind. Der eben erwähnte Umstand, dass die Strandschnecken bei den Fütterungsversuchen die angebotene Nahrung nicht beachteten, lässt sich vielleicht zum Theil auch auf Mangel an Witterungsvermögen zurückführen. Nagel ') konute wenigstens bei Litorina und anderen Meeresschnecken „irgend welche Anziehungsreaktionen nicht erzielen“. Bue rke l") fing in seinen Reusen im ganzen nur drei Exemplare dieses gemeinen Thieres. Andere hier vorkommende grössere Prosobranchier habe ich nur vereinzelt oder garnicht gefangen und darum keine Untersuchungen an ihnen anstellen können. Bei der Besprechung der Räuber komme ich auf einige zurück. - Zum Schluss sei noch erwähnt, dass der Darminhalt bei Litorina, und auch bei Rissoa und Cerithium stets aus kleinen regelmässigen Ellipsoiden bestand. Bei Litorina waren sie etwa $0,8 \mathrm{~mm}$ lang, bei den kleineren Schnecken erheblich kürzer.

Acera bullata.

\begin{tabular}{|c|c|c|c|c|c|c|c|c|}
\hline $\mathrm{Nr}$. & $\left|\begin{array}{c}\text { Länge } \\
\text { in } \\
\text { mm }\end{array}\right|$ & Fangzeit & Fangort & Diatomeen & Gewebspflanzen & Metazoen & $\begin{array}{l}\text { Unkennt- } \\
\text { liche } \\
\text { Masse }\end{array}$ & Sand \\
\hline 1.-3. & ? & $\begin{array}{l}11.2 . \\
1899\end{array}$ & $\begin{array}{c}\text { Grenze des } \\
\text { lebenden } \\
\text { und toten } \\
\text { Seegrases } \\
\text { bei Bellevie } \\
\end{array}$ & $\begin{array}{c}\text { Grunddiatomeen: } \\
\text { Cocconeis, } \\
\text { Naviculaceen, Rhoico- } \\
\text { sphenia, Gramma- } \\
\text { tophora und andere } \\
\end{array}$ & $\begin{array}{c}\text { grosse zartwandige, } \\
\text { meist leere Zellen, } \\
\text { vermuthlich von } \\
\text { Algen }\end{array}$ & - & wenig & sehr viel \\
\hline 4. & $?$ & $\begin{array}{l}18.6 \\
1900\end{array}$ & $\begin{array}{c}\text { Mud } \\
\text { zwischen } \\
\text { Bellevue und } \\
\text { Holtenau } \\
\end{array}$ & - & $\begin{array}{l}\text { grössere } \\
\text { Pflanzenstijcke } \\
\text { spärlich }\end{array}$ & $\begin{array}{c}\text { kleine } \\
\text { Crustaceenreste } \\
\text { vereinzell }\end{array}$ & sehr viel & viel \\
\hline 5. 11. 6. & $\begin{array}{l}8 \\
9\end{array}$ & $\begin{array}{l}23.7 \\
1900\end{array}$ & $\begin{array}{c}\text { Fucus } \\
\text { am } \\
\text { Kleverberg }\end{array}$ & $\begin{array}{l}\text { sehr viel } \\
\text { Grunddiatomeen }\end{array}$ & $\begin{array}{c}\text { grössere } \\
\text { Florideenstücke } \\
\text { ziemlich viel }\end{array}$ & 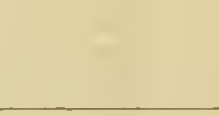 & ziemlich & ziemlich viel \\
\hline 7. & 8 & " & $\begin{array}{l}\text { Algen und } \\
\text { totes } \\
\text { Seegras } \\
\text { am Stoller } \\
\text { Grund }\end{array}$ & $\begin{array}{c}\text { wenig } \\
\text { Grunddiatomeen }\end{array}$ & $\begin{array}{l}\text { Pflanzenstüeke } \\
\text { spărlich }\end{array}$ & -. & viel & $\begin{array}{l}\text { viel } \\
\text { selar grosse } \\
\text { Körner }\end{array}$ \\
\hline 8. & 6 & .. & . & $\begin{array}{l}\text { Grunddiatomeen viel, } \\
\text { vorwiegend Synedren }\end{array}$ & - & - & viel & $\begin{array}{c}\text { viel, } \\
\text { keine grossen } \\
\text { Köoner } \\
\end{array}$ \\
\hline 9. & 6 & , & $"$ & Grunddiatomeen viel & $\begin{array}{c}\text { Pflanzenstücke } \\
\text { vereinzelt }\end{array}$ & - & viel & wenig \\
\hline
\end{tabular}

Von Acera bullata, der gemeinen Kugelschnecke, habe ich neun Exemplare untersuclıt. Im Darm von acht Thieren labe ich Pflanzenstücke gefunden, jedoch fast immer nur in geringer Menge. Ebenfalls mit einer Ausnalme batten sämmtliche neun Thiere Grunddiatomeen aufgenommen, zum Theil in grosser Menge. Dic Kugelsclnnecken bewohnen vorzugsweise das Gebiet der toten Pflanzen, und sechs der unter-

1) C. Irr. W. Krnkenherg: Grundzïge einer vergleichenden Physiologie der Verdaung. Heidelleerg 1882.

$\Rightarrow$ W. A. Nagel: Vergleichende plysiologische und anatomische Untersuchungen ïher den Geruchs- und Geschrnackssinn und ihre Organe mit einleitenden Betracirtungen aus der allgemeinen vergleichenden Simnesphysiologie. Gekrönte Preissehrift. Bibliotheca zoologica. Bd. 70. 189496 . Stuttgart.

$$
\text { i) 1. } c \text {. }
$$


suchten Exemplare habe ich dort gefangen. Der Darm dieser sechs so wie eines im Mud gefangenen enthielt die pflanzlichen Bestandtheile in besonders spärlicher Menge, während sich bei zwei in der Region des lebenden Fucus gefundenen Thieren pflanzliche Zellkomplexe ziemlich viel nachweisen liessen. Die abgestorbenen Pflanzentheile sind, wie schon oben erwähnt, der Verdanung leichter zugänglich als die lebenden. Kleine thierische Reste fand ich nur in dem einen Exemplar, das aus dem Mud der Wiker Bucht stamnt, und zwar waren es kleine Crustaceenreste. Spongiennadeln habe ich ausser acht gelassen, weil sie doch nur zufällig aufgenommen sind, ebensowenig lege ich dem Sand, der im Darm sämmtlicher Thiere vorhanden war, Bedeutung bei. Unkenntliche Masse bildete fast stets einen grossen Bestandtheil des Darminhaltes; ob es sich um feinen Detritus oder mm Verdaumgsprodukte handelt, komnte ich nicht cntscheiden. Im Aquarium habe ich eine Acera Miesmuschelfleisch fressen sehen, und konnte durcl diese freilich nur gelegentliche Beobachtung, „die schon früher von Möbius gemachte Beobachtung, dass sich das Thier nicht allein von Pflanzen nährt, sondern auch Fleisch geniesst", bestätigen. Buerkel ${ }^{1}$ ) hat in seinen Reusen im ganzen 32 Kugelschnecken gefangen, davon 27 in solchen, die mit faulem Köder versehen waren, 4 in leeren und 1 in Reusen mit frischem Fleischköder. Offenbar bevorzugt das Thier demnach faules Fleisch. Aber damit ist keineswegs die Behauptung Buerkel's gerechtfertigt, dass Acera „ein offenbarer Fleischfresser" ist.

\section{Thiere, die sich vorzugsweise von kleinpflanzlicher Kost nähren.}

Von solchen Thieren, die hauptsächlich Grunddiatomeen fressen, habe ich zwei gefunden, Risson octona L. und Cerithium reticulatum da Costa.

Rissoa octona (Tabelle siehe S. 26) findet sich in grossen Mengen in den Regionen der lebenden Pflanzen. Im Seegras der Wiker Bucht habe ich sie massenhaft gefangen; manchmal bildeten sic den Hauptinhalt des Netzes, und an den Seegrasblättern, die von der Dredge losgerissen wurden, sassen sie in grosser Zahl. Auch im Aquarium habe ich sie wiederholt am Seegras und an andern Pllanzen kriechend gesehen. Jedoch ergab die Darmuntersuchung, dass Pflanzenstücke nur eine untergeordnete Rolle als Nahrung für die Schnecken spielen. 18 von den von mir untersuchten Exemplaren hatten bestimmt keine Pflanzenstücke im Darm, bei drejen ist es unsicher, weil ich im Untersuchungsprotokoll keine bestimuten Angaben gemacht habe, und in Darm der übrigen 13 waren vegetabilische Zellkomplexe spärlich oder vereinzelt. Dagegen waren Grunddiatomeen immer vorhanden, in vier Thieren in spärlicher Menge, im Darm der übrigen zahlreich. Die häufigsten unter den Diatomeen waren Cocconcis, Synedra, Melosira, Grammatophora, Rhoicosphenia; Coscinodiscus, der ebenfalls nicht selten war, fand sich meist in Bruclistücken. Cocconeis war die gemeinste Form in Darm der Thiere, die bei Bellevule geiangen waren, während sie, je weiter der Fangort im äussern Theile der Föhrde lag, desto mehr zurücktrat. Die vier Thiere, deren Darm nur spärlich Diatomeen enthielt (Nr. 12-15) stammten aus dem Seegras der Wiker Bucht, von einem Dredgezuge, der fast nur Rissoa zu Tage gefördert hatte. Vielleicht war die Zahl der Konsumenten zu gross im Verhältniss zur Nahrung gewesen. Die Schwammnadeln, die ich wiederholt bemerkte, sowie die winzigen Crustaceenborsten und die andern unkenntlichen thierischen Reste, ferner das leere Prorocentron und die beiden Tintinnen, werden mit dem Sand und der unkenntlichen Masse als rein accessorische Bestandtheile in den Darm gerathen sein.

Ganz ähnlich wie bei Rissoa war auch der Darminhalt bei Cerithillm beschaffen. (Tabelle siehe S. 27.) Zwar habe ich Stücke von Gewebspflanzen in jedem der 16 untersuchten Exemplare gefunden, aber immer nur vereinzelt. Grunddiatomeen bildeten stets den Hauptbestandtheil des Darminhaltes. Cocconeis war selten; in einigen Därmen war Grammatophora vorherrschend, in den übrigen waren die schon bei Rissoa erwähnten Formen vorhanden. Das seltene Vorkommen von Cocconeis im Darminhalt von Cerithium erklärt sich daraus, dass diese Schnecke nur in äusseren Theil der Föhrde vorkonmıt, und dass Cocconeis sich vorzugsweise in der Secgraszone der inneren Bucht findet. Was ich über die thierischen Bestandtheile im Darminhalt von Rissoa gesagt habe, gilt anch für Cerithium. 


\begin{tabular}{|c|c|c|c|c|c|c|c|c|c|c|c|c|c|c|}
\hline $\begin{array}{l}\vdots \\
\vdots \\
\vdots \\
\vdots \\
\end{array}$ & $\ddot{\infty}$ & 心 & \pm & 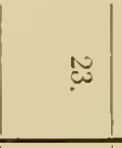 & 10 & $\cong$ & $\ddot{\sigma}$ & $\bar{\theta}$ & $\infty$ & $\begin{array}{l}\bar{\sigma} \\
\bar{y} \\
\bar{y}\end{array}$ & $\bar{v}$ & $=$ & $=$ & $z$ \\
\hline$v$ & $v$ & $=$ & $=$ & $=$ & $=$ & $=$ & $=$ & $=$ & $=$ & $\infty$ & oderer & $\nu$ & $v$ & 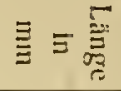 \\
\hline : & $\begin{array}{l}-\infty \\
\infty \\
d \\
d \\
0\end{array}$ & $=$ & $=$ & $=$ & : & $=$ & $=$ & $=$ & $=$ & 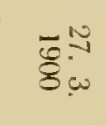 & $=$ & $\left|\begin{array}{l}\overline{8} . \overline{1} \\
\bar{\delta}_{\infty}\end{array}\right|$ & $\begin{array}{l}\bar{\alpha}= \\
0 \\
0 \\
0\end{array}$ & 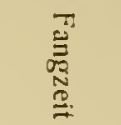 \\
\hline$=$ & 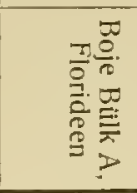 & $=$ & $=$ & $=$ & $=$ & $=$ & $=$ & : & $=$ & 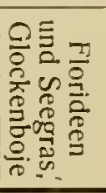 & $=$ & 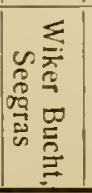 & 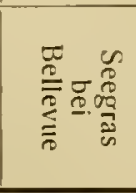 & 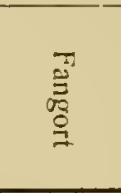 \\
\hline 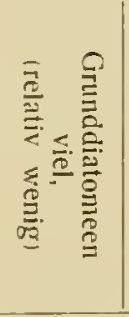 & 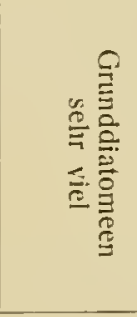 & 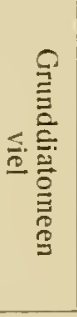 & 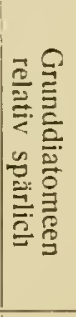 & 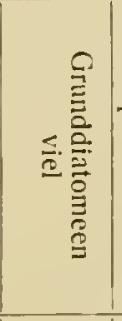 & 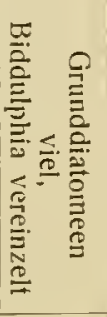 & 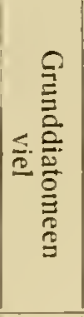 & 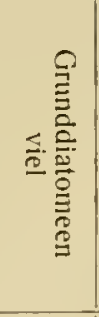 & 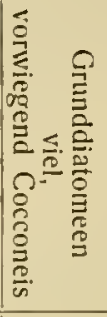 & 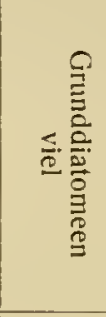 & 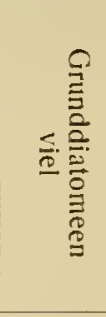 & 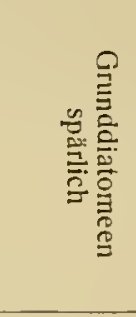 & 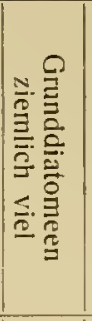 & 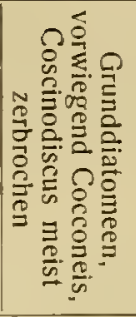 & 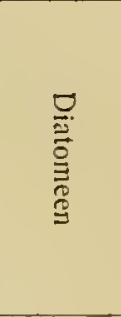 \\
\hline 7 & . & 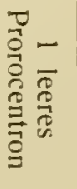 & t & & & 1 & 1 & | & 1 & & 1 & & & 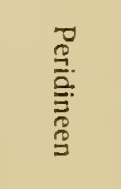 \\
\hline & 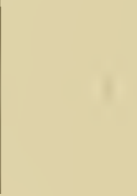 & 1 & & & & 1 & 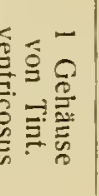 & 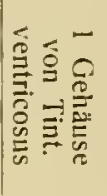 & & & & & & 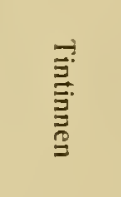 \\
\hline 6 & ? & $v$ & $\nu$ & 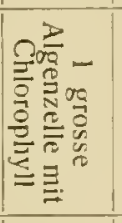 & $v$ & $i$ & 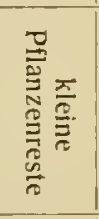 & & 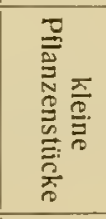 & & & & 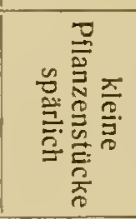 & 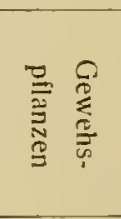 \\
\hline$\nu$ & 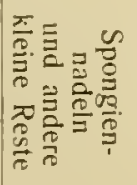 & $v$ & $v$ & $v$ & 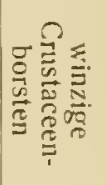 & $v$ & $\nu$ & 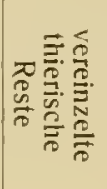 & 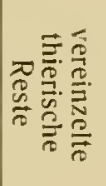 & 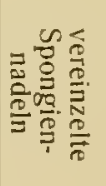 & 1 & & & 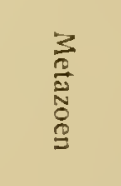 \\
\hline 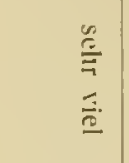 & $\underline{\underline{a}}$ & 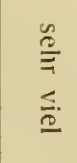 & 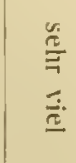 & 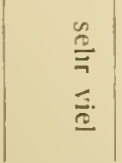 & 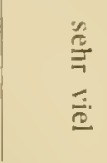 & $\begin{array}{l}\text { 足 } \\
\stackrel{0}{二} \\
\leq \\
\underline{0}\end{array}$ & 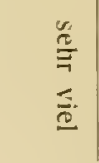 & & $\begin{array}{l}\frac{\infty}{2} \\
\frac{c}{4} \\
\frac{1}{0}\end{array}$ & $\begin{array}{l}\stackrel{0}{\frac{0}{3}} \\
\frac{1}{0 .} \\
\frac{1}{0}\end{array}$ & 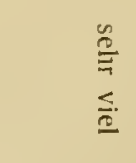 & 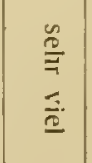 & $\omega$ & 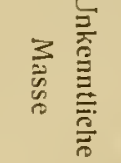 \\
\hline 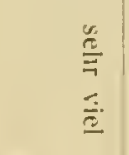 & $\overline{\bar{a}}$ & $\overline{\overline{\underline{a}}}$ & $\overline{\overline{\underline{Q}}}$ & $\underline{\underline{\underline{a}}}$ & $\underline{\underline{\underline{S}}}$ & $\overline{\overline{\underline{\theta}}}$ & $\stackrel{\leq}{\underline{D}}$ & $\overline{\overline{\underline{Q}}}$ & $\overline{\bar{c}}$ & $\bar{a}^{2}$ & 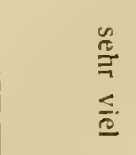 & 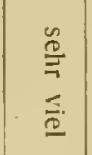 & $\underline{\underline{\underline{a}}}$ & שֶ \\
\hline & & & 1 & 1 & & & 1 & & | & & & & 1 & 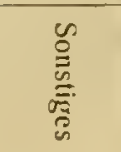 \\
\hline
\end{tabular}


E. Rauschenplat, Ueber die Nahrung vou Thieren aus der Kieler Bucht.

Cerithium reticulatum da Costa.

\begin{tabular}{|c|c|c|c|c|c|c|c|c|c|c|}
\hline Nr. & \begin{tabular}{|c|} 
Länge \\
in \\
mmm
\end{tabular} & Fangzeit & Fangorl & Diatomeen & Tintinnen & $\begin{array}{l}\text { Gewebs- } \\
\text { pflanzen }\end{array}$ & Metazoen & $\begin{array}{l}\text { Unkennt- } \\
\text { liclie } \\
\text { Masse }\end{array}$ & Sand & $\begin{array}{l}\text { Son- } \\
\text { stiges }\end{array}$ \\
\hline 1.5 & $?$ & $\begin{array}{l}24.7 \\
1899\end{array}$ & $\begin{array}{c}\text { Florideen } \\
\text { bei } \\
\text { Boje C }\end{array}$ & $\begin{array}{l}\text { Grunddiatomeen, } \\
\text { vorwiegend } \\
\text { Crammatophora }\end{array}$ & & $\begin{array}{l}\text { vereinzelte } \\
\text { kleine } \\
\text { Pflanzen- } \\
\text { stïcke }\end{array}$ & $\begin{array}{l}\text { kleine } \\
\text { Crustaceen- } \\
\text { reste } \\
\text { vereinzelt, } \\
\text { Spongien- } \\
\text { nadeln } \\
\end{array}$ & selir viel & viel & \\
\hline 6. & ? & ", & " & $\begin{array}{l}\text { Grunddiatomeen, } \\
\text { vorwiegend } \\
\text { Grammatophora }\end{array}$ & $\begin{array}{l}1 \text { Tint. } \\
\text { ventricosus }\end{array}$ & 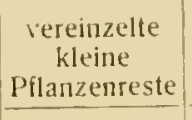 & $\begin{array}{l}\text { Spongien- } \\
\text { nadeln }\end{array}$ & sehr viel & viel & \\
\hline 7. 13 & 8 & $\begin{array}{l}23.7 . \\
1900\end{array}$ & $\begin{array}{l}\text { Florideen } \\
\text { am } \\
\text { Strander } \\
\text { Grasberg }\end{array}$ & $\begin{array}{c}\text { Sehr viel } \\
\text { Grunddiatomeen, } \\
\text { (Synedren, } \\
\text { Naviculaceen, } \\
\text { Grammatophora, } \\
\text { Rhoicosphenia } 11 \text {. a.) } \\
\end{array}$ & & $\begin{array}{l}\text { vereinzelte } \\
\text { kleine } \\
\text { Pflanzen- } \\
\text { sliicke }\end{array}$ & ? & viel & viel & 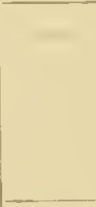 \\
\hline 14. 11. 15. & $8-10$ & ", & " & $\begin{array}{l}\text { sehr viel } \\
\text { Grunddiatomeen }\end{array}$ & $\begin{array}{l}1 \text { Tinl. } \\
\text { ventricosis }\end{array}$ & $\begin{array}{l}\text { vereinzelte } \\
\text { kleine } \\
\text { Pflanzen- } \\
\text { stiocke }\end{array}$ & $?$ & viel & $\begin{array}{l}\text { ziemlich } \\
\text { viel }\end{array}$ & 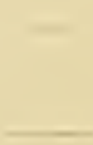 \\
\hline 16. & $\begin{array}{ll}8 & 10\end{array}$ & " & $"$ & $\begin{array}{l}\text { sehr viel } \\
\text { Grunddiatomeen }\end{array}$ & . & $\begin{array}{l}\text { vereinzelte } \\
\text { kleine } \\
\text { Pflanzen- } \\
\text { stiicke }\end{array}$ & $\begin{array}{l}\text { l leere } \\
\text { Eihille }\end{array}$ & viel & viel & 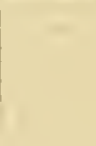 \\
\hline
\end{tabular}

Schliesslich sei noch eine Angabe von Henking ') über die Nahrnng von Hydrobia ulvae Penn., einer Schnecke, die ich nicht untersucht habe, citirt. "Was die Nahrung von Hydrobia anbelangt, so habe ich in ihrem Darmtraktus grosse Mengen von Steinchen, Schalenstückchen, Bruchstücken von Diatomeenpanzern, ganzen Diatomeen, Bruchstücken von Kieselnadeln und kleine Körnchen gesehen, so dass wohl kleine Organismen als gewöhnliche Nahrung bezeichnet werden dürfen."

\section{Thiere, die sich vorwiegend von Fleischkost nähren.}

Je nachdem, ob sich die Thiere von toten oder von lebenden Thieren nähren, unterscheide ich Aasfresser und Räuber.

Was die Aasfresser anbetrifft, so habe ich unter den hierhergehörigen Thieren keins gefunden, das diese Bezeichnung zweifellos verdient, und auch keins, das ich als vorwiegend vom Aasfrass lebend hinstellen könnte.

Zu den Räubern rechne ich diejenigen Thiere, die sich von lebenden thierischen Organismen nähren, gleichviel, ob sie sie erjagen oder erlauern.

Zu den Räubern gehören Vertreter sämmtlicher Stämme der Metazoen. Die von mir untersuchten Thiere, die hierher zu stellen sind, sind:

Asteracanthion rubens L. $\mid$ Crangon vulgaris L.

Nephthys.

Nereis pelagica L.

Harmothoe imbricata L.

Lepidonotus squamatus L.
Spinachia vilgaris Flem.

Nerophis ophidion L.

Siphonostoma typhle L.

Pleuronectes platessa L.

Pleuronectes flesus $\mathrm{L}$.

Von den Coelenteraten sind die Aktinien zu nennen. Ich selbst habe keine Gelegenheit gehabt, die in der Kieler Föhrde vorkommenden Arten zu untersnchen, aber in den mir zugänglichen Werken, in denen überhaupt die Ernährungsweise der Aktinien berücksichtigt wird, wird angegeben, dass diese Thiere

1) H. Henking: Beilrăge zur Kenntniss ron Hydrobia ulvae und deren Brutpflege, Bericht der naturforschenden Gesellschaft zu Freiburg i. Br. 8. Bd. p. 99 (11). 
eine räuberische Lebensweise führen. Ueber die bei uns vorkommende Actinia mesembryanthemum spricht sich Möbius ${ }^{1}$ ) folgendermassen aus: „... Wenn ein Wurm, eine Schnecke, ein kleiner Fisch sie in Vorbeigehen berührt, so stossen sie plötzlicl tansende feiner Fäden aus, um sie zu umspinneı, zu fangen und in den Mund zu führen." Marshall’²) schildert die Aktinien ebenfalls als gefrässige Räuber, ebenso Voges. $\left.{ }^{3}\right)$ Dieser erwähnt auch, dass Johnson eine Tealia crassicomis gefunden hat, welche eine grosse Schale einer Jakobsmuschel verschlungen hatte. van Beneden hat nach Marshall Aktinien an der belgischen Küste studirt und schreibt, dass sie zu den gefürchtetsten Feinden der Mysideen gehören. „Jene Krebschen verschwinden im Augenblick, wenn sie einer Aktinie ansichtig werden. Man kann Hunderte, ja selbst Tausende jener Thierchen in ein Aquarium thun; befindet sich darin nur eine einzige Aktinie von gewöhnlicher Grösse, so darf man nicht erwarten, 24 Stundeı später noch ein einziges Krebschen am Leben zu finden." Im Aquarium des zoologischen Institnts zu Kiel werden die Aktinien gewöhnlich mit Miesmuschelfleisch gefüttert.

Ein ausgesprochener Räuber ist Asteracanthion rubens, und zwar stellt er in erster Linie den Muscheln und Schnecken nach. Er ist der Hauptfeind der Austernzucht. Collins hat den Schaden berechnet, den Asteracanthion auf den amerikanischen Austernbänken anrichtet. Die obere Zahlenreihe in der folgenden Tabelle, welche der gleich weiter zu berücksichtigenden Arbeit von Schiemenz entnommen ist, bedeutet die Zahlen der Jahre, die Collins zu seinen Berechnungen gewählt hat, die zweite und dritte geben in Dollars den Schaden an, den die Seesterne, beziehungsweise Frost, Schlamm, Schnecken angerichtet haben.

\begin{tabular}{c|c|c}
1887 & 1888 & 1889 \\
\hline 469600 & 631500 & 412450 \\
39200 & 46750 & 52450.
\end{tabular}

Ich habe eine grosse $Z$ ahl von Seesternen untersucht, aber nur ganz vereinzelt Mageninhalt gefunden, nämlich in zwei Exemplaren kleine Miesmuschelschalen. Der Grund dafür liegt in dem Umstand, dass der Seestern seinen Magen ausstïlpen und damit grössere Mollusken aussaugen kann. Lange ist es ein Räthsel gewesen, wie der Seestern die Muschel öffnet. Man hat vermuthet, dass er sie solange belagere, bis sie durch Atem-oder Nahrungsbedürfniss gezwungen würden, die Schalen zu öffnen; ferner, dass er sie durch einen giftigen Saft betäube, oder mit Hülfe einer Säure ein Loch in die Schale bohre, durch das er den Weiclıkörper aufsauge. Marshall ${ }^{4}$ ) unterschiebt einem dänischen Naturforscher, Heins, sogar die abenteuerliche Ansicht, dass der Seestern der Muschel einen Arm zwischen die Schalen schiebe und sich abquetschen lassen solle ${ }^{5}$ ); aus der Wunde solle sich ein für die Muschel tötliches Gift ergiessen und das Klaffen der Schalen zur Folge haben. Paulus Schiemenz(i) hat nachgewiesen, dass der Asteracanthion die Muschel lediglich durch mechanische Kraft öffnet. Zunächst bestimmte Schiemenz die Kraft, die erforderlich ist, um eine Muschel zu öfnen. Venus verrucosa, die Schiemenz zum Experiment diente, hielt die momentane Einwirkung einer Zugkraft von $4000 \mathrm{gr}$ ans, dagegen genügte eine fünfzehn Minuten lange Einwirkung von $900 \mathrm{gr}$, um die Schalen klaffen zu lassen. Durch geeignete Versuche fand Schiemenz ferner, dass ein Seestern über eine Kraft von etwa 1350 gr verfügt. Im Aquarium habe ich uicht selten beobachtet, dass ein Seestern eine Muschel (Mytilus, Mya und Tellina) umklammert hielt; wenn er dann nach geraumer Zeit weiterkroch, waren die Schalen offen und leer. In Hinblick auf den Schaden, den Asteracanthion rubens unter den Muscheln aurichtet, ist es kaum angebracht, dass Voges i)

\footnotetext{
1) K. Möbius: Das Thierleben am Boden der dentschen Ost- und Nordsee. Berlin 1871.

?) 1. c. p. 127 .

3) 1. c.

4) 1. c. p. 160 .

5) Da Marshall keine Quelle hierfür angiebt, so glaube ich, dass ein frrthum obwaltet. in einer Schrift "Ueber den Muschelfang* (Schleswig 1868) sagt der Fischereidirektor W. F. G. Heins, der vermuthlich identisch mit dem „dänischen Naturforscher" ist: "Wenn die Muschel dann und wann ihre Schalen öffnet, ..., so wirft der Kreuzfisch einige durchsichtige Fàden oder Stengel zwischen dieselben hinein". Das Weitere stimmt mit den Angaben von Marshall überein.

6) Pautus Schiemenz: .Wie öfnen die Seesterne Austern?" Mitth. d. d. Seefischereivereins, Bd. 12. Nr. 6.1896.

j) 1. c.
} 
ihm eine grosse Bedeutung als "Wohlfahrtspolizei" beimisst. „Man kann sie [dje Seesterne] mit den Geicrn, Hyänen und ähnlichen Geschöpfen verglcichen, welche von der Natur bei der Wohlfahıtspolizei angestellt sind, um die Leichen wegzuschaffen, ehe ihre Fäulniss für andere lebende Thiere verderblich wird “. Dass Asteracanthion Aas frisst, unterliegt allerdings keinem Zweifel. Im Aquarium verzehrte er tote Schlangenmadeln; Buerkel fing in den Reusen, die mit faulem Köder gefüllt waren, im Ganzen 2543 Exemplarc, in solchen mit frischem Köder nur 304 und endlich in leeren oder mit glänzenden Scherben nur 64 Thiere.

Unter den Würmern gelten die freischwimmenden Polychäten, und unter ihnen besonders die Nereiden als Räuber. Nereis diversicolor muss ich jedoch ausnehmen und zu den Thieren stellen, die vorwiegend Detritus fressen.

Von Nereis pelagica habe ich nur zwei Exemplare untersuchen kömnen, die beide im Dezember 1900 am Kleverberg gefangen worden warell. Im Darm beider habe ich grosse Stücke von Halichondria panicea und mehrere kleine, bis zu $4 \mathrm{~mm}$ lange Mytilus gefunden. Von pflanzlichen Bestandtheilen enthielt der Darm des einen Exemplares Florideenstücke, der des andern Florideen- und Seegrasstücke. Ein Haufen Ceratien, der sich im Darm des einen Wurmes fand, hat höchstwahrscheinlich die Nahrung einer gefressenen Muschel gebildet. Sandkörnchen sind wohl zufällig aufgenommen worden.

Harmothoë imbricata L.

\begin{tabular}{|c|c|c|c|c|c|c|c|c|c|c|c|}
\hline Nr. & $\begin{array}{l}\text { Lănge } \\
\text { in } \\
\text { mm }\end{array}$ & Fangzeit & Fangort & Diatomeen & Peridineen & $\begin{array}{l}\text { Gewebs- } \\
\text { pflanzen }\end{array}$ & Polychåten & Crustaceen & Schnecken & $\begin{array}{l}\text { Un- } \\
\text { kennt- } \\
\text { liche } \\
\text { Masse }\end{array}$ & Sand \\
\hline 1. & ? & $\begin{array}{l}11.2 . \\
1899\end{array}$ & $\begin{array}{c}\text { Grenze des } \\
\text { lebenden } \\
\text { und toten } \\
\text { Seegrases, } \\
\text { Bellevue }\end{array}$ & $\begin{array}{l}\text { Cocconeis } \\
\text { und andere } \\
\text { Grundiormen }\end{array}$ & & $\begin{array}{c}\text { Stiicke von } \\
\text { Seegras und } \\
\text { Algen }\end{array}$ & - & $\begin{array}{c}\text { Trü̈mmer } \\
\text { von Panzern } \\
\text { init Borsten }\end{array}$ & - & wenig & wenig \\
\hline 2. & 30 & $\begin{array}{c}15.11 . \\
1899\end{array}$ & $\begin{array}{l}\text { Strander } \\
\text { Grasberg }\end{array}$ & vorhanden & - & $\begin{array}{l}1 \text { ziemlich } \\
\text { grosser } \\
\text { Algenfaden }\end{array}$ & $\begin{array}{l}\text { sehr viel } \\
\text { Borsten der } \\
\text { eignen Art, } \\
\text { Nereisborsten }\end{array}$ & $\begin{array}{l}\text { Amphipoden- } \\
\text { reste }\end{array}$ & - & ? & ? \\
\hline 3. & 24 & $\begin{array}{l}2.6 . \\
1900\end{array}$ & $\begin{array}{c}\text { Sand mit } \\
\text { Florideen, } \\
\text { Stoller } \\
\text { Grund }\end{array}$ & - & $\sqrt{2}$ & - & - & - & . & - & - \\
\hline 4. & 23 & ", & , & $\rightarrow$ & - & 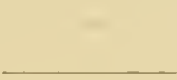 & 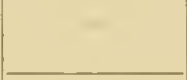 & $\begin{array}{c}\text { Reste } \\
\text { ziemlich viel } \\
\end{array}$ & $\ldots$ & vorh. & rorlt. \\
\hline 5. & $?$ & " & " & 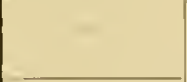 & 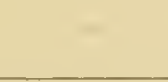 & - & $\begin{array}{c}\text { ziemlich viel } \\
\text { Borsten }\end{array}$ & - & - & viel & viel \\
\hline 6. & ? & $\begin{array}{c}6.12 . \\
1899\end{array}$ & Kleverberg & & $\begin{array}{l}\text { vereinzelte } \\
\text { Ceratium- } \\
\text { stuicke }\end{array}$ & Algentriebe & - & Reste & $\begin{array}{c}\text { ca. } 20 \text { Reilien } \\
\text { einer nicht } \\
\text { weiter zu be- } \\
\text { stimmenden } \\
\text { Radula } \\
\end{array}$ & vorh. & vorli. \\
\hline 7. & 25 & $\begin{array}{l}23.7 \\
1900\end{array}$ & $\begin{array}{l}\text { Strander } \\
\text { Grasberg }\end{array}$ & $\begin{array}{l}\text { zahlreich, } \\
\text { besonders } \\
\text { Synedren }\end{array}$ & & $\begin{array}{c}\text { grosse } \\
\text { Pflanzen- } \\
\text { stiicke } \\
\text { ziemlich viel }\end{array}$ & - & - & - & $?$ & ? \\
\hline 8. & 25 & " & .. & sparrlich & - & spärlich & $\begin{array}{c}\text { sehr viel } \\
\text { Polynoiden- } \\
\text { borsten }\end{array}$ & - & - & ? & ? \\
\hline 9. & 25 & " & ", & - & $\ldots$ & & $\begin{array}{c}\text { viel } \\
\text { Polynoiden- } \\
\text { borsten }\end{array}$ & - & - & vorh. & vorli. \\
\hline $10 .-13$ & $\begin{array}{l}24 \\
24 \\
24 \\
23\end{array}$ & ", & " & $\ldots$ & - & & & -. & - & - & \\
\hline
\end{tabular}


Von Harmothoë imbricata habe ich 13 Exemplare untersucht; bej fünf von ihnen war gar kein Darminhalt vorhanden. Von den andern acht hatten sieben thierische Stoffe geiressen. Im Darm von vier Exemplaren waren Polychätenborsten in beträchtlicher Menge, so dass es zweifellos ist, dass es sich in diesen Fällen um den Frass von Würmern gehandelt hat. Bemerkenswerth ist es, dass die im Darm gefundenen Borsten meist von Polynoiden stammten; einmal waren aucl Nereidenborsten dabei, und einmal habe ich bei der Untersuchung nur "Polychätenborsten" notirt. Reste von Crustaceen habe ich in Darm von vier Exemplaren gefunden. In einem Falle waren sie noch als Amphipodentheile zu bestimmen, sonst waren sie unkenntlich. In Darm eines der letzteren vier Thiere befand sich auch ein aus 50 Reihen bestehendes Stück einer Radula, die aber auch nicht mehr zu bestimmen war. Einen nur aus vegetabilischen Bestandtheilen gebildeten Darminhalt habe ich nur in einen Fall gefunden. Das betreffende Thier hatte grosse Pflanzenstücke, Synedren und andere Diatomeen gefressen; die Diatomeen haben vermuthlich auf den Pflanzenstücken gesessen. In einem Thier habe ich noch einige Algentriebe, in einem andern einen Algenfaden und in einem dritten Stücke von Seegras und Algen gefunden, in den beiden letzten auch Grunddiatomeen.

Ganz ähnliche Resultate hatten meine Untersuchungen an Lepidonotus squamatus, dt. auf Mudgrund lebt. Auch dies Thier bevorzugt thierische Kost entschieden. Zwölf Thiere habe ich untersucht;

Lepidonotus squamatus L.

\begin{tabular}{|c|c|c|c|c|c|c|c|c|c|c|c|}
\hline Nr. & $\begin{array}{c}\text { Länge } \\
\text { in } \\
m m\end{array}$ & Fangzeit & Fangort & Diatomeen & Peridineen & $\begin{array}{l}\text { Gewebs- } \\
\text { pflanzen }\end{array}$ & Polychäten & Crustaceen & Schnecken & \begin{tabular}{|c|} 
Un- \\
kennt- \\
liche \\
Masse
\end{tabular} & Sand \\
\hline 1. & ? & $\begin{array}{l}22.4 \\
1899\end{array}$ & $\begin{array}{l}\text { Mud auf } \\
\text { der Höhe } \\
\text { der Marine- } \\
\text { Akademie }\end{array}$ & $\begin{array}{c}\text { Chaetoceros } \\
\text { selten, Grund- } \\
\text { diatomeen } \\
\text { ziemlich viel }\end{array}$ & $\begin{array}{l}\text { vereinzelte } \\
\text { Ceratium- } \\
\text { reste }\end{array}$ & & - & $\begin{array}{l}\text { Reste eines } \\
\text { grösseren } \\
\text { Krebses }\end{array}$ & - & viel & viel \\
\hline 2. & $?$ & $\begin{array}{l}6.12 . \\
1899\end{array}$ & Kleverberg & - & - & $\begin{array}{c}\text { kleine } \\
\text { Seegrasstücke }\end{array}$ & $\begin{array}{l}1 \text { kleine } \\
\text { Polynoë } \\
\text { cirrata }\end{array}$ & - & & viel & rorh. \\
\hline 3. & $?$ & " & ", & - & - & $\begin{array}{c}\text { kleine } \\
\text { Seegrasstücke }\end{array}$ & - & $\begin{array}{c}\text { grosse } \\
\text { Crustaceen- } \\
\text { reste } \\
\end{array}$ & - & ? & ? \\
\hline 4. 6. & $?$ & ." & $\therefore$ & - & $=$ & $=$ & - & - & $=$ & $=$ & - \\
\hline 7. & 30) & $\begin{array}{l}27.3 . \\
1900\end{array}$ & $\begin{array}{c}\text { Florideen } \\
\text { und Seegsas, } \\
\text { Glockenboje }\end{array}$ & $\begin{array}{c}\text { Grundformen } \\
\text { vorlianden }\end{array}$ & - & $\begin{array}{l}\text { grosse } \\
\text { Stiicke }\end{array}$ & $\begin{array}{c}\text { viele z. Th. } \\
\text { noch in } \\
\text { Buindeln } \\
\text { liegende } \\
\text { Borsten } \\
\end{array}$ & - & - & viel & viel \\
\hline 8. & 30 & $"$ & " & $\begin{array}{c}\text { viel } \\
\text { Grundformen }\end{array}$ & - & $\begin{array}{l}\text { Algentriebe } \\
\text { spärlich }\end{array}$ & $\begin{array}{c}\text { sehr viel } \\
\text { Borsten von } \\
\text { Polynoë } \\
\text { cirrata; } \\
\text { andere, ver- } \\
\text { muthlich von } \\
\text { Terebellides } \\
\end{array}$ & - & - & viel & viel \\
\hline 9. & 26 & " & " & $\begin{array}{c}\text { Grundformen } \\
\text { spärlich }\end{array}$ & - & - & $\begin{array}{c}\text { sehr viel } \\
\text { Borsten von } \\
\text { Terehellides } \\
\text { (?) }\end{array}$ & - & $\begin{array}{c}\text { über } \\
100 \text { Radula- } \\
\text { zähne eines } \\
\text { Opistlo- } \\
\text { branch. } \\
\end{array}$ & $\begin{array}{l}\text { sehr } \\
\text { viel }\end{array}$ & $\begin{array}{l}\text { selır } \\
\text { viel }\end{array}$ \\
\hline 10. & 28 & " & " & -.. & - & - & $\begin{array}{l}\text { sehr viel } \\
\text { Borsten }\end{array}$ & $\ldots$ & - & vorh. & vorh. \\
\hline 11. & 29 & ", & " & - & - & - & - & $=$ & - & - & - \\
\hline 12. & 25 & " & " & - & - & $\begin{array}{l}\text { kleine } \\
\text { Pllanzen- } \\
\text { stiicke in } \\
\text { spărlicher } \\
\text { Menge }\end{array}$ & $\begin{array}{c}\text { viel } \\
\text { Borsten }\end{array}$ & $\ldots$ & - & vorh. & vorl. \\
\hline
\end{tabular}


bei vieren war der Darm leer, bei den übrigen enthielt er thierische Bestandtheile und zwar bei zweien grössere Crustaceenreste, bei sechs Polychätenborsten in beträchtlicher Menge. Ausser Borsten von Polynoiden liessen sich auch solche von Terebcllides nachweisen, dagegen fehlten Nereidenborsten. Grössere oder kleincre Pflanzenstücke waren in Darm von fünf Individuen vorhanden; Grunddiatomeen habe ich in vier Fällen, zweinal in ziemlicher Menge bemerkt. Im Darm eines Thieres sind mir vereinzelte Chaetoceroszellen und Bruchstiicke von Ceratien aufgefallen; ich vermuthe, dass sie den Darminhalt eimes ebenfalls in den Wurm geiunden Krebses gebildet haben. Auch bei Lepidonotus habe ich in einem Falle Radulazähne konstatiren können; es waren über humdert, die, nach ihrer Form zu urtheilen, zu einem Hinterkiemer gehört haben müssen.

Die Darmuntersuchungen von Nephthys ${ }^{1}$ ) haben mich zu keinem klaren Ergebniss geführt. In den meisten Fällen war der Darm leer. Vermuthlich wird der Darminhalt im Alkohol ausgestossen, denn vicle

Nephthys.

\begin{tabular}{|c|c|c|c|c|c|c|c|c|c|c|}
\hline Nr. & $\begin{array}{c}\text { Länge } \\
\text { in } \\
\text { mm }\end{array}$ & Fangzeit & Fangort & Diatomeen & $\begin{array}{l}\text { Gewebs- } \\
\text { pflanzen }\end{array}$ & Potychaeten & Crustaceen & $\begin{array}{l}\text { Un- } \\
\text { kennt- } \\
\text { liche } \\
\text { Masse }\end{array}$ & Sand & $\begin{array}{l}\text { Be- } \\
\text { merkungen }\end{array}$ \\
\hline 1. 6 & ? & $\begin{array}{l}24.4 . \\
1899\end{array}$ & $\begin{array}{c}\text { Mud auf der } \\
\text { Höhe von } \\
\text { Duisternbrook }\end{array}$ & vorbanden & $\begin{array}{l}\text { vereinzelte } \\
\text { kleine Stucke }\end{array}$ & - & $\begin{array}{l}\text { vereinzelte } \\
\text { kleine Reste }\end{array}$ & vorh. & vorh. & - \\
\hline 7. & $?$ & $\begin{array}{l}6.12 . \\
1899\end{array}$ & $\begin{array}{c}\text { Mud bei der } \\
\text { Gasboje }\end{array}$ & - & & $\begin{array}{l}\text { Stücke von } \\
\text { Harmothoë } \\
\text { imbricala } \\
\end{array}$ & - & ? & ? & - \\
\hline 8. 11. 9. & $\begin{array}{l}40 \\
39\end{array}$ & $\begin{array}{l}18.6 . \\
1900\end{array}$ & $\begin{array}{c}\text { Mud auf der } \\
\text { Höhe der } \\
\text { Wiker Bucht }\end{array}$ & vorhanden & - & $\begin{array}{c}\text { Sehr viel } \\
\text { Nephtliys- } \\
\text { horsten }\end{array}$ & - & viel & viel & \\
\hline 10. & 45 & $"$ & " & - & & - & - & vorh. & vorh. & $\begin{array}{l}\text { Darm } \\
\text { spărliclt } \\
\text { gefiullt }\end{array}$ \\
\hline 11. 11. 12 & ? & $\begin{array}{l}\text { 8. } 11 . \\
1899\end{array}$ & $\begin{array}{c}\text { Mud vor } \\
\text { dem Stoller } \\
\text { Grund }\end{array}$ & - & - & - & - & viel & viet & 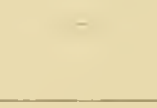 \\
\hline 13. 11. 14 & $\begin{array}{l}70 \\
50\end{array}$ & $\begin{array}{c}28.10 \\
1899\end{array}$ & $\begin{array}{c}\text { Mud } \\
\text { zwisclien } \\
\text { Hentboje und } \\
\text { Boje Büth A }\end{array}$ & - & - & $\begin{array}{l}\text { Borsten, } \\
\text { vermulthlich } \\
\text { von Potynoë }\end{array}$ & $\begin{array}{l}\text { Resle, } \\
\text { anscheinend } \\
\text { von einem } \\
\text { Amphipoden }\end{array}$ & viet & viet & \\
\hline 15. & 60 & $"$ & , & - & & - & & $\begin{array}{l}\text { sehr } \\
\text { viel }\end{array}$ & $\begin{array}{l}\text { selur } \\
\text { viet }\end{array}$ & \\
\hline
\end{tabular}

in Alkohol getöteten Thiere hatten den Rüssel ausgestülpt. Unter den fünizehu Thieren, die Darminhalt besassen, wurde dieser bei vier nur aus Sand und unkenntlicher Masse gebildet; bei fünf Exemplaren war Fleischfrass sicher nachzuweisen. Eins von diesen enthielt Stücke einer kleinen Harmothoë imbricata, zwei enthielten Borsten von Polychäten - vermuthlich von Polynoiden, - und die andern zwei sehr viel Borsten der eignen Art. Im Darm von sechs Exemplaren habe ich vercinzelte kleine Crustaceenreste gefunden. Dieser Befand berechtigt jedoch nicht zu dem Schluss, dass Crustaceenfrass vorliegt. Wahrscheinlicher ist es, dass die spärlichen winzigen Theile, ebenso wie kleine Pflanzenstücke, die ich vereinzelt im Darm derselben Würmer fand, als Detritusbestandtheile aufgenommen worden sind. In zwei Fällen stiess ich auf grössere Crustaceenreste, die anscheinend von einem Amphipoden stammten. Aus den Resultaten meiner Darmuntersuchungen lässt siclı nicht entscheiden, ob Nephthys zu deu Räubern oder zu deı Detritusfressern gehört, jedoch sprechen einige Beobachtungen dafür, dass sie eine räuberische Lebensweise führt. Schack $\rightleftharpoons$ ) hielt ein $47 \mathrm{~mm}$ langes Exemplar vou $N$. coeca mit cinem $30 \mathrm{~mm}$ langen und einen $12 \mathrm{~mm}$ langen Exenplar

1) Ich habe die beiden Arten von Niphthys, N. coeca und N. ciliata niclut gesondert untersucht.

$\Rightarrow$ Friedrich Scluack: Anatomisch-histologische Untersuchung von Nephthys roeca Fabr. Ein Beitrag zur Kenntniss der Fauna der Kieler Bucht. luaugural-Dissertation. Kiel 1886. 
derselben Art zusammen; nach acht Tagen hatte das erste das zweite bis auf ungefälır 10 Kopfsegmente und das dritte bis auf einige Endsegmente aufgefressen. Icl habe in dem Fange eines Dredgezuges eine Nephthy's gefunden, die eine andere zum Theil übergeschluckt hatte.

Unter den in der Kieler Föhrde vorkommenden Crustaceen sind als Räuber anfzuführen: Crangon z'nlgaris L, Leander adspersus Rathke und Carcinns maenas L.

Von Crangon alulgaris (Tabelle siehe S. 32) habe ich vierundzwanzig Exemplare auf ihren Mageninhalt untersucht. Bei acht von ihnen war der Magen leer; bej den übrigen liess sich vorzugsweise aus Wurm- und Crustaceentheilen bestehende animalische Kost konstatiren. Die Krebstheile waren meist so zertrümmert, dass sie nicht gedentet werden konnten, nur in zwei Fällen konnte ich je einen Ostracoden erkennen. Unter den Wurmresten ist das Ueberwiegen von Polynoidenborsten auffallend; Nereidenborsten habe icl nur in einem Darm gefunden, und in zwei Untersuchungsprotokollen labe ich nur "Polychätenborsten“ verzeichnet, weil ich sie nicht bestimmen konnte. Zerbrochene Muschelschalen befanden sich im Darm von drei Exemplaren, eims hatte eine kleine Schnecke gefressen, von der aber auch nur einige Windungen zu finden waren. Pilanzenstücke habe ich nur in einem Darm gesehen, freilich in grosser Menge, sodass nicht daran zu zweifeln ist, dass sie direkt als Nahrung aufgenommen worden sind. Dem vereinzelten Vorkommen von Diatomeen lege ich keine Bedeutung bei. Was die Garneelen der Nordsee anbelangt, so besteht nach Ehrenbaum ${ }^{1}$ ) ein wesentlicher Unterschied in der Ernährung zwischen den Thieren, die im Salzwasser und denen, die im Brackwasser leben. Erstere sollen Pilanzen - Ulva lactuca und Enteromorpha intestinalis - ferner an thierischer Kost Polychäten - Nereis pelagica ${ }^{2}$ ) - bevorzugen; auch sollen sie vielfach, wie die Larven, Schlick fressen. Die Thiere des Brackwassers dagegen sollen in viel höherem Grade Räuber sein. Schlickfresser sind unter ihnen sehr selten, und statt der Würner werden Krebse - Corophium longicome, Gammarus locusta, Mysis vulgaris und Podopsis Slabberi - gefressen. Auch Fischirass hat Ehrenbaum luäuig nachgewiesen; in einem Thier fand sich ein 23 mm langes Stück einer Wirbelsäule. Auch die eignen Artgenossen werden gefressen. Ehrenbaum berichtet darüber, dass im Aquarium die frisch gehäuteten Thiere regelmässig überfallen wurden, ferner dass ein Weibchen ijber die Hälfte der eben ausschlüpfenden Larven frass. Ich selbst hielt mehrere Exemplare lange an Leben, indem ich sie mit Miesmuschelfleisch fütterte. Als ich sie mehrere Tage hungern liess, fielen sie zu melıreren über ein Thier her, und frassen davon. Menschliche Leichen, die längere Zeit jm Wasser gelegen haben, sind oft von Garneelen angefressen. Crangou besitzt ein ausgezeichnetes Witterungsvermögen. Ehrenbaum blendete Individuen und sah, wie diese trotzdem einen im Sande vergrabenen Wurm fanden. Ehrenbaum betont auch, dass er sehr viel Exemplare mit vollständig leerem Magen gefunden hat, aber nur wälırend des Winters und des zeitigen Frühjahres. Ich habe solche Thiere auch im Sommer gefunden. Leider habe ich zu Anfang meiner Untersuchungen diesen Umstand unbeachtet gelassen und Thiere mit leeren Magen garnicht protokollirt. Bei dem gleich zu besprechenden Leander adspersus ist es sicher, dass er seinel Mageninhalt im Alkohol wieder ausbricht; ich vermuthe, dass dies auch bei dem in Alkohol noch lange lebenden Crangon der Grund ist, weshalb man oft Exemplare mit leerem Darm findet.

Bei leander adspersus (Palaemon squilla) liegen die Nahrungs- und Ernährungsverhältnisse ganz ähnlich wie bei Crangon. Ich habe eine grosse Zahl der sogenannten Ostseekrabben untersucht, aus demselben Grunde, wie bei Crangon, jedoch us über sechsundzwanzig Untersuchnngen Angaben gemacht. Polychäten, Krebse und Mollusken bilden auch für Leander die Hauptnahrung; Krebstheile überwogen im Darm der von mir untersuchten Thiere in höheren Grade, als es bei Crangon der Fall war. Einmal liessen sich noch grosse Stücke von einem Amphipoden erkennen, sonst handelte es sich immer um stark zerbrochene Theile von Panzern und Extremitäten, nach denen die gefressenen Crustaceen nicht mehr zu bestimmen waren. Reste von Muscheln und Schuecken habe ich in fün Thieren gefunden, eimmal stiess ich auf ein ganz erhaltenes Gehäuse von lacmna und einmal auf eine etwa 2 mm lange Schale von Mytilus. Unter den Wurmresten habe ich in zwei Fiallen Borsten von Polynoiden gefunden.

1) Ernst Ehrenbaun: Zur Naturgeschichte von Crangon wulgaris Fabr. Sonderbeilage zu den Mittheilungen der Sektion tỉis Kiisten- und Hochseefischerei. Jahrgang 1890 . p. $10.1 \mathrm{etc}$

-) Dah! glaubt, dass Ehrenbaum Nereis pelagica mit $N$. diversicolor verwechselt. 


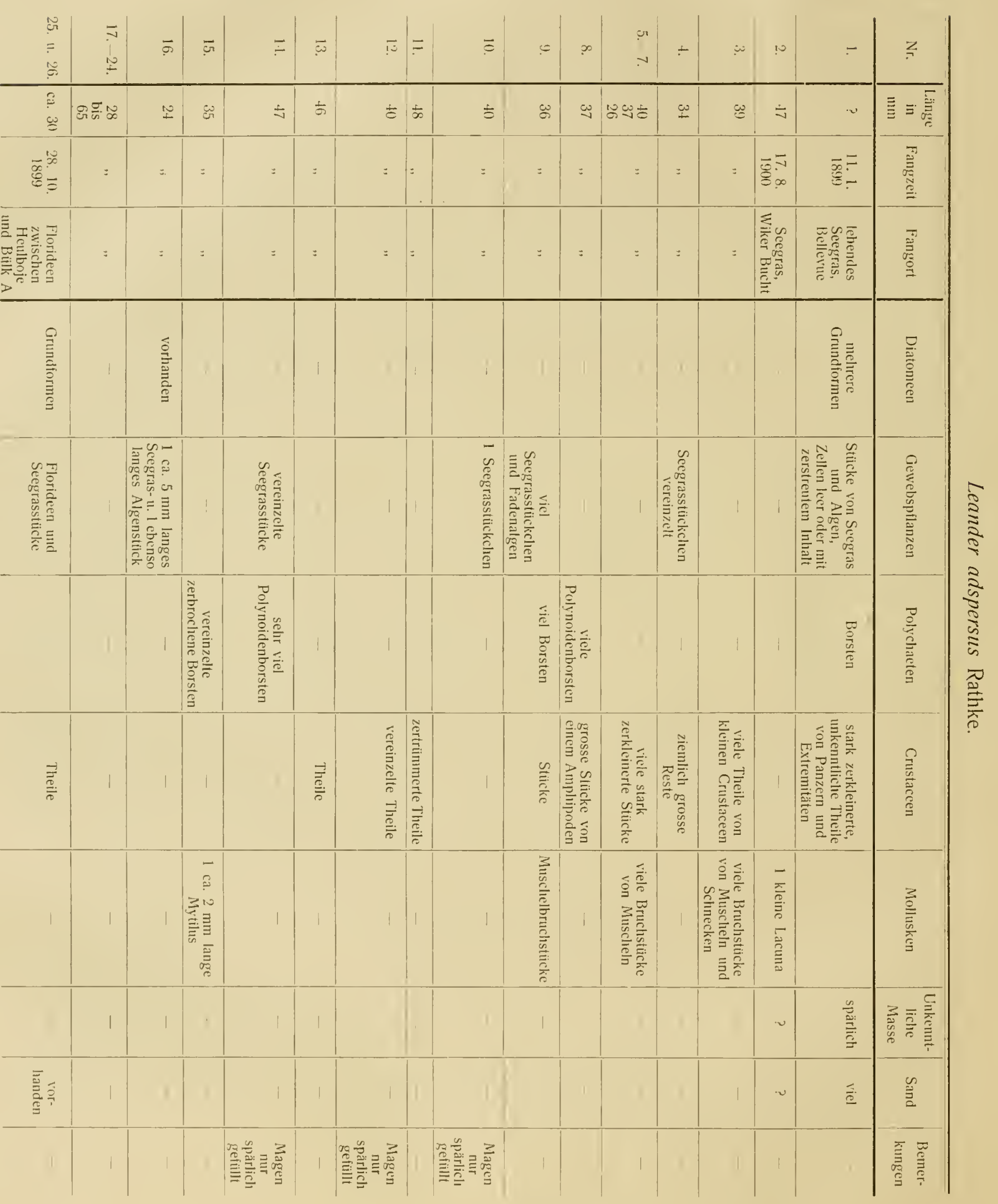


Pflanzenstücke waren bei Leander häuliger anzutreffen als bei Crangon, der Mageninhalt eines Exemplares wurde ausschliesslich von einem etwa $5 \mathrm{~mm}$ langen Seegrasstück und einem etwa ebenso grossen Algenstück gebildet. Marshall'1) stellt Leander ebenfalls zu den Räubern und giebt an, dass die Ostseekrabbe die gleiche Lebensweise wie sein grösserer Verwandter, Palaemon serratus, führt. Dieser soll sogar deı Aktinien die schon verschlungene Nalıung wieder wegrauben. Heincke ${ }^{2}$ ) vergleicht die Garneelen, unter denen er Crangon und Leander versteht, mit den Stichlingen. „Sie benutzen jede Gelegenheit, thierische Nahrung zu ergreifen. Die abfallenden Brocken einer Hummermahlzeit packen sie kühn mit den Scheeren des zweiten Fusspaares, jedem Angriff ilhres riesigen Verwandten geschickt ausweichend. Selbst die nesselnden Tentakeln der Seerosen schrecken sie nicht ab, an der Beute derselben mitzunaschen “.

Bei Carcinus maenas waren die Magenuntersuchungen fast immer erfolglos, nur in wenigen Fällen konnte ich konstatiren, dass Raubfrass vorlag, und zwar handelte es sich um Polychätenborsten. Doch lassen Beobachtungen, die ich an lebenden Exemplaren gemacht habe, und übereinstimmende Litteraturangaben keinen Zweifel daran aulkommen, dass dieser muntere und intelligente Krebs Fleischifesser ist. Im Aquarium habe ich beobachtel, wie Carcinus mit hochgehaltenen Scheeren auf vorbeischwimmende Fische lauerte. Einmal war es ihm gelungen, eine grosse Seenadel zu fassen. Er hielt den sich heftig windenden Fisch am Kopfende und verzehrte ihn allmählich. Ein anderes Mal sah ich einen Carcinus eine Miesmuschel ausfressen. In der Muschelschale befand sich ein Loch, ob es vom Krebs herrührte, konnte ich nicht entscheiden. Der Taschenkrebs langte mit seiner einen Scheere in die Muschel, riss Stücke des Weichkörpers los und führte sie zum Munde. In Cuxhaven habe ich früher viele Carcinus mit der Angel gefangen, an der sich Irisches Fleisch oder Würmer (Lumbricus) befanden. Die Krebse klammerten sich an dem Köder so fest, dass ich sie fast immer an Land ziehen konnte. Nagel") schreibt, dass von den Badegästen der friesischen lnseln in einer halben Stunde viele Dutzende von Taschenkrebsen gefangen wurden; indem vom Boot aus einige Schnüre mit einem Wurm als Köder bis aul den Grund herabgelassen wurden. In Brehms Thierleben ${ }^{4}$ ) heisst es: "Sie (die Krabbe) nährt sich vom Rogen der Fische, von Garneelen und anderen Krebsen, geht jedoch auch an tote Fische und überhaupt an thierische Nahrung ". Nach Heincke ${ }^{5}$ ) soll Carcinus tote Thiere der lebenden animalischen Kost vorziehen. "Ein toter angespülter Fisch wird überfallen, und schnell gehen die Scheeren, wahre Hände an Geschicklichkeit, ans Werk, um die Beute zu zerpflücken und stückweise den Mundtheilen zu überliefern. Findet sich nichts Totes, so beginnt die Jagd auf lebende Thiere, namentlich Garneelen und Sandhüpler (Talitrus)“. Mit diesen Angaben stimmen die Ergebnisse der Buerkelschen Reusenversuche überein. Von 62 Exemplaren, die Buerkel im ganzen gefangen hat, sind 56 in Reusen mit faulem Köder gefunden worden, vier in solchen mit frischem Fleisch und zwar in Reusen, die helle Scherben enthielten. Danach übt faules Fleisch sicherlich eine grössere Anziehungskraft auf Carcinus aus als frisches; damit ist aber noch nicht entschieden, ob Carcinus das faule Fleisch als Nahrung bevorzugt, oder nur von dem wegen seines stärkeren Geruches leichter wahrzunehmenden Aas angelockt wird. Man kann den Taschenkrebs leicht fangen, wenn man einen leuchtenden Knopi als Angelköder benutzt; Nagel hat Kinder Krebse sogar mit einer einfachen Schnur ohne jeglichen Köder fangen sehen.

Unter den von mir untersuchten Weichthieren habe ich keine Räuber gelunden. Doch werden übereinstimmend von Meyer und Möbius(i), Marshalli), Keller ${ }^{8}$ ) und Hecht'), die Äoliden als solche aufgeführt. „Die Äolidier sind gefrässige Räuber, die selbst die Eier ihrer Art nicht verschonen“. (Marshall). "lhre Nahrung sind Thierstoffe, besonders liebt sie (Äolis) Aktinien. Kleinere Exemplare greift sie am Fussende an 'und frisst ein Loch hinein, das sie immer mehr vergrössert. Endlich legt sie den ansgedehnten

l) 1. c. p. 252 .

2) Fr. Heincke: Krebse und niedere Thiere, in: Illustrirte Naturgeschichte der Thiere von Pliil. Leop. Martin. Leipzig 1884. p. 336.

3) 1. c. p. 139.

1) Brehms Thierleben: 3. Aufl. 10. Bd., neu bearbeitet von W. Marshall. p. 31

5) I. c. p. 350 .

i) $1 . c$.

T) I. c. H. A. Meyer und K. Möbius: Die Hinterkiemer der Kieler Bucht. Leipzig 1865. p. 31

b) I. c. p. 403 .

") E. Hecht: Remarques sur quelques moyens de défense des Eolidiens. Comptes-Rendus tome 115. p. 746 elc. 
Mund um den ganzen Körper der Beute herum und vertilgt ihn allmählich ohne äusserlich sichtbare Schlingbewegungen. Eines Nachmittags sass eine Äolis papillosa bei einer Actinia plumosa, die fast so dick wie sie selbst war und senkte ihren Mund in den Fussrand ein. Sie hatte ihre Mahlzeit noch nicht beendigt, so kroch eine zweite und endlich eine dritte heran, um theilzunehmen. Nach vier Stunden war alles verzehrt und keine Spur mehr war von der Aktinie zu sehen. (Meyer und Möbius). „Die zierlichen, zartgebauten Äolisarten sieht man häıfig auf Hydroidstücken, wo sie die Köpfchen der Polypen abweiden“. (Keller.) Hecht giebt an, dass Calma glancoides sich von den Eiern von Gobills nährt, denen sie infolge ihrer Rückenpapillen sehr gleicht, und dass andere Arten Cölenteraten fressen. - Von den Prosobranchen verdient Buccinum undat um hier der Erwähnung. Nach Heincke') lebt die Schuecke von Weichthieren, und bei Marshall:) findet sich eine Angabe von Harvey, nach der die Zunge von Buccinum "eine Art Feile oder Bohrer bildet, mit der feste Substanzen rasch durchbohrt werden"; Marshall vermuthet, dass die Schnecke die Radula gebraucht, um in räuberischer Absicht Löcher in die Muschelschalen zu bohren. Bei mehreren, hier nicht vorkommenden Vorderkiemern ist freie Schwefelsäure nachgewiesen worden. Semon $\left.{ }^{3}\right)$ hat die Zusammensetzung eines von Dolium ausgespritzten Flüssigkeitsstrahles ermittelt: $\mathrm{H}_{2} \mathrm{SO}_{4}$ (frei) $=2,7^{\circ} .0, \mathrm{H}_{2} \mathrm{SO}_{4}$ (an Basen gebunden) $=1,4^{\circ} \%, \mathrm{HCl}$ (frei) $=0,4^{\circ}$. . Während diese Säuren Dolimm (Heincke, niedere Thiere, p. 493) und mehreren anderen Schnecken zur Vertheidigung dienen sollen, vermuthet Semon, dass sie bei Tritonium den Zweck hat, den Kalk der Lieblingsspeisen dieser Schnecke - Seesterne und Holothurien - aufzulösen. Simroth glaubt, dass manche Schnecken mit Hülfe der Säuren die Schalen anderer Mollusken zerstören und deren Weichkörper dann fressen. Schiemenz ${ }^{4}$ ) hat bewiesen, dass die als Raubschnecke bekannte 'Natica die ilır zur Beute fallenden Muscheln]nicht, ¡wie früher angenommen wurde, mit der Radula, sondern mit Hülfe freier Säure anbohrt.

"The rule of „eat or be eaten" applies to them in unusual force". So sagt Günther ${ }^{5}$ ) von den Fischen; die von "mir untersuchten Fische rechtfertigen die Behauptung vollkommen, und auch in der übrigen mir $\mathrm{Zu}$ gänglichen Litteratur habe ich überall Angaben in gleichem Sinne gefunden. Im Darm der gemeinen kleineren Strandfische der Kieler Bucht, die ich in grösserer Menge bekommen habe - Gobius Ruthensparri Euphr., Gasterosteus pungitins L., Spinachia vulgaris Flem., Nerophis ophidion L. und Siphonostoma typhle L. - , habe ich vor wiegend Krebse gefunden, und zwar kommen hauptsächlich Copepoden, Amphipoden, 1sopoden und Schizopoden in Betracht. Die verschiedenen Fischarten wählen aber in verschiedener Weise unter diesen Gruppen aus.

Von Gobius Ruthensparri habe ich 16 Exemplare untersucht, von denen eins keinen Darminhalt besass. Von den Exemplaren, deren Darmtraktus mehr oder weniger gefüllt war, hatten acht ausschliesslich Copepoden, drei neben anderen Bestandtheilen viel, und zwei Copepoden in geringer Zahl in Magen und Darm. Das Ueberwiegen von Copepoden im Darminhalt betont anch Heincke ${ }^{6}$. Dagegen luat Kröyer`) im Magen von Gobius Ruthensparri viel kleine Amphipoden gefunden. Meist handelte es sich bei meinen Befunden um Temora longiremis, die leicht an ihrer tiefgespaltenen Furka zu erkennen ist. Ein Thier (Nr. 4) hatte auch Evadne und Podon gefressen, also echte Planktonorganismen ${ }^{8}$ ). Im Darm von vier Exemplaren waren Ostracoden vorhanden; unbestinmbare Amphipoden habe ich in drei Fällen gefunden, einmal sogar in der beträchtlichen Länge von $7 \mathrm{~mm}$. Unbestimmbare Reste von grösseren Krebsen waren wiederholt anzutreffen, ebenso Mücken- und Muschellarven. Ein Exemplar hatte einen Wurm, höchst wahrscheinlich eine Polynoide, im Darm. Mit diesem Befund stimmt eine Angabe von Möbius und Heincke") überein. „Er (Gobius) nährt sich hauptsächlich von kleinen Krustern, doch greift er nach Beobaclıłungen im Aquarium aucl grössere Thiere, wie Polynö̈ cirrata, an.

1) 1. c. p. 491.

2) 1. c. p. 401 .

3) Semon: Freie Schwefelsänre bei Schnecken. Biologisches Centralblatt 1889.

1) Paulus Schiemenz: Wie bohrt Natica die Muscheln an? Mittheilungen a. d. zool. Station zu Neapel. 10. 13d. 1. J.

i) A. C. L. G. Ginther: An introduction to the study of fishes. Edinburgh 1880. p. 12.

15) Fr. Heincke: Die Gobidae und Syngnathidae der Ostsee nehst biologischen Bemerkungen. Arch. f. Naturgeschichte.

46. Jhrg. 1. Bd. p. 307 .

i) Henrik Kröyer: Danmarks Fiske. Kjöbenlıavn, 1838 - 40. p. 406.

4) Nach Giesbrecht soll Temora, wie alle Calaniden, das Seegras meiden.

9) 1. c. p. 224. 


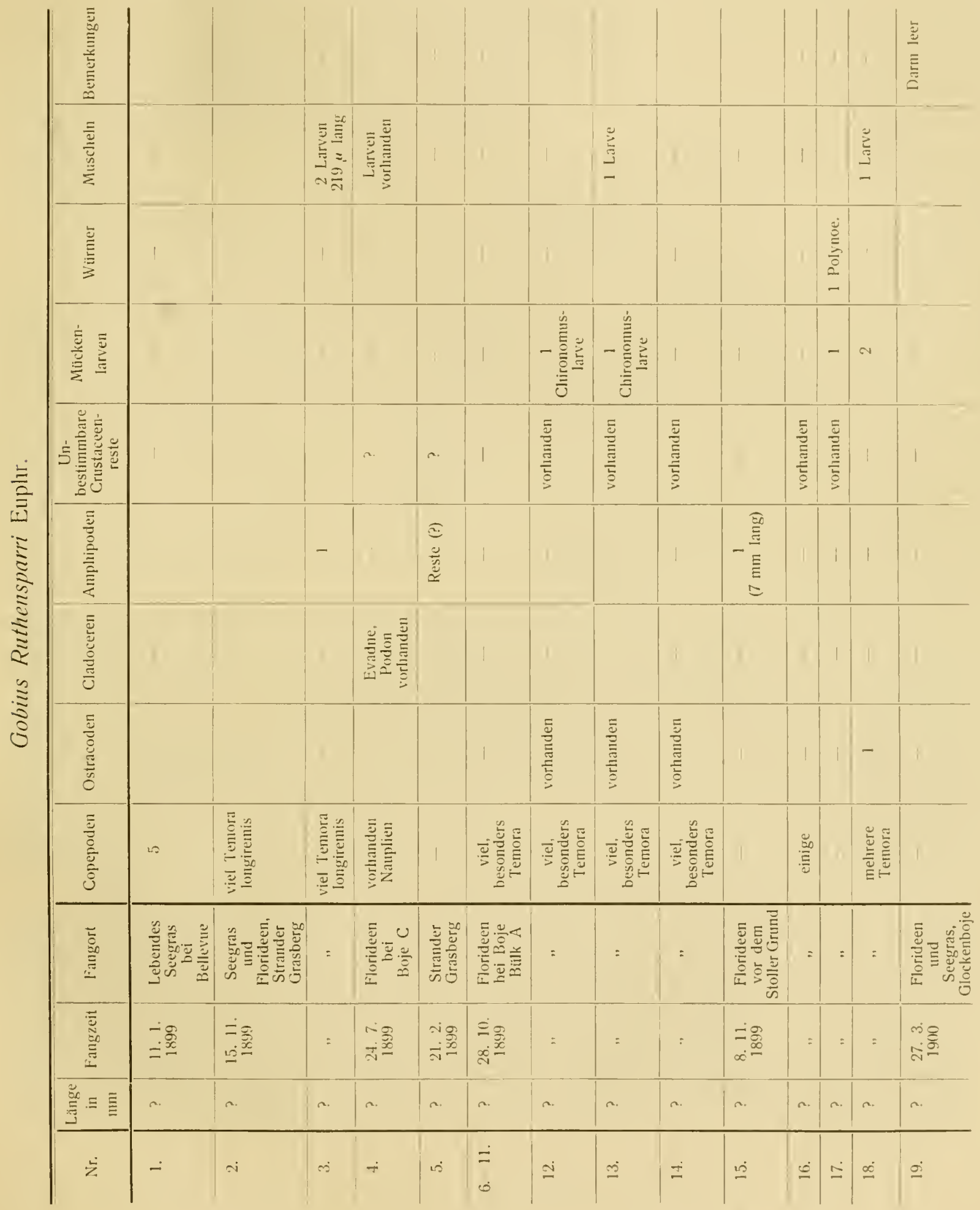


Gasterosteus pungitius L.

\begin{tabular}{|c|c|c|c|c|c|c|c|c|c|c|}
\hline Nr. & $\begin{array}{c}\text { Länge } \\
\text { in } \\
\mathrm{mm}\end{array}$ & Fangzeit & Fangort & Copepoden & $\begin{array}{l}\text { Ostra- } \\
\text { coden }\end{array}$ & Isopoden & $\begin{array}{l}\text { Amphi- } \\
\text { poden }\end{array}$ & $\begin{array}{l}\text { Un- } \\
\text { bestimmbare } \\
\text { Crustaceen- } \\
\text { reste }\end{array}$ & Eizellen & $\begin{array}{c}\text { Be- } \\
\text { merkungen }\end{array}$ \\
\hline 1. & $30-40$ & $\begin{array}{l}11.1 . \\
1899\end{array}$ & $\begin{array}{l}\text { lebendes } \\
\text { Seegras, } \\
\text { Bellevue }\end{array}$ & - & - & - & & & $=$ & $\begin{array}{l}\text { nichts } \\
\text { Erkennbares, } \\
\text { breige Mlasse }\end{array}$ \\
\hline 2. & $\because$ & $"$ & $\because$ & spärliche Reste & - & - & - & - & & " \\
\hline 3. -5 . & $"$ & $"$ & $"$ & $\begin{array}{c}\text { in beträchtlicher } \\
\text { Menge }\end{array}$ & - & - & - & - & - & - \\
\hline 6. & 40 & $\begin{array}{l}10.7 \\
1899\end{array}$ & $\begin{array}{c}\text { lebendes } \\
\text { Seegras, } \\
\text { Wiker Bucht } \\
\end{array}$ & 9 & - & $\begin{array}{c}2 \text { Jaera } \\
(1,5 \text { แ. } 2 \mathrm{~mm})\end{array}$ & - & - & $\begin{array}{c}1 \\
\text { (ca. } 1 \mathrm{~mm})\end{array}$ & - \\
\hline 7. & 38 & 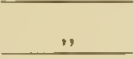 & , & - & - & - & $=$ & vorhanden & 2 & - \\
\hline 8. & 29 & $\begin{array}{l}17.8 . \\
1900\end{array}$ & $"$ & $\begin{array}{c}\text { ziemlich viel } \\
\text { Harpactiden }\end{array}$ & vereinzelt & $\begin{array}{c}\text { mehrere } \\
\text { Jaera }\end{array}$ & $\begin{array}{c}1 \text { Gamma- } \\
\text { rus }\end{array}$ & - & - & - \\
\hline 9. & 28 & , & 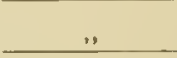 & Harpactiden & 1 & Jaera & $\ldots$ & 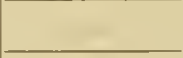 & - & - \\
\hline 10. & 31 & " & " & $\begin{array}{c}\text { ca. } \\
12 \text { Haspactiden }\end{array}$ & $\ldots$ & $\begin{array}{l}\text { Jaera in } \\
\text { grösserer } \\
\text { Zahl }\end{array}$ & - & - & 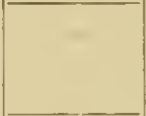 & - \\
\hline 11. & 33 & $"$ & $"$ & $\begin{array}{c}\text { ca. } \\
12 \text { Harpactiden }\end{array}$ & 1 & $\begin{array}{c}\text { Jaera } \\
\text { in } \\
\text { grösserer } \\
\text { Zahl }\end{array}$ & -. & - & & \\
\hline 12. & 29 & $"$ & , & $\begin{array}{c}\text { Harpactiden } \\
\text { in } \\
\text { grösserer Menge }\end{array}$ & - & Jaera & 1 & - & - & - \\
\hline
\end{tabular}

Im Darmtraktus 'der elf — der Darm des zwölften enthielt nur breiige Masse - untersuchten Exemplare von Gasterosteus pungitius habe ich mit einer Ausnahme auch Copepoden gefunden, doch waren es vorwiegend Harpactiden. Daneben spielten auch Isopoden eine wichtige Rolle als Nahrungsbestandtheile. Immer waren es kleine Jaera marina, die zum Theil in grösserer Zahl anzutreffen waren. Ostracoden und Amphipoden fanden sich nur vereinzelt, Reste grösserer Krebse waren selten. Benecke ${ }^{1}$ ) nennt Gasterosteus pungitius „einen der gefährlichsten Laichräuber" und auch Kröyer ${ }^{2}$ ) schreibt, dass dieser Fisch besonders Fischlaich frisst. Ich habe Eizellen nur im Darm zweier Exemplare gefunden, doch ist zu berücksichtigen, dass die zartwandigen Zellen leicht der Verdaumng verfallen. Heincke ${ }^{3}$ ) hat beobachtet, dass Stichlinge grösseren Fischen Stücke aus den Flossen und dem Leibe beissen. Einen Gasterosteus pungitius hielt ich sechs Tage in einem Glashafen mit lebendem Plankton. Nach dieser Zeit, während der der Stichling sehr lebendig war, fand ich in seinem Darm Melosira, Sceletonema, Ceratium und Copepoden. Aus diesem Versuch geht hervor, dass Gasterosteus auch mit Plankton fürlieb nimmt.

lm Darm der elf untersuchten Seestichlinge - Spinachia vulgaris - traten Copepoden auffallend zurück, nur zwei Exemplare hatten welche gefressen. Isopoden bildeten den Hauptbestandtheil des Magen- und Darminhaltes. Sehr bemerkenswerth ist es, dass unter den Isopoden die Idotheen überwogen. Auch die Amphipoden spielen für Spinachia anscheinend eine wichtigere Rolle als für Gasterosteus; in zwei Fällen thabe ich deutlich erkennbare Gammariden und in drei Fällen nicht näher zu bestimmende Flohkrebse gefunden. Mysideen, die ich im Darm von Gasterostells garnicht bemerkt habe, waren bei Spinachia nicht selten; in einem Darm habe ich deren füufundzwanzig gefunden. Ein Exemplar hatte über sechzig Balanidenlarven (Cyprisstadium) gefressen. Eine Spinachia die sich schon längere Zeit in einem grösseren Aquarium befunden hatte, setzte ich in einen Glashafen mit lebendem Plankton. Nach fünf

1) 1. c.

$\Rightarrow$ 1. c. p. 184.

3) Fr. Heincke: Fische, in: Illustritte Naturgeschichte der Thiere von Phil. Leop. Marlin l. c. Leipzig 1882, p. 403. 
Tagen war der Fisch gestorben; im Darm waren noch einige Nereidenborsten von einer früheren Mahlzeit vorhanden, von Planktonorganismen war dagegen nichts zu finden.

Spinadia vnlgaris Flem.

\begin{tabular}{|c|c|c|c|c|c|c|c|c|c|c|c|}
\hline Nr. & $\begin{array}{l}\text { Linge } \\
\text { in } \\
\text { m111 }\end{array}$ & $\begin{array}{l}\text { Fang- } \\
\text { zeit }\end{array}$ & Fangort & $\begin{array}{l}\text { Cope- } \\
\text { poden }\end{array}$ & $\begin{array}{c}\text { Balaniden- } \\
\text { larven } \\
\text { (Cypris- } \\
\text { stadium) }\end{array}$ & Isopoden & Amplsipoden & Schizopoden & $\begin{array}{l}\text { Unkenn- } \\
\text { liche } \\
\text { Cruslia- } \\
\text { ceenreste }\end{array}$ & $\begin{array}{l}\text { andere } \\
\text { Thiere }\end{array}$ & $\begin{array}{l}\text { Bemer- } \\
\text { kungen }\end{array}$ \\
\hline 1. & 160 & 11.1. & $\begin{array}{l}\text { lebendes } \\
\text { Seegras, } \\
\text { Bellerue }\end{array}$ & & & & $\ldots$ & $\begin{array}{l}1 \text { Mysis } \\
\text { flexuosa }\end{array}$ & $=$ & $x^{2}$ & $\begin{array}{c}\text { vie] } \\
\text { breiige } \\
\text { Masse' }\end{array}$ \\
\hline 2. & 140 & .. & , & - & - & $\begin{array}{l}4 \text { Idotheen } \\
(3,8,10 \\
10 \mathrm{~mm})\end{array}$ & 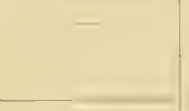 & . & $\begin{array}{l}\text { vor- } \\
\text { handen }\end{array}$ & & " \\
\hline 3. & $?$ & $\therefore$ & ". & - & - . & Idotheen & - & 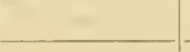 & 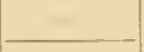 & - & - \\
\hline t. & 43 & $\begin{array}{l}10.7 \\
1899\end{array}$ & $\begin{array}{c}\text { lebendes } \\
\text { Seegras, } \\
\text { Wiker Buch1 } \\
\end{array}$ & $12-15$ & 1 & $\begin{array}{l}\text { Idotheen, } \\
18 \text { Jaera }\end{array}$ & 2 Ganmarus & - & $\begin{array}{l}\text { vor- } \\
\text { handen }\end{array}$ & & \\
\hline 5. & 40 & , & $"$ & ca. 35 & iiber 60 & $\begin{array}{c}\text { einige } \\
\text { Idotheen, } \\
\text { ca. } 12 \text { Jaera } \\
\text { (1-2 mm) }\end{array}$ & - & - & - & $=$ & - \\
\hline 6. & 87 & $\begin{array}{l}17.8 \\
1900\end{array}$ & " & - & - & $\begin{array}{l}10 \text { Jaera } \\
(3 \mathrm{~mm})\end{array}$ & $\begin{array}{c}\text { melirere } \\
\text { kleine }\end{array}$ & $\begin{array}{l}\text { Mysidee } \\
\text { (15 mm) }\end{array}$ & $\begin{array}{c}\text { vor- } \\
\text { handen }\end{array}$ & 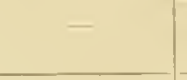 & 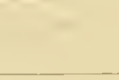 \\
\hline 7. & $?$ & $\begin{array}{l}21.2 . \\
1899\end{array}$ & Kleverberg & - & - & - & - & 5 Mysideen & $\begin{array}{l}\text { vor- } \\
\text { handen }\end{array}$ & $\begin{array}{l}1 \text { Stiick } \\
\text { von einem } \\
\text { Hydroidpol. }\end{array}$ & $\begin{array}{l}\text { viel } \\
\text { breiige } \\
\text { Masse }\end{array}$ \\
\hline 8. & $?$ & $\begin{array}{r}6.12 . \\
1899 \\
\end{array}$ & , & - & - & Idolheen & vorlianden & Mysideen & - & - & - \\
\hline 9. & $?$ & $"$ & " & 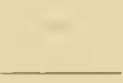 & - & $\begin{array}{l}\text { einige } \\
\text { Idotheen }\end{array}$ & - & $\begin{array}{c}\mathrm{ca} \\
25 \text { Mysideen }\end{array}$ & - & - & - \\
\hline 10. & 50 & $\begin{array}{r}237 \\
1900 \\
\end{array}$ & ," & - & - & 1 Idothea & 1 Gammarus & - & viel & - & - \\
\hline 11. & 85 & $\begin{array}{c}28.10 \\
1899\end{array}$ & $\begin{array}{c}\text { Florideen, } \\
\text { Boje Bullk A }\end{array}$ & 一 & $\cdots$ & vorhandell & vorhanden & - & - & $\begin{array}{l}\text { 1. Stück von } \\
\text { einem Wurml }\end{array}$ & - \\
\hline
\end{tabular}

Mysideen und Isopoden werden auch von Kröyer') als Nahrung des grossen Scestichlings angegeben; auch soll er Fischlaich fressen. Nach Möbius und Heincke²) soll er anch jungen Fischen nachstellen. Andere Litteraturangaben besagen nur ganz allgemein, dass Spinachia kleine Thiere frisst.

Siphonostoma typhle bevorzngt, nach meinen Untersuchungen zu urtheilen, entschieden Schizopoden. Von den einundzwanzig Exemplaren, die ich untersucht habe, hatten achtzehn Mysideen gefressen. Freilich ist zu berücksichtigen, dass die meisten Exemplare gleichzeitig und an derselben Stelle gefangen worden sind, nämlich im August 1900 im Seegras der Wiker Bucht. Nach den Mysideen waren Isopoden im Darminhalt, und zwar sowoln Jaera marina als auch Idothe atricuspidata. Amphipoden waren nur im Darm von zwei Exemplaren vorhanden. Beide stammten aus der Florideenregion zwischen Boje Bülk A und der Heulboje; und waren im Oktober 1899 gefangen. Da beide Exemplare keine Mysideen gefressen hatten, und da andererseits unter den vielen, im Seegras der Wiker Bucht gefangenen Secnadeln keine war, dic Amphipoden im Darm hatte, so scheint es mir doch zweifelhaft, ob das ansschliessliche Vorhandensein von Mysideen beziehungsweise Amphipoden die Folge einer Auswahl oder vielleicht des Ueberwiegens der einen beziehungsweise andern Krebssorten war. 
Siphonostoma typhle L.

\begin{tabular}{|c|c|c|c|c|c|c|c|c|}
\hline Nr. & $\left|\begin{array}{c}\text { Länge } \\
\text { in } \\
\mathrm{mm}\end{array}\right|$ & Fangzeit & Fangort & Isopoden & Amphipoden & Schizopoden & $\begin{array}{c}\text { Unkenntliche } \\
\text { Crustaceen- } \\
\text { reste }\end{array}$ & Bemerkungen \\
\hline 1. & - & $\begin{array}{l}11.1 . \\
1899\end{array}$ & $\begin{array}{c}\text { lebendes } \\
\text { Seegras } \\
\text { bei Bel!evue } \\
\end{array}$ & - & - & 1 Mysis flexuosa & $\begin{array}{c}\text { einige } \\
\text { Chitinreste }\end{array}$ & \\
\hline 2. & ? & $\begin{array}{l}10.7 . \\
1899\end{array}$ & $\begin{array}{c}\text { lebendes } \\
\text { Seegras, } \\
\text { Wiker Buclit } \\
\end{array}$ & $\begin{array}{c}2 \text { gut erhaltene } \\
\text { und } 4 \text { zerstückelte } \\
\text { Jaera marina } \\
\end{array}$ & - & 1 Mysis flexuosa & viel & - \\
\hline 3. & 53 & $\begin{array}{r}17.8 \\
1900 \\
\end{array}$ & $"$ & - & - & 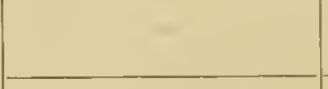 & - & $\begin{array}{c}\text { nichts } \\
\text { Erkennbares }\end{array}$ \\
\hline 4. & 60 & " & $"$ & $\begin{array}{c}3 \text { Jaera marina } \\
(2 \mathrm{~mm} \text { lang })\end{array}$ & - & viel Mysideenreste & - & - \\
\hline 5. & 68 & " & $n$ & - & 一 & Mysideenreste & vorhanden & 一 \\
\hline 6. & 73 & $"$ & $"$ & 一 & - & $\begin{array}{l}3 \text { gut erhaltene } \\
\text { Mysideen ( } 8 \text { mm) } \\
\text { und Mysideenreste }\end{array}$ & - & - \\
\hline 7. & 80 & " & $"$ & - & - & $\begin{array}{c}\text { grössere } \\
\text { Mysideenreste }\end{array}$ & - & - \\
\hline 8. & 80 & $"$ & $"$ & $\begin{array}{l}3 \text { Jaera marina } \\
(3 \mathrm{~mm}) \\
\end{array}$ & - & J Mysidee (12 mm) & vorlianden & - \\
\hline 9. & 85 & $"$ & " & - & - & $\begin{array}{c}2 \text { Mysideen (ca. } 15 \mathrm{~mm} \text { ) } \\
\text { und Mysideenreste }\end{array}$ & - & - \\
\hline 10 & 85 & $"$ & " & $\begin{array}{c}3 \text { gut erhaltene } \\
\text { Idotheen }(\mathrm{ca} .3 \mathrm{~mm}) \\
\end{array}$ & - & 1 Mysidee (ca. $5 \mathrm{~mm}$ ) & vorhanden & - \\
\hline 11 & 86 & ". & $"$ & 5 Jaera marina & - & Mysideenreste & vorhanden & $\ldots$ \\
\hline 12. & 87 & " & " & - & - & $\begin{array}{c}15 \text { Mysideen (ca. } 6 \text { mm) } \\
\text { und Mysideenreste }\end{array}$ & 一 & - \\
\hline 13. & 87 & " & " & - & - & $\begin{array}{c}1 \text { Mysidee } \\
\text { und Mysideenreste }\end{array}$ & - & - \\
\hline 14 & 88 & , & $"$ & $\begin{array}{c}5 \text { Jaera marina } \\
(3 \mathrm{~mm}) \\
\end{array}$ & - & 1 kleine Mlysidee & vorhanden & - \\
\hline 15. & 90 & , & $\because$ & & - & Mysideenbruchstiicke & - & 二 \\
\hline 16. & 142 & $"$ & $"$ & - & - & $\begin{array}{c}1 \text { ca. } 20 \mathrm{~mm} \text { lange } \\
\text { Mysidee } \\
\text { und eire stark zersetzte }\end{array}$ & vorlianden & - \\
\hline 17. & 76 & $"$ & $"$ & - & - & $\begin{array}{c}5 \text { gut erhaltene } \\
\text { Mysideen (ca. } 10 \mathrm{~mm} \\
\text { usd viele Reste }\end{array}$ & - & - \\
\hline 18. & $?$ & $\begin{array}{l}21.2 . \\
1899\end{array}$ & $\begin{array}{c}\text { lebendes } \\
\text { Seegras, } \\
\text { Strander } \\
\text { Buclit }\end{array}$ & - & - & Mysideenreste (?) & (?) & - \\
\hline 19. & 337 & $\begin{array}{l}17.7 . \\
1899\end{array}$ & ", & $\begin{array}{c}\text { Jaera marina } \\
\text { vothanden }\end{array}$ & - & $\begin{array}{l}2 \text { ca. } 12 \text { mum lange } \\
\text { Mysideen }\end{array}$ & vorhanden & \\
\hline 20. & $?$ & $\begin{array}{l}28.10 \\
1899\end{array}$ & $\begin{array}{c}\text { Florideen } \\
\text { bei } \\
\text { Boje Biilk A }\end{array}$ & $\begin{array}{l}\text { vorlianden } \\
(1-6 \mathrm{~mm})\end{array}$ & $\begin{array}{l}\text { vorlianden } \\
(1-6 \text { mm })\end{array}$ & - & - & $\begin{array}{l}\text { Amphipoden } \\
\text { und lsopoden, } \\
\text { zusammer } \\
\text { ca. } 50 \\
\end{array}$ \\
\hline 21 & $?$ & $"$ & $\begin{array}{c}\text { Florideen } \\
\text { zwischen } \\
\text { 'Heulboje } \\
\text { und Biilk A }\end{array}$ & - & $\begin{array}{l}\text { Atylus bispinosus } \\
\text { und andere }\end{array}$ & 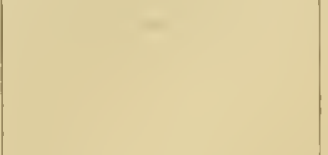 & - & - \\
\hline
\end{tabular}


Am mantgfaltigsten war der Darminhalt bei Nerophis ophidion zusammengesetzt. Copepoden, Isopoden und Amphipoden bildeten den Hauptbestandtheil des Darminhaltes der elf von mir untersuchten Schlangemadeln. Eine hatte ïber 150 Copepoden gefressen; aber solche Mengen von Krebsen habe ich in keinem anderen Darm gesehen. Von andern thierischen Organismen habe ich Muschellarven und kleine Schnecken bemerkt. Ein Exemplar hatte von den ersteren über 105 aufgenommen, ein anderes hatte im Magen Radulastücke von Hydrobia ulvae und ein drittes Sclıneckengehäuse in grösserer Zahl. Bei der Untersuchung eines Darmes stiess ich auch auf ein Seegrasstiickchen; da es abcr ganz vereinzelt blieb, halte ich es für unwesentlich. Im Verdaunngstraktus ciner Schlangennadel, die ich mehrere Tage in einem Behälter mit lebendem Plankton hielt, konnte ich keinen Inhalt nachweisen.

Nerophis ophidion L.

\begin{tabular}{|c|c|c|c|c|c|c|c|c|c|c|c|c|c|c|}
\hline Nr. & $\begin{array}{c}\text { Länge } \\
\text { in } \\
\text { mm }\end{array}$ & $\begin{array}{c}\text { Fang- } \\
\text { zeit }\end{array}$ & Fangort & $\begin{array}{l}\text { Cope- } \\
\text { poden }\end{array}$ & $\begin{array}{l}\text { Ostra- } \\
\text { coden }\end{array}$ & $\begin{array}{c}\text { Cirripedi- } \\
\text { enlarven } \\
\text { (Cypris- } \\
\text { stad.) }\end{array}$ & Isopoden & $\begin{array}{l}\text { Amplıi- } \\
\text { poden }\end{array}$ & \begin{tabular}{|c|} 
Unbe- \\
stimmbare \\
Crusta- \\
ceenreste
\end{tabular} & $\begin{array}{c}\text { Hala- } \\
\text { cariden }\end{array}$ & $\begin{array}{c}\text { Mu- } \\
\text { schel- } \\
\text { larven }\end{array}$ & $\begin{array}{c}\text { Schnek- } \\
\text { ken }\end{array}$ & \begin{tabular}{|} 
See- \\
gras- \\
stiucke
\end{tabular} & $\begin{array}{l}\text { Bener- } \\
\text { kungen }\end{array}$ \\
\hline 1. & $?$ & $\begin{array}{l}11.1 . \\
1899\end{array}$ & $\begin{array}{l}\text { lebendes } \\
\text { Seegras bei } \\
\text { Bellevue }\end{array}$ & - & - & - & - & - & - & - & - & - & - & $\begin{array}{l}\text { nichts } \\
\text { Erkenn- } \\
\text { bares }\end{array}$ \\
\hline 2. & $?$ & $\begin{array}{c}10.7 . \\
1899\end{array}$ & $\begin{array}{c}\text { lebendes } \\
\text { Seegras } \\
\text { in der } \\
\text { Wiker Bucht }\end{array}$ & 一 & - & 2 & $\begin{array}{c}\text { mehrere } \\
\text { kleine Jaera } \\
\text { marina I ldo- } \\
\text { lhea tricusp. } \\
\text { (3 mm) }\end{array}$ & - & - & - & - & $\begin{array}{l}\text { Radula- } \\
\text { slücke v. } \\
\text { Hydrobia } \\
\text { ulvac }\end{array}$ & - & - \\
\hline 3. & 173 & $\begin{array}{c}17.8 . \\
1900\end{array}$ & $n$ & - & $\begin{array}{l}\text { meh- } \\
\text { rere }\end{array}$ & - & 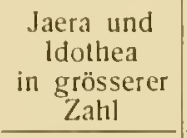 & $\begin{array}{c}\text { Gamma- } \\
\text { rus in } \\
\text { grösserer } \\
\text { Zah! } \\
\end{array}$ & ? & - & $\rightarrow$ & $\begin{array}{c}\text { kleine } \\
\text { Schnek- } \\
\text { ken in } \\
\text { gröss.Zahl }\end{array}$ & - & - \\
\hline 4. & 220 & $\begin{array}{c}19.6 . \\
1899\end{array}$ & $\begin{array}{l}\text { lebendes } \\
\text { Seegras bei } \\
\text { Mönkeberg }\end{array}$ & $\begin{array}{l}\text { über } \\
150\end{array}$ & - & - & 49 Idolheen & ca. 22 & vorh. & - & - & $\cdots$ & - & - \\
\hline 5. & 190 & $\begin{array}{c}23.7 \\
1900\end{array}$ & Kleverberg & vorh. & - & - & $\begin{array}{l}\text { mehrere } \\
\text { Idolheen }\end{array}$ & meltrere & vorh. & - & 105 & - & 1 & 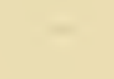 \\
\hline 6. น. 7. & ? & $\begin{array}{c}6.12 . \\
1899\end{array}$ & $n$ & - & - & - & - & - & vorh. & 一 & 一 & & - & - \\
\hline 8. & ? & $\begin{array}{c}\text { 18. } 10 . \\
1899\end{array}$ & $\begin{array}{l}\text { Fucus und } \\
\text { Seegras bei } \\
\text { Boje Kiel B }\end{array}$ & vorh. & - & $\begin{array}{l}\text { ziemlich } \\
\text { viel }\end{array}$ & $\begin{array}{l}\text { melirere } \\
\text { Idotheen }\end{array}$ & - & - & - & - & - & $\ldots$ & \\
\hline 3. & $?$ & $n$ & n & - & - & vorls. & - & & - & $\begin{array}{l}1 \text { Rhom- } \\
\text { bogual- } \\
\text { llus }\end{array}$ & & $\ldots$ & - & - \\
\hline 10 & 145 & $\begin{array}{c}28.10 \\
1899\end{array}$ & $\begin{array}{l}\text { Florideen } \\
\text { bei Boje } \\
\text { Biilk A }\end{array}$ & - & - & - & 11 Idotheen & vorh. & 一 & - & $\ldots$ & - & - & - \\
\hline 11. & 150 & n & n & vorh. & rorh. & - & $\ldots$ & vorls. & & - & - & - & - & - \\
\hline
\end{tabular}

Von Pleuronectes platessa und Pleuronectes flesus habe ich nur junge Exemplare untersucht. Veranlasst, diese Nutzfische überhaupt in den Rahmen meiner Untersuchungen zn zichen, wurde ich durch eine Mittheilung von Herrn Dr. Apstein. Herr Dr. Apstein fand bei jungen Goldbutt und Flundern durchgehends verschiedenen Darminhalt, und zwar bildeten bei ersteren Muscheln, bei letzteren Chaetopoden den Hauptbestandtheil der gefressenen Kost. Meine Untersuchungen stimmten mit denjenigen von Hern Dr. Apstein überein. Bevor ich auf einen Vergleich der Befunde bei beiden Fischarten eingehe, möchte ich jede für sich kurz besprechen. 
Pleuronectes platessa L.

\begin{tabular}{|c|c|c|c|c|c|c|c|c|c|c|c|c|}
\hline Nr. & $\begin{array}{c}\text { Länge } \\
\text { in } \\
\mathrm{mm}\end{array}$ & Fangzeit & Fangort & Copepoden & $\begin{array}{c}\text { Andere } \\
\text { Crustaceen }\end{array}$ & 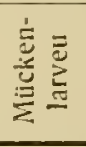 & Wïrmer & Muscheln & 竎 & 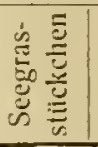 & Sand & $\begin{array}{l}\text { Bemer- } \\
\text { kungen }\end{array}$ \\
\hline 1. & 15 & $\begin{array}{l}\text { Juni } \\
1898\end{array}$ & $\begin{array}{l}\text { Eckern- } \\
\text { förde }\end{array}$ & $\begin{array}{c}\text { viele } \\
\text { Harpactiden }\end{array}$ & - & $=$ & $\begin{array}{c}\text { Nereidenborsten } \\
\text { in beträchtlicher } \\
\text { Menge }\end{array}$ & $=$ & 一 & - & wenig & $=$ \\
\hline 2. & 21 & ", & " & $\begin{array}{c}\text { viele } \\
\text { Harpactiden }\end{array}$ & - . & - & $\begin{array}{c}\text { Nereidenborsten } \\
\text { in beträchtllicher } \\
\text { Menge }\end{array}$ & - & - & - & viel & - \\
\hline 3. & 28 & $"$ & $"$ & $\begin{array}{c}\text { viele } \\
\text { Harpactiden }\end{array}$ & - & - & $\begin{array}{c}\text { Nereidenborsten } \\
\text { in beträchtlicher } \\
\text { Menge }\end{array}$ & - & - & & viel & - \\
\hline 4. & 27 & " & $"$ & - & - & - & $\begin{array}{c}\text { sehr viel } \\
\text { Nereidenborsten }\end{array}$ & - & - & - & wenig & - \\
\hline 5. & 31 & $"$ & $"$ & - & $\begin{array}{l}\text { 1. Gammarus } \\
\text { (3 mm) }\end{array}$ & - & $\begin{array}{c}\text { viele Nereiden } \\
\text { (durchschnittlich } \\
4 \text { mnl lang) }\end{array}$ & - & - & - & viel & - \\
\hline 6. & 37 & $\begin{array}{c}3 .-5.8 \\
1899\end{array}$ & $"$ & $\begin{array}{l}\text { ither } 100 \\
\text { Harpactiden }\end{array}$ & - & - & $\begin{array}{l}1 \text { macerirte } \\
\text { Nereis }\end{array}$ & - & $=$ & - & $\begin{array}{c}\text { sehr } \\
\text { Wenig }\end{array}$ & - \\
\hline 7. & 37 & $"$ & $"$ & $\begin{array}{l}\text { ïber } 70 \\
\text { Harpactiden }\end{array}$ & - & $\cdots$ & - & $\begin{array}{ll}7 & \text { Larven } \\
1 & \text { Mytilus } \\
1 & \text { Cardium }\end{array}$ & - & - & $\begin{array}{c}\text { sehr } \\
\text { wenig }\end{array}$ & \\
\hline 8. & 38 & $"$ & $"$ & $\begin{array}{l}\text { ca. } 2500 \\
\text { Harpactiden }\end{array}$ & - & $=$ & - & 3 Larven & - & 1 & ? & $=$ \\
\hline 9. & 44 & $"$ & $"$ & $\begin{array}{l}\text { ca. } 1000 \\
\text { Harpactiden }\end{array}$ & - & - & $\begin{array}{l}1 \text { macerirte } \\
\text { Nereis }\end{array}$ & $\begin{array}{c}\text { mehrere Larven, } \\
\text { Mytilus } \\
\text { und Cardium }\end{array}$ & - & - & ? & - \\
\hline 10. & 45 & $"$ & " & $\begin{array}{l}\text { ca. } 1000 \\
\text { Harpactiden }\end{array}$ & - & - & $\begin{array}{l}\text { mehrerc mace- } \\
\text { rirte Nereiden; } \\
1 \text { Enchitraeide }\end{array}$ & $\begin{array}{c}\text { mehrere Larven, } \\
\text { Mytilus } \\
\text { und Cardium }\end{array}$ & $\begin{array}{c}2 \text { La- } \\
\text { cuna } \\
(?)\end{array}$ & 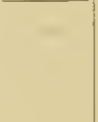 & $?$ & - \\
\hline 11. & 53 & " & " & - & - & - & $\begin{array}{l}1 \text { macerirte } \\
\text { Nereis }\end{array}$ & $\begin{array}{c}\text { Mytilus in } \\
\text { betrăchtlicher } \\
\text { Zahl }\end{array}$ & - & - & $\begin{array}{l}\text { sehr } \\
\text { viel }\end{array}$ & \\
\hline 12. & 53 & " & $"$ & - & - & - & $\begin{array}{c}1 \text { Nereidenkopf } \\
\text { mit } \\
10 \text { Segmenten; } \\
\text { sehr riel Borsten }\end{array}$ & $\begin{array}{c}\text { Mytilus in } \\
\text { beträchtlicher } \\
\text { Zahl }\end{array}$ & - & - & viel & $\begin{array}{c}\text { viel } \\
\text { breiige } \\
\text { Massc }\end{array}$ \\
\hline 13. & 57 & " & $"$ & $=$ & $\begin{array}{c}4 \text { Gammarus } \\
\text { (durch- } \\
\text { schnittlich } \\
6 \mathrm{~mm} \text { ) }\end{array}$ & - & $\begin{array}{c}1 \text { Nereis } \\
(45 \text { Segmente) }\end{array}$ & $\begin{array}{l}2 \text { Mytilus ( } 3 \text { mms) } \\
1 \text { Cardium (2 m })\end{array}$ & - & - & ? & \\
\hline 14. & 58 & $"$ & , & einige & - & - & $\begin{array}{c}1 \text { macerirte } \\
\text { Nereis, viele } \\
\text { Neplithys- } \\
\text { borsten; } \\
\text { 1 Enchytraeide }\end{array}$ & 8 kleine Mytilus & - & 1 & viel & - \\
\hline 15. & 58 & $"$ & , & & - & - & $\begin{array}{c}1 \text { Nereis (75 Seg- } \\
\text { mente) mehrere } \\
\text { macerirte. }\end{array}$ & 1 Mytilus & - & $\begin{array}{l}\text { melt- } \\
\text { rere }\end{array}$ & vicl & \\
\hline 16. & 61 & $"$ & ", & - & - & - & $\begin{array}{c}1 \text { Nereis } \\
\text { (65 Segmente) }\end{array}$ & 1 Mytilus (1 mun) & - & - & viel & - \\
\hline
\end{tabular}


E. Rauschenplat, Ueber die Nahrung von Thieren aus der Kieler Bucht.

Plenronectes platessa L. (Fortsetzung.)

\begin{tabular}{|c|c|c|c|c|c|c|c|c|c|c|c|c|}
\hline Nr. & $\begin{array}{l}\text { Länge } \\
\text { in } \\
m m ?\end{array}$ & Fangzeit & Fangort & Copepoden & $\begin{array}{c}\text { Andere } \\
\text { Crustaceen }\end{array}$ & 产㐫 & lliurmer & Muscheln & 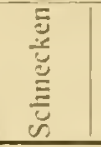 & 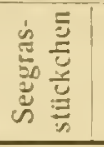 & Sand & $\begin{array}{l}\text { Bemer- } \\
\text { kungen }\end{array}$ \\
\hline 17. & 62 & 3. 5.8 & $\begin{array}{l}\text { Eckern- } \\
\text { förde }\end{array}$ & & $\begin{array}{l}2 \text { Jdothea } \\
\text { (2 } 11.6 \text { min), } \\
5 \text { Gammarus } \\
\text { (ca. } 6 \text { mum), } \\
2 \text { Balanus } \\
\text { mit Theilen } \\
\text { der Schale } \\
\end{array}$ & 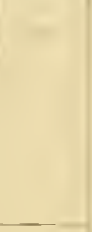 & & $\begin{array}{c}1 \text { Mytilus (3 mus) } \\
1 \text { zerbrochenes } \\
\text { Cardinn }\end{array}$ & $\begin{array}{l}2 \text { La- } \\
\text { cluna } \\
\text { l? }\end{array}$ & & ? & \\
\hline 18. & 61 & $\begin{array}{l}7.9 \\
1898 \\
\end{array}$ & ". & - & 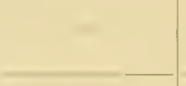 & - & $\begin{array}{l}\text { viel macerirte } \\
\text { Nereidentheile }\end{array}$ & 8 Mytilus (2 mm & $=$ & - & $?$ & $\ldots$ \\
\hline 19. & 62 & $"$ & " & - & $\ldots$ & $x^{2}$ & $\begin{array}{l}\text { viel macerirte } \\
\text { Nereidentheile }\end{array}$ & 7 Mytilus (2 $\mathrm{mm})$ & $a^{2}$ & 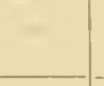 & $?$ & 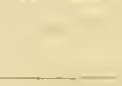 \\
\hline 20. & 65 & " & " & - & - & 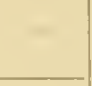 & $\begin{array}{l}\text { viel macerirte } \\
\text { Nereidentheile }\end{array}$ & 6 Mytilus (2 mm) & 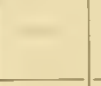 & - & ? & 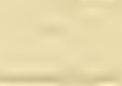 \\
\hline 21. & 65 & $"$ & ". & - & 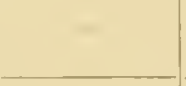 & - & 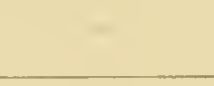 & $\begin{array}{l}\text { ca. } 20 M y \text { tilus } \\
\text { (bis zu } 3 \text { mm }\end{array}$ & $x^{2}$ & - & $?$ & 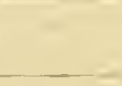 \\
\hline 22. & 69 & $\begin{array}{c}10 . \quad 13 \\
8 . \\
1897 \\
\end{array}$ & $"$ & - & 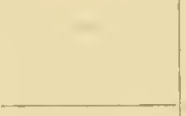 & - & $\begin{array}{l}\text { sehr viel } \\
\text { Nereisborsten }\end{array}$ & mehrere Mytilus & - & - & $\begin{array}{l}\text { sehr } \\
\text { viel }\end{array}$ & $\ldots$ \\
\hline 23. & 74 & $"$ & ". & & & & & $\begin{array}{l}\text { viele Cardium, } \\
\text { Mya und Mytilus }\end{array}$ & - & - & wenig & \\
\hline 24. & 78 & $"$ & ,. & - & - & - & & $\begin{array}{c}\text { viele Cardinm, } \\
\text { daneben auch } \\
\text { Mya und Mytilus }\end{array}$ & $\begin{array}{c}1 \\
\text { Doris } \\
\text { (?) }\end{array}$ & - & wenig & - \\
\hline 25. & 80 & , & ," & - & - & - & - & $\begin{array}{c}\text { viele Mytilus, } \\
\text { Cardium u. Mya } \\
\text { (meist } \\
\text { zerbrochen) }\end{array}$ & - & - & ? & - \\
\hline 26. & 90 & , &, & - & - & & $=$ & $\begin{array}{c}\text { viele Mytilus, } \\
\text { Cardium u. Mya } \\
\text { (meist } \\
\text { zerbrochen) }\end{array}$ & $\begin{array}{c}\text { ca. } 12 \\
\text { Doris } \\
\text { (?) }\end{array}$ & - & $?$ & - \\
\hline 27. & 103 & $\begin{array}{c}9 .-12 . \\
10 . \\
1899\end{array}$ & , & - & $\begin{array}{l}1 \text { Mysidee } \\
\text { (ca. } 18 \mathrm{~mm} \text { ) }\end{array}$ & - & - & $\begin{array}{c}\text { sehr viel Mytilus, } \\
\text { Cardium u. Mya } \\
\text { (meist } \\
\text { zerbrochen) }\end{array}$ & - & - & $?$ & - \\
\hline 28. & 106 & , & , & - & $\begin{array}{c}1 \text { kleines } \\
\text { Carcinus } \\
\text { (zerbrochen) }\end{array}$ & - & & $\begin{array}{c}\text { Mya, Mytilus } \\
\text { und Cardium je } \\
\text { ca. } 4 \\
\text { (zerbrochen) }\end{array}$ & - & $\begin{array}{c}1 \\
99 \mathrm{~mm} \\
\text { lang. } \\
1^{1}= \\
\text { breit } 1 \\
\end{array}$ & $?$ & - \\
\hline 29. & 110 & ", & ". & - & $\begin{array}{l}1 \text { unkenntl. } \\
\text { Amplipod. } \\
\end{array}$ & - & - & + Mya, Cardium & - & - & $?$ & - \\
\hline 30. & 115 & ," & " & - & 1 Gammarus & - & & $\begin{array}{l}\text { viel zerbrochene } \\
\text { Schalen }\end{array}$ & - & - & viel & $\begin{array}{l}\text { breiige } \\
\text { Masse }\end{array}$ \\
\hline 31. & 115 & " & ". & - & - & - & - & $\begin{array}{c}\text { ca. } 20 \text { guterhalt. } \\
\text { Cardium; viele } \\
\text { zerbrochene } \\
\text { Sclialen, auch } \\
\text { von Mya und } \\
\text { Mytilus } \\
\end{array}$ & - & - & wenig & - \\
\hline 32. & 115 & , & " & - & & - & & $\begin{array}{c}11 \text { guterlaaltene } \\
\text { Cardium } \\
(2 \quad 4,5 \text { mm }) \\
1 \text { Myaa (3 nmi) }\end{array}$ & & - & viel & \\
\hline
\end{tabular}


Pleuronectes flesus L.

\begin{tabular}{|c|c|c|c|c|c|c|c|c|c|c|c|c|c|}
\hline Nr. & $\begin{array}{c}\text { Länge } \\
\text { in } \\
\mathrm{mm}\end{array}$ & Fangzeit & Fangort & Copepoden & $\begin{array}{l}\text { Andere } \\
\text { Crusta- } \\
\text { ceen }\end{array}$ & 离 & Würmer & Muscheln & 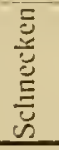 & 言 & 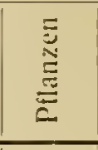 & Sand & $\begin{array}{l}\text { Bemer- } \\
\text { kungen }\end{array}$ \\
\hline 1. & 12 & $\begin{array}{l}11.4 . \\
1897\end{array}$ & $\begin{array}{l}\text { Eckern- } \\
\text { förde }\end{array}$ & $\begin{array}{c}\text { ca. } 50 \\
\text { Harpactiden }\end{array}$ & - & & - & - & - & - & - & wen. & \\
\hline 2. & 18 & $"$ & " & $\begin{array}{c}\text { ca. } 40 \\
\text { Harpactiden } \\
1 \text { Temora }\end{array}$ & - & & - & - & - & & - & wen. & - \\
\hline 3. & 18 & " & , & $\begin{array}{c}\text { ca. } 80 \\
\text { Harpactiden }\end{array}$ & - & - & - & 1 Larve & 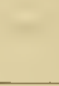 & - & - & wen. & - \\
\hline 4. & 22 & $"$ & , & $\begin{array}{c}\text { ca. } 60 \\
\text { Harpactiden, } \\
\text { ca. } 20 \text { Temora }\end{array}$ & - & - & 1 Enchytraeide & - & - & $=$ & $\begin{array}{l}1 \text { See- } \\
\text { gras- } \\
\text { stück }\end{array}$ & wen. & - \\
\hline 5. & 27 & $"$ & $"$ & $\begin{array}{c}\text { ca. } 50 \\
\text { Harpactiden, } \\
\text { ca. } 100 \text { Temora }\end{array}$ & - & - & - & - & - & - & - & $\begin{array}{l}\text { sehr } \\
\text { wen. }\end{array}$ & - \\
\hline 6. & 28 & ", & " & $\begin{array}{c}\text { ca. } 250 \\
\text { Copepoden } \\
\text { (Harpactiden } \\
\text { und Tenuora) }\end{array}$ & $\begin{array}{c}1 \text { kleiner } \\
\text { Amphipod }\end{array}$ & - & $\begin{array}{c}\text { ca. } 15 \\
\text { Enchytraeiden }\end{array}$ & 1 Larve & - & - & & wen. & - \\
\hline 7. & 30 & , & " & $\begin{array}{c}\text { vereinzelte } \\
\text { Harpactiden }\end{array}$ & - & - & $\begin{array}{c}\text { viel macerirte } \\
\text { Enchytraeiden; } \\
\text { viel } \\
\text { Nereisborsten }\end{array}$ & 1 Larve & - & - & $\begin{array}{l}1 \text { See- } \\
\text { gras- } \\
\text { stück }\end{array}$ & viel & - \\
\hline 8. & 32 & " & " & $\begin{array}{c}\text { ca. } 90 \\
\text { Copepoden } \\
\text { (Harpactiden } \\
\text { und Temora) }\end{array}$ & $\ldots$ & - & $\begin{array}{c}\text { einige } \\
\text { Enchytraeiden }\end{array}$ & - & - & - & - & wen. & $\begin{array}{l}\text { breiige } \\
\text { Masse }\end{array}$ \\
\hline 9. & 32 & " & $"$ & $\begin{array}{c}\text { ca. } 80 \\
\text { Harpactiden }\end{array}$ & - & - & $\begin{array}{c}\text { vijel } \\
\text { Enchytraeiden- } \\
\text { borsten; } \\
1 \text { zersetzte } \\
\text { Nereis } \\
\end{array}$ & - & -. & - & $\begin{array}{c}2 \text { See- } \\
\text { gras- } \\
\text { stïcke }\end{array}$ & ? & \\
\hline 10. & 34 & $"$ & " & $\begin{array}{c}\text { ca. } 100 \\
\text { Harpactiden }\end{array}$ & - & - & $\begin{array}{c}\text { einige } \\
\text { Enchytraeiden- } \\
\text { borsten; } \\
1 \text { macerirte } \\
\text { Nereis } \\
\end{array}$ & - & - & - & - & $?$ & - \\
\hline 11. & 25 & $\begin{array}{c}3 . \quad 5.8 . \\
1899 \\
\end{array}$ & $"$ & $\begin{array}{c}\text { ca. } 700 \\
\text { Harpactiden }\end{array}$ & - & $=$ & $=$ & - & - & - & $=$ & $?$ & $=$ \\
\hline 12. & 26 & " & " & $\begin{array}{l}\text { ca. } 600 \\
\text { Copepoden } \\
\text { vorwiegend } \\
\text { Harpactiden }\end{array}$ & - & - & - & - & - & - & - & ? & - \\
\hline 13. & 30 & " & " & $\begin{array}{c}\text { ca. } 700 \\
\text { Harpactiden }\end{array}$ & & & - & - & $\ldots$ & $\ldots$ & - & ? & - \\
\hline 14. & 39 & ," & " & $\begin{array}{c}\text { wenig } \\
\text { Harpactiden }\end{array}$ & $=$ & - & $\begin{array}{c}2 \text { zersetzte } \\
\text { Nereis }\end{array}$ & - & - & - & - & ? & - \\
\hline 15. & 39 & " & " & $\begin{array}{l}\text { über } 1500 \text {, } \\
\text { lorwiegend } \\
\text { Harpactiden }\end{array}$ & $\ldots$ & $=$ & $\begin{array}{c}\text { Enchytraeiden- } \\
\text { borsten }\end{array}$ & $\left|\begin{array}{c}2 \text { kleine } \\
\text { Mytilus } \\
\text { und } \\
3 \text { Larven }\end{array}\right|$ & - & $\begin{array}{l}\text { mels- } \\
\text { rere } \\
\text { Stiüche }\end{array}$ & $\begin{array}{c}\text { 1 See- } \\
\text { gras- } \\
\text { und } 1 \\
\text { Algen- } \\
\text { stiick }\end{array}$ & ? & - \\
\hline
\end{tabular}


E. Rauschenplat, Ueber die Nahrmg von Thieren aus der Kieler Bucht.

Pleuronectes flesus L. (Fortsetzung.)

\begin{tabular}{|c|c|c|c|c|c|c|c|c|c|c|c|c|c|}
\hline Nr. & $\begin{array}{c}\text { Lainge } \\
\text { in } \\
\text { rnm }\end{array}$ & Fangzeit & Fangort & Copepouden & $\begin{array}{l}\text { Andere } \\
\text { Crusta- } \\
\text { ceen }\end{array}$ & 㝘 & Würmer & Musclieln & 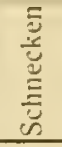 & 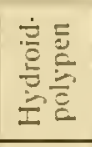 & 를 & Sand & $\begin{array}{l}\text { Bemer- } \\
\text { kumgen }\end{array}$ \\
\hline 16. & 39 & 3. $\frac{5.8}{1899}$ & $\begin{array}{l}\text { Eckern- } \\
\text { förde }\end{array}$ & $\begin{array}{c}\text { ca. } 550 \\
\text { rorwiegend } \\
\text { Harpactiden }\end{array}$ & & & & & & - & & wen. & $\begin{array}{l}\text { breiige } \\
\text { Masse }\end{array}$ \\
\hline 17. & 39 & . & . & $\begin{array}{c}\text { ca. } 700 \\
\text { Harpactiden }\end{array}$ & & & & & & & $\begin{array}{c}1 \text { ver- } \\
\text { zweig- } \\
\text { te } \\
\text { Alge }\end{array}$ & wen. & $\begin{array}{l}\text { breiige } \\
\text { Masse }\end{array}$ \\
\hline 18. & 40 & " & ". & $\begin{array}{l}\text { ca. } 800 \\
\text { Harpactiden }\end{array}$ & & & Nereisborsten & I Larve & & 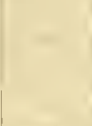 & $\begin{array}{l}\text { I See- } \\
\text { gras- } \\
\text { stijek }\end{array}$ & wen. & \\
\hline 19. & 41 & . & . & $\begin{array}{c}\text { ca. } 450 \\
\text { Harpactiden }\end{array}$ & & & & I Larve & & $=$ & $\left|\begin{array}{c}2 \text { See- } \\
\text { gras- } \\
\text { stiicke }\end{array}\right|$ & ? & $=$ \\
\hline 20. & 44 & $"$ & " & $\begin{array}{l}\text { Vereinzelte } \\
\text { Harpactiden }\end{array}$ & 1 Amphi- & 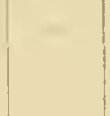 & $\begin{array}{c}\text { macerirte } \\
\text { Nereisreste und } \\
\text { viele Borslen }\end{array}$ & & & 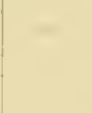 & $=$ & viel & $=$ \\
\hline 21. & 50 & $\begin{array}{l}\text { 7. } 9 . \\
1898\end{array}$ & . & & - & $a^{2}$ & $\begin{array}{l}\text { viel macerirte } \\
\text { Nereistheile und } \\
\text { viele Borsten }\end{array}$ & & & 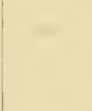 & $=$ & viel & - \\
\hline 22. & 53 & " & " & - & - & $=$ & $\begin{array}{l}\text { I gut erhaltene } \\
\text { Nereis, } \\
\text { viele macerirte } \\
\text { Stücke }\end{array}$ & $=$ & $=$ & 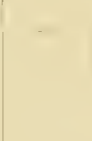 & - & viel & - \\
\hline 23. & 53 & . & " & & - & & $\begin{array}{c}\text { I Nereiskopf } \\
\text { mit H Segm., } \\
\text { viele starke } \\
\text { macerirte Theile }\end{array}$ & & & - & $\begin{array}{l}\text { mejs- } \\
\text { rere } \\
\text { Algen- } \\
\text { lriebe }\end{array}$ & viel & - \\
\hline 24. & 54 & & $"$ & - & - & - & $\begin{array}{l}1 \text { Nereisstück } \\
\text { von } 42 \text { Segm.; } \\
\text { viele stark } \\
\text { macerirte Theile }\end{array}$ & - & - & 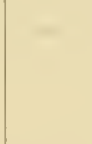 & - & viel & - \\
\hline 25. & 54 & $"$ & " & . & & - & $\begin{array}{c}\text { selur viel } \\
\text { Nereidenborsten }\end{array}$ & $=$ & 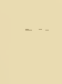 & & & $?$ & - \\
\hline 26. & 56 & $\begin{array}{c}\text { Oktober } \\
1899\end{array}$ & $"$ & & 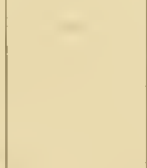 & $\begin{array}{c}\text { viel } \\
\text { Larven } \\
\text { und } \\
\text { Pup- } \\
\text { pei }\end{array}$ & $\begin{array}{c}\text { sehr viel } \\
\text { Nereidenborsten }\end{array}$ & $=$ & - & 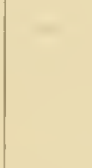 & 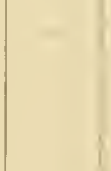 & viel & 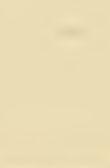 \\
\hline 27. & 6.5 & . & " & - & - & $\begin{array}{l}\text { ca. 50 } \\
\text { Larven } \\
\text { und } \\
\text { Pup- } \\
\text { pent }\end{array}$ & $\begin{array}{c}1 \text { slark macerirte } \\
\text { Nereis; vicle } \\
\text { Encliytraeiden- } \\
\text { borsten }\end{array}$ & - & - & - & & werl. & \\
\hline 28. & 66 & " & $\because$ & - & & 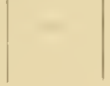 & $\begin{array}{l}\text { stark macerirte } \\
\text { Nereidenstiicke }\end{array}$ & $=$ & & 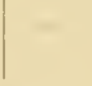 & $=$ & viel & $\begin{array}{l}\text { hreiige } \\
\text { Masse }\end{array}$ \\
\hline
\end{tabular}


Von Pl. platessa habe ich 32 Exemplare untersucht, die sämmtlich aus der Eckernförder Bucht stammen (Tabelle siehe S. 42 u. 43). Hinsichtlich ihres Magen- und Darminhaltes kann ich vier Gruppen unterscheiden. Die erste Gruppe umfasst Individuen von 15 bis $37 \mathrm{~mm}$ Länge. Bei diesen wurde der Magenund Darminhalt aus Harpactiden und Nereiden gebildet. Die Nereiden waren zum Theil noch erkennbar, zum Theil schon verdaut, sodass nur Borsten und Kiefer übrig geblieben waren. In die zweite Gruppe gehören Nr. 7 bis 10; zu den Nahrungsbestandtheilen der ersten Gruppe kommen auch Muscheln, und die Würmer treten gegen diese zurück. Im Verdauungstraktus der Exemplare, die ich zu der dritten Abtheilung rechne, fehlen die Copepoden mit einer Ausnahme gänzlich; Nereiden und Muscheln - Cardium und vorwiegend Mytilus - bilden den Hauptbestandtheil der gefressenen Nahrung. Dazu kommen in einem Falle vier Gammariden und in einem andern zwei ldotheen, fünf Gammariden und zwei Balaniden mit Theilen der Schale. In der letzteı Gruppe endlich, welche die Exemplare Nr. 23 bis 32 umfasst, spielen die Würmer als Nahrung garkeine Rolle mehr, sie sind gänzlich durch Muscheln verdrängt; im Darm einiger lndividuen fanden sich ausserdem kleinere, nicht mehr zu bestimmende Krebse, und in zwei Fällen habe ich Körper gefunden, die schon stark macerirt waren, sich aber trotzdem mit ziemlicher Bestimmtheit als Opisthobranchen (Polycera oder Doris) ermitteln liessen. Seegrasstückchen habe ich wiederholt gesehen, aber immer nur vereinzelt, so dass icl glaube, dass sie zufällig in den Darmtraktus gekommen sind. Für die erwachsenen Goldbutt geben Möbius und Heincke ${ }^{1}$ ) als Nahrung an ,junge Muscheln, welche in weichgrundigen tieferen Regionen leben (Tellina solidula, Corbula gibba, Scrobicularia piperata, Cardium edule, junge Mya arenaria), Würmer (besonders Pectinaria), kleine Krustenthiere (besonders Cuma Rathkei) und Stachellıäuter"; oft sollen auch Algen im Magen gefunden worden sein. Nach Kröyer²) frisst Platessa auch gerne Getreide, das von Schiffen verloren wird oder auf andere Weise in das Meer geräth.

Von Pleuronectes flesus habe ich 28 Exemplare aus der Eckernförder Bucht untersucht (Tabelle siehe S. 44 u. 45); hinsichtlich ihrer Nahrung lassell sie sich ebentalls gruppenweise zusammenstellen. In die erste Gruppe gehören in erster Linie diejenigen Exemplare, die etwa bis $30 \mathrm{~mm}$ lang sind (in der Tabelle Nr. 1 bis 5 und 11 bis 13). Sie hatten fast nur Copepoden in Magen und Darm, sowohl Harpactiden als auch Calaniden. Bei Nr. 16 und 17 konnte ich freilich ebenfalls nur Copepoden nachweisen, doch liess viel breiige Masse im Darm dieser beiden Fische darauf schliessen, dass andere, schon verdaute Stoffe mitgefressen waren. Die zweite Gruppe umfasst Nr. 6 bis 10 und Nr. 14 bis 20, denen ausser Copepoden auch noch andere Thiere als Nahrung gedient haben. Abgesehen vor vereinzelten Amphipoden, Hydroidpolypenstücken, Muschellarven und kleinen Miesmuschelı, waren es Chaetopoden, und zwar Enchyträiden und Nereiden. In die dritte und letzte Gruppe gehören die über $50 \mathrm{~mm}$ langen Exemplare (Nr. 21 bis 28). Sie hatten ausschliesslich Würmer der ebengenannten Familien gefressen, zwei von ihnen ausserdem viele Mückenlarven und -puppen. Pflanzenstücke waren im Darmtraktus von Flesus häufiger als in dem von Platessa, in acht Fällen habe ich solche bemerkt, jedoch auch immer nur in spärlicher Menge.

Zu einem Vergleich des Darminhaltes beider Fischarten eignen sich nur die ersten 21 Exemplare von Platessa, weil die übrigen die längsten Flundern an Grösse übertreffen. Der Vergleich zeigt erstens, dass sämmtiche untersuchten Exemplare bejder Spezies in dem Alter, dem die Grösse von 12 bis 45 mm entspricht, viel Copepoden gefressen haben, zweitens, dass in weiter vorgeschrittenem Alter vom Flunder entschieden Wurmnahrung vorgezogen wird, während die Goldbutt in gleicher Grösse sowohl Würmer als auch Muscheln frisst. - Aus der mir zugänglichen Litteratur habe ich nicht nit Sicherheit entnehmen können, ob erwachsene Exemplare eine ähnliche Auswahl treffen. Direkte diesbezügliche Mittheilungen habe ich wicht gefunden, es sclueinen aucl keine eingehende Spezialuntersuchungen in dieser Richtung angestellt worden zu seill. Heincke:3) nemnt beide Arten „echte Friedfische“, ohne einen Unterschied der Nahrung zu erwähnen; „sie suchen ihre Nahrung aus Schlamm und Sand hervor. Diese besteht aus kleinen Muscheln (in der Ostsee Scrobicularia albida

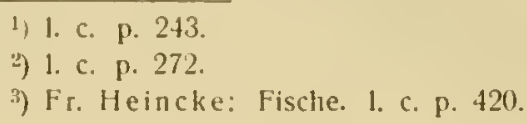


und Tellina baltica), Würmern und Krustenthieren; äusserst selten verschlingen sie kleine Fische". Cunningham') giebt für Platessa Muschclı als Hauptnahrung an, dic Fragc wach der Nahrung von Flesus lässt er aber unbeantwortet, weil die Darmuntersuchungen meist an laichenden Individuen vorgenommen wurden und deshalb kin Resultat hatten. Im Aquarium zu Plymouth, schrcibt Cunningham, sollen die Flundern mit grosser Begierde Nereiden und alle andern Seewürmer Iressen, Yarrel gicbt Wasserinsekten, Würmer und kleine Fische als Hauptkost an, dagcgen fand Buckland „mussel spawn-Muschellarven? (Cunningham) - Sandwürmer und kleine Garncelen im Darm von Flesus. Kr ö yer "2) bezeichnet als Hauptnahrung des Flunder Weiclithiere (Tellina, Mactra, Mytilus und andere).

\section{Planktonzehrer.}

Die von mir untersuchten Thiere, die zn den Planktonzehrern zu rechnen sind, gehören den Klassen der Cölenteraten, der Krebse und der Mantelthiere an. Die von mir untersuchten Vertrcter sind:

Aurelia aurita L.
Scyphostoma.
Balanus crenatus Brugière
Balumus improvisus Darwin.
Mysis inermis Rathke
Mysis flexuosa Müller
Mytilus edulis L.
Cyprina islandica L.
Astarte borcalis Chemnitz.

Aurelia aurita L.

Scyphostoma.

Balanus crenatus Brugière

Balanus improvisus Darwin.

Mysis flewnosa Mïlle

Mytilus edulis L.

Astarte borealis Chemnitz.

\author{
Mya arenaria $\mathrm{L}$. \\ Mya truncata $\mathrm{L}$. \\ Cardium edule L. \\ Cardium fasciatum Montagu \\ Tellina baltica $\mathrm{L}$. \\ Scrobicularia piperata Gmelin \\ Ascidia canima O. F. Müller \\ Cynthia rustica L. \\ Cynthia grossularia van Beneden.
}

Wie bei den Pflanzenfressern und den Räubern, so ist auch bei den Planktonzelıren hinsichtlich ihrer Ernährung die Einschränkung "vorzugsweise" dringend geboten, denn reines Plankton habe ich unr ganz vereinzelt in den verdauenden Kavitäten gefunden. Die meisten von mir untersuchten Planktonfresser sind festsitzende Thiere, oder sind doch nur einer unbedentenden Ortsbewegung rähig. Grosses Lokomotionsvermögen ist für sie auch überflüssig, weil sie ihrer Nahrung nicht nachzustellen brauchen. Durch Strömungen und Wellenschlag wird ihnen immer neues Plankton zugeführt, und wichtiger als die Ortsbewegungsfähigkeit sind für die planktonfressenden Thiere Einrichtungen, die es ihnen crmöglichen, möglichst viel Nahrung aufzunehmen. Die Muscheln ${ }^{3}$ ) und Ascidien erzcugen durch Flimmerepithcl cinen konstanten Strom, der den Körper durchzieht; die im Wasser suspendirten organischen Bestandtheile werden zurückgehalten und in den Darm geführt, während das Wasser selbst die Kiemen versorgt. Bci den Muschelı wird, wie Thieled) gezeigt hat, der Strom durch die Bewegungen der Mundlappen verstärkt"). Bei den Ascidien entsteht der Wasserstrom durch die Bewegung der "feinen, flimmernden Kiemenspalten“. „Während das Atemwasser durch die Kiemenspalten direkt in den Perithorakalraum gelangt, schlagen dic Nahrungsbestandtheile den weiteren Weg durch den hinteren oder nutritorischen Darmabschnitt ein. Durch Vermittelung der den Eingang zur Atemhöhle umgreifenden Flimmerbögen und umbüllt vom Sclılein des Endostyls... kommen sie in dem an Grund des Kiemensacks beginnenden Oesoplagus. " Hertwigi"). Die Balaniden bewirken einen Wasserstron, indem sie ihre Rankenfüsse rhythmisch ansbreiten und wicder einziehen. Ueber die Fang- und Siebapparate der in dieser Arbeit nicht berücksichtigten Appendicularien bringt Lohmann ) wichtige Angaben. - Sehr wichtig ist die Frage, ob dic Planktonfresser unter den

1) J. T. Cunningliam: The natural history of the marketable fishes of the British Islands. London 1896. p. 214 (Platessa), p. 228 (Flesus).

ㄱ 1. c. p. 295 .

") Herm. Griesbach: Ueber das Gefăsssystem und die Wasseraufnalune bei den Najaden und Mytiliden. Zlschr. R. Wiss. Zool. Bd. 38 (1883). p. 24.

4) Joh. Thiele: Mundlappen der Lamellibranchen. Zlsclir. f. wiss. Zool. Bd. 44 (1886). p. 239.

i) Eine klare Darstellung der Nalirungsaufnahme bei den Musclieln findet siclı bei Lang l. c. p. 56 .

6) Rich. Hertwig: Lelurbuch der Zoologie. Jena 1895. p. 277.

j) H. Lohmann: Die Appendicularien der Planktonexpedition. Kiel und Lejpig 1896. 
Organismen des Planktons auswählen. Eine vom Willen der Planktonzehrer nicht abhängige Nahrungsauswahl wird durch die Grösse der zur Nahrungsaufnahme dienenden Körperaufnahme und durch die die Stärke des erzeugten Wasserstromes übertreffende Kraft mancher Planktonorganismen bedingt. Für eine beabsichtigte Auswahl spricht die Thatsache, dass an der Einfuhröffnung sich oft Sinnesorgane befinden. So sind an der Ingestionsöffnung von Ciona intestinalis Augenflecke vorhanden und Thiele ${ }^{1}$ ) giebt an, dass die Mundlappen von Mytilus reich an Sinnesorganen sind; von Lotsy*) und Griesbach ${ }^{3}$ ) wurde auch ein Wiederausstossen von aufgenommenen Bestandtheilen beobachtet. Aus meinen Darmuntersuchungen habe ich keinen Anhalt für die Annahme gefunden, dass eine vom Willen des Thieres abhängige Auswahl getroffen wird. Denn erstens habe ich im Darm von verschiedenen Planktonzehrern, die zu gleicher Zeit und an gleicher Stelle gefangen worden sind, fast immer die gleichen Bestandtheile gefunden; zweitens waren in den verdauenden Kavitäten, mit seltenen Ausnahmen auch viel unverdauliche Stoffe, wie Spongiennadeln, Chaetopodenborsten und Sandkörnchen zu finden.

Bevor ich zur Einzelbesprechung der Planktonzehrer übergehe, möchte ich noch einmal an dieser Stelle auf die bereits früher besprochene unkenntliche Masse zurückkommen. Gerade im Darm von Planktonfressern habe ich sie fast immer in grösserer Menge bemerkt, oft bildete sie den Hauptbestandtheil des Darminhaltes. Ob es sich um Verdauungsprodukte oder um Detritus in der feinsten Form handelt, habe ich mit Hülfe des Mikroskopes nicht entscheiden können. Da die unkenntliche Masse aber meist daun am stärksten vertreten war, wenn auch Sandkörnchen in grösserer Menge vorhanden waren, so möchte ich mich doch der ersteren Ansicht zuneigen. Vielleicht kann eine chemische Untersuchung Aufklärung bringenl.

Ob Aurelia a urita zu den Planktonfressern oder besser zu den Räubern zu stellen ist, will ich nicht entscheiden. Bei sehr vielen Exemplaren war die Untersuchung ergebnisslos, bei einigen habe ich in den Radikalkanälen - immer nur spärlich - kleine Klumpen gefunden, die von Ceratien und andern Planktonorganismen (Copepoden, Tintinulls acuminatus, Rhizosolenia styliformis, Dinophysis u. s. w.) gebildet wurden. Reste von höheren Thieren habe ich in den Exemplaren aus dem Sommer 1900 nicht bemerkt; dagegen habe ich in einem dichten Quallenschwarm, den ich an einem Augustage 1899 durchfuhr, viele gesehen, die einen braunen, $3-5 \mathrm{~cm}$ langen Körper in den Magentaschen trugen. Bei näherer Betrachtung erwiesen sich diese als halbverdaute Heteronereiden. In Bronns Klassen und Ordnungen der Thiere ${ }^{4}$ ) ist angegeben, dass die grösseren Quallen Würmer, Salpen, nackte und Schalenmollusken, Krebse und Fische, auch andere Medusen, zuweilen von der eignen Art, fressen. Keller ${ }^{5}$ ) schreibt: "die Lebensweise der Medusen ist eine räuberische: vermöge ihrer meist grossen Schwimmfähigkeit gelangen sie in ergiebige Nährbezirke, wo sie allerlei kleineres Gethier, selbst kleinere Fische erbeuten; die nesselnden Eigenschaften unterstützen sie dabei in hohem Grade."

Von Scyphostoma habe ich 15 Exemplare untersucht, die am 15. 11. 1899 auf Seegras am Strander Grasberg gefangen worden waren. Eins war leer, im Innern der übrigen habe ich Ceratien in grösserer oder sehr grosser Menge gefunden. Vereinzelt waren auch kleine Ketten von Melosira und Sandkörnchen.

Aelnnlich wie bei Scyphostoma dürfte auch die Nahrung der Hydroidpolypen sein. Von Cordylophora lacustris und Gonothyraea Lovenii habe ich eine Reihe untersucht, aber nur im lnnern eines Exemplars der ersteren Art zwei kleine Eizellen bemerkt.

Auch über die Nahrung der Schwämme kann ich keine Angaben bringen, da die Untersuchung der Amorphina panicea stets ergebuisslos war und da ich auch in der Litteratur keine diesbezüglichen Mitheilungen, die auf Beobachtungen und Untersuchungen fussen, gefunden habe.
1) l. c.
?) 1. c.
3) $1 . c$.
4) H. S. B r a un: Die Klassen und Ordnungen der Strahlenthiere (Actinozoa) in Wort und Bild. Heidelberg und Leipzig. 1860 p. 105. 5) 1. c. p. 462 . 
Sicher gehören zı den Planktonzehrenı die beiden häufiger in der Kieler Bucht vorkommenden Balanidenarten, Balanus crenatus und B. improvisus. Von dreizchn untersuchten Exemplaren der letzteren Art hatten acht Darminhalt. Eins von ihnen, das auf einer Muschelschale sitzend anf der Muschelbank zwischen Gas- und Glockenboje gedredgt worden war, hatte vorzugsweise Ceratien aufgenommen. Im Darm der übrigen, die aus dem Kaiser Wilhelm-Kanal stammten, habe ich Balanidennauplien, Pollenkörner von Koniferen und, immer vercinzelt, Diatomeen gefunden. In einem Fall habe ich vereinzelte grössere Pflanzenstücke und zerbrochene Chaetopodenborsten bemerkt. Stets waren Sand und unkenntliche Masse vorluanden. Der in der Tabelle als "Corycacidenlarve" aufgeführte Organismus ist eine Cirripedienlarve, die von Hansen (Cirripedien der Planktonexpedition) als Nauplins $\mathrm{V}$ beschrieben und auf Taf. III Fig. 5 abgebildet ist.

Balanus crenatus Brugière.

\begin{tabular}{|c|c|c|c|c|c|c|c|c|c|c|c|}
\hline Nr. & $\begin{array}{c}\text { Basal- } \\
\text { durch- } \\
\text { messer } \\
\text { in } \\
\text { mmm }\end{array}$ & Fangzeit & Fangort & Diatomeen & Peridineen & $\begin{array}{l}\text { Gewebs- } \\
\text { pflanzen }\end{array}$ & Crustaceen & $\begin{array}{l}\text { Andere } \\
\text { Metazoen }\end{array}$ & $\begin{array}{l}\text { Un- } \\
\text { kennt- } \\
\text { liche } \\
\text { Masse }\end{array}$ & Sand & $\begin{array}{l}\text { Bemer- } \\
\text { kungen }\end{array}$ \\
\hline 1. & 25 & $\begin{array}{l}13.12 . \\
1899\end{array}$ & $\begin{array}{c}\text { Muschelbank } \\
\text { zwischen } \\
\text { Gas- und } \\
\text { Glockenboje }\end{array}$ & $?$ & $\begin{array}{c}\text { Ceratium } \\
\text { tripos in } \\
\text { beträchtlicher } \\
\text { Menge }\end{array}$ & $?$ & & $?$ & $?$ & $?$ & \\
\hline 2. 11. 3. & ca. 4 & 9. 6. & $\begin{array}{l}\text { K. W.-K. } \\
\text { km 95 } \\
\text { Knoop. } \\
\text { Dredge }\end{array}$ & $\mid \begin{array}{c}\text { vereinzelte } \\
\text { Diatomeen (?) }\end{array}$ & - & - & - & - & $\begin{array}{l}\text { selır } \\
\text { riel }\end{array}$ & $\begin{array}{l}\text { selur } \\
\text { viel }\end{array}$ & - \\
\hline 4. & . & n & " & $\mid \begin{array}{c}\text { vereinzelte } \\
\text { Diatomeen (?) }\end{array}$ & - & $\begin{array}{l}\text { 1 Pollenkorn } \\
\therefore \text {. Conifere }\end{array}$ & $\begin{array}{l}\text { Balaniden- } \\
\text { nauplius }\end{array}$ & - & $\begin{array}{l}\text { seltr } \\
\text { viel }\end{array}$ & $\begin{array}{l}\text { sehr } \\
\text { viel }\end{array}$ & \\
\hline 5. & . & " & . & - & - & - & - & - & $\begin{array}{l}\text { yor- } \\
\text { han- } \\
\text { den }\end{array}$ & $\begin{array}{l}\text { vor- } \\
\text { lian- } \\
\text { den }\end{array}$ & $\begin{array}{l}\text { Darm nur } \\
\text { spärlich } \\
\text { gefüllt }\end{array}$ \\
\hline 6. & . & - & n & $\begin{array}{c}\text { vereinzelte } \\
\text { Diatomeen (?) }\end{array}$ & - & $\begin{array}{c}\text { mehrere } \\
\text { Pollenkörner }\end{array}$ & $\begin{array}{c}1 \text { "Corycae- } \\
\text { idenlarve" } \\
\text { mehrere Bala- } \\
\text { nidennaupl. }\end{array}$ & - & $\begin{array}{l}\text { selyr } \\
\text { viel }\end{array}$ & $\begin{array}{l}\text { sehr } \\
\text { viel }\end{array}$ & $\leftarrow$ \\
\hline$i$. & . & , & . & $\mid \begin{array}{c}\text { yereinzelte } \\
\text { Diatomeen (?) }\end{array}$ & - & $\begin{array}{c}\text { vereinzelt } \\
\text { grösser. Pflian- } \\
\text { zenstücke }\end{array}$ & - & $\begin{array}{l}\text { mehr. Stiicke } \\
\text { von Chaeto- } \\
\text { podenborsten }\end{array}$ & $\begin{array}{l}\text { selir } \\
\text { viel }\end{array}$ & $\begin{array}{l}\text { sehr } \\
\text { viel }\end{array}$ & \\
\hline 8. & n & " & . & $\mid \begin{array}{c}\text { vereinzelte } \\
\text { Diatomeen (?) }\end{array}$ & - & - ? & $\begin{array}{l}\text { mehrere } \\
\text { Balaniden- } \\
\text { nauplien }\end{array}$ & 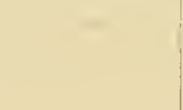 & $\begin{array}{l}\text { sehr } \\
\text { viel }\end{array}$ & $\begin{array}{l}\text { selir } \\
\text { viel }\end{array}$ & \\
\hline 9. -13. & n & " & " & - & - & - & - & 一 & - & - & Darm leer \\
\hline
\end{tabular}

Als Nahrungsbestandtheile der achtzehn von mir untersuchten Exemplare von Balanus improvisus (Tabelle s. S. 51) sind zu nennen: Diatomeen, Peridincen, Protoccoideen, Pflanzenstücke, Pollen. körner, Copepoden, Balanidenlarven, kleine Reste anderer Krebse und Anuräen. Fast immer habe ich viel unkenntliche Masse vorgefunden. Sand, zerbrochene Schwammnadeln und Chaetopodenborsten lasse ich ausser Acht. Diatomeen waren im Darm sämmtlicher Excmplare; meist waren Synıdren, Melosireen, Naviculaceen und andere Grundformen in wechselnder Menge. Typische Planktondiatomeen (Rhizosolenia und Chaetoceros) luabe ich nur in drei Fällen bemerkt. Peridineen und zwar Ceratien und Prorocentren habe ich nur im Darm der Exemplare aus der Kieler Bucht gefunden, bei den Exemplaren, die ich an einer Steinnole bei Cuxhaven gefunden habe, und bei denjenigen aus dem Kaiser Wilhelm-Kanal, fehiten sic. Im letzten Falle wurden sie, freilich nur theilwcise durch Protococcoideen (Pediastrum) vertretcn. Kleinc Seegras. und Algenstücke waren häufig beobachtete Bestandtheile des Darminhaltes. Sie könnell 
natürlich nur in schwimmendem Zustande auggenommen worden sein. Pollenkörner waren im Darm der aus dem Kanal stammenden Exemplare nicht selten. Meist waren es solche von Koniferen und besassen etwa hantelförmige Gestalt. Daneben fanden sich auch runde, grün gefärbte Pollenkörner mit mehreren, meist drei Oeffnungen. Von Krebsen habe ich im Darm der in der Kieler Bucht gefangenen Individuen Copepoden und Nauplien nachweisen können; auch die Cuxhavener Exemplare hatten Copepoden, eins sogar in grosser Menge, gefressen. Im Darminhalt der Thiere aus dem Kanal habe ich Balanidennauplien und -metanauplien, zum Theil in beträchtlicher Menge, gesehen. Von grösseren Krebsen habe ich nur Bruchstücke bemerkt. Im Darm fast aller aus dem Kanal stammenden Exemplare fanden sich Räderthierchen, die sich noch deutlich als Anuraea tecta erkennen liessen; Anuraea ist eins der häufigsten Thiere des Süsswasserplanktons, und ist in der Kieler Bucht nur noch selten anzutreffen.

Was die beiden gemeinen Mysideen der Kieler Bucht, Mysis inermis und Mysis flexuosa anbetrifft, so habe ich im Magen der sieben untersuchten Exemplare der ersten Art reines

Mysis inermis Rathkei.

\begin{tabular}{|c|c|c|c|c|}
\hline Nr. & $\begin{array}{l}\text { Höhe } \\
\text { in } \\
\mathrm{mm}\end{array}$ & Fangzeit & Fangort & Mageninhalt \\
\hline 1. แ1. 2. & ? & $\begin{array}{c}6.12 . \\
1899 \\
\end{array}$ & Kleverberg & Reines Plankton, vorwiegend Ceratien \\
\hline 3. & ? & $\because$ & $"$ & Plankton, vorwiegend Ceratien; Crustaceenbruchstücke \\
\hline 4. & ? & $\because$ & . & Plankton, vorwiegend Ceratien; kleine Algenstilcke \\
\hline 5. 11. 6 . & ? & $\begin{array}{c}28.10 \\
1899\end{array}$ & $\begin{array}{c}\text { Florideen } \\
\text { zwischen } \\
\text { Heulboje } \\
\text { und } \\
\text { Boje Bülk A }\end{array}$ & Vorwiegend Copepoden; Ceratien und andere Planktonorganismen \\
\hline
\end{tabular}

Plankton (Copepoden und Peridineen) gefunden. Meine Untersuchungen, Mysis flexuosa (Tabelle siehe S. 52) betreffend, haben nur ergeben, dass Plankton von diesem Schizopoden auch gefressen wird; $\mathrm{ob}$ es vorgezogen oder ob Pfanzenkost bevorzugt wird, habe ich nicht entscheiden können. Diatomeen habe ich uur im Magen von fünf Exemplaren gefunden. Peridineen, besonders Ceratien, waren häufig. Seegrasund Algenstücke, zum Theil mit gut erhaltenem Zellinhalt, waren fast immer vorhanden. Tintinnen dagegen habe icl nur vereinzelt bemerkt. Von Metazoen sind in erster Linie Crustaceen, und unter ihneı besonders Copepoden zu erwähnen. Zertrümmerte Theile von Krebspanzern und -extremitäten gehörten theilweise auch zu Copepoden, theilweise liessen sic sich nicht mehr bestimmen. Im Magen eines Exemplares habe ich eine Muschellarve gefunden. Vereinzelte Nereidenborsten sind ohue Zweifel als accessorische Bestandtheile anzusehen. Von der im Brackwasser lebenden Mysis vulgaris schreibt Mortensen ${ }^{1}$ ), dass sie Plankton frisst. Buerkel²) zieht aus seinen Reusenversuchen den Schluss, dass erstens glänzende Gegenstände eine, wenn auch nur geringe Anlockungskraft auf Mysis inermis haben, und dass zweitens frischer Köder von dieser Mysideenart ausgesprochen bevorzugt wird. Abgesehen davon, dass die Anwesenheit vieler Exemplare in einer nit Fleisclıköder bestellten Reuse noch nicht beweist, dass das Fleisch auch ais Nahrung gedient hat, scheint mir das Ergebniss der Versuche in diesem Falle zufällig zu sein. Die beideı Mysideenarten führen eine ganz ähnliche Lebensweise und darum ist es schon auffällig, dass Buerkel von M. inermis insgesammt 337 Stück, von M. flexuosa aber keines gefangen hat. Die Schizopoden leben zeitweise in grossen dichten Schaaren, deshalb scheint es mir wahrscheinlich, dass ein Theil eines von $M$. inermis gebildeten Schwarmes in eine Reuse gerathen ist. In der Arbeit von Buerkel fehlen genaue Protokolle über die einzelnen Fänge, sodass ich mich auf die Vermuthung beschränken muss, dass die Schlussfolgerungen irrig sind.

1) Th. Mortensen: Ringköbing Fjords muvarende og tidligere Fauna (Sartryk af S. H. A. Rambusch: Studier over Ringköbing Fjord) 1900 p. 52 (4) 11. 54 (6).

:) $1 . \mathrm{c}$. 
Balanus improvisus Darw.

\begin{tabular}{|c|c|c|c|c|c|c|c|c|c|c|c|}
\hline Nr. & $\begin{array}{c}\text { Längc } \\
\text { in } \\
\text { min }\end{array}$ & $\begin{array}{c}\text { Fang- } \\
\text { zeil }\end{array}$ & Pangort & Diatomeen & Peridineen & $\begin{array}{l}\text { Proto- } \\
\text { cocco- } \\
\text { ideen }\end{array}$ & $\begin{array}{l}\text { Gewebs- } \\
\text { pflanzen }\end{array}$ & Cruslaceen & \begin{tabular}{c|} 
Andere \\
Gewebsthiere
\end{tabular} & $\begin{array}{l}\text { Un- } \\
\text { kennt- } \\
\text { liche } \\
\text { Masse }\end{array}$ & Sand \\
\hline 1. & $?$ & $\begin{array}{c}16.6 . \\
1899\end{array}$ & $\begin{array}{c}\text { Pfahl der } \\
\text { Seeburg- } \\
\text { briicke } \\
\text { gegenüber }\end{array}$ & wertig Diatomeen (?) & $\begin{array}{l}\text { Prorocentron } \\
\text { ziemlich viel }\end{array}$ & 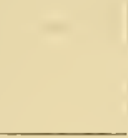 & 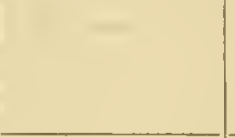 & $\begin{array}{l}5 \text { oder } 6 \\
\text { Nauplienl }\end{array}$ & 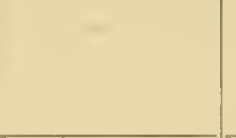 & $?$ & Wenig \\
\hline 2. & $?$ & , & $"$ & $\begin{array}{l}\text { selir wenig Diato- } \\
\text { meen } \text { ? : Pleuro- } \\
\text { sigma vereinzelt }\end{array}$ & $\begin{array}{c}\text { Prorocentron } \\
\text { und Ceratium } \\
\text { viel }\end{array}$ & - & - & - & - & $?$ & $?$ \\
\hline 3. & $?$ & . & ." & $\begin{array}{l}\text { sehr wenig Diato- } \\
\text { meen (?) Pleuro- } \\
\text { sigma vereinzelt }\end{array}$ & $\begin{array}{c}\text { Prorocentron } \\
\text { und Ceratium } \\
\text { viel; vereinz. } \\
\text { Dinophysis }\end{array}$ & - & $\begin{array}{l}\text { kleine Zell- } \\
\text { komplexe }\end{array}$ & - & & $?$ & $?$ \\
\hline 4. & 7,5 & $\begin{array}{c}24.3 . \\
1899\end{array}$ & $\begin{array}{l}\text { Steinmole } \\
\text { bei Cux- } \\
\text { haven am } \\
\text { Seedeicls }\end{array}$ & $\begin{array}{l}\text { Melosira, Coscino- } \\
\text { discus Vorhanden }\end{array}$ & & & $\begin{array}{l}\text { kleine Algen- } \\
\text { triebe und } \\
\text { Pflanzenstiicke }\end{array}$ & $\begin{array}{l}\text { 1 Copepode und } \\
\text { Copepodentlieile }\end{array}$ & & ? & $?$ \\
\hline 5. & 5 & 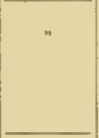 & " & $\begin{array}{c}\text { Melosira und Cosci- } \\
\text { nodiscus in } \\
\text { spärlicher Anzahl }\end{array}$ & 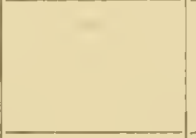 & 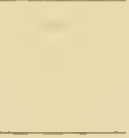 & $\begin{array}{l}\text { kleine Algen- } \\
\text { stücke in } \\
\text { spärlicher Zalıl }\end{array}$ & $\begin{array}{c}\text { sehr viel Cope- } \\
\text { podentheile, melnrere } \\
\text { noch deutlich } \\
\text { erkennhare Thiere } \\
\end{array}$ & 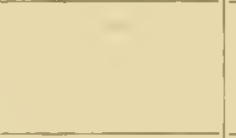 & $?$ & Wenig \\
\hline 6. & 15 & $\begin{array}{l}9.6 \\
1900\end{array}$ & $\begin{array}{l}\text { k. W.-k. } \\
\text { kim } 89.5, \\
\text { Pfahl }\end{array}$ & $\begin{array}{c}\text { sehr viel Melosiren } \\
\text { (auch varians) } \\
\text { Synedren, Navicula- } \\
\text { ceen u. a. } \\
\end{array}$ & - & - & $\begin{array}{l}\text { mehrere Pollen- } \\
\text { körner; kleine } \\
\text { Pflanzenstücke }\end{array}$ & $\begin{array}{l}\text { ziemlich viel } \\
\text { Crustaceenreste, } \\
\text { ansclieinend von } \\
\text { Cladoceren }\end{array}$ & $\begin{array}{l}\text { Anuraca tecta } \\
\text { ziemlicl vicl }\end{array}$ & $\begin{array}{l}\text { sehir } \\
\text { viel }\end{array}$ & viel \\
\hline 7. & 7 & " & .. & $\begin{array}{l}\text { sehr viel Melosiren, } \\
\text { Synedren, Navicu- } \\
\text { laceen u. andere }\end{array}$ & - & - & $\begin{array}{l}\text { mehrere Pollen- } \\
\text { körner; kleine } \\
\text { Pflanzensticke }\end{array}$ & $\begin{array}{c}\text { ziemliclı viel z. T. } \\
\text { grosse zusaminen- } \\
\text { hängende Brucls- } \\
\text { stiocke }\end{array}$ & $\begin{array}{l}\text { Anuraea tecta } \\
\text { ziemlich vial }\end{array}$ & $\begin{array}{l}\text { Schr } \\
\text { viel }\end{array}$ & viel \\
\hline 8. & $?$ & " & " & $\begin{array}{l}\text { sehr viel Melosiren, } \\
\text { Synedren, Navicu- } \\
\text { laceen u. andere }\end{array}$ & - & - & $\begin{array}{c}\text { tnehrere Pollen- } \\
\text { körner; kleine } \\
\text { Pflanzenstücke } \\
\end{array}$ & $\begin{array}{c}\text { mehrere Balaniden- } \\
\text { mauplien, viel } \\
\text { Crustaceenreste }\end{array}$ & $\overline{1}$ & $\begin{array}{l}\text { selır } \\
\text { viel }\end{array}$ & viel \\
\hline 9. & 6 & " & $"$ & $\begin{array}{l}\text { sehr viel Melosiren, } \\
\text { Synedren, Navicu- } \\
\text { laceen und andere }\end{array}$ & $一$ & $\begin{array}{c}\text { mehrere } \\
\text { Pedi- } \\
\text { astrum } \\
\end{array}$ & $\begin{array}{l}\text { mehrere Pollen- } \\
\text { körner; kleine } \\
\text { Pflanzenstiicke } \\
\end{array}$ & $\begin{array}{l}\text { ziemlich viel } \\
\text { Crustaceenreste } \\
\text { (Cladoceren?) }\end{array}$ & $\begin{array}{l}\text { I lange } \\
\text { Nereisborste }\end{array}$ & $\begin{array}{l}\text { selir } \\
\text { viel }\end{array}$ & viel \\
\hline 10 & 7 & 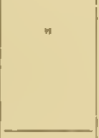 & . & $\begin{array}{c}\text { Melosiren, Synedren, } \\
\text { Naviculaceen, } \\
\text { Pleurosigma. }\end{array}$ & - & $\begin{array}{l}\text { Pedi- } \\
\text { astrum }\end{array}$ & $\begin{array}{l}\text { mehrere Pollen- } \\
\text { körner; kleine } \\
\text { Pflanzensticke }\end{array}$ & $\begin{array}{c}\text { Balanidemauplien } \\
\text { und -metamauplien } \\
\text { in beträclitliclier } \\
\text { Menge }\end{array}$ & $\begin{array}{l}\text { Anuraea in he- } \\
\text { trächtl. Menge; } \\
\text { Spongiemadeln: } \\
\text { I Nereisborste }\end{array}$ & $\begin{array}{l}\text { sehr } \\
\text { viel }\end{array}$ & viel \\
\hline 11. & 12 & " & , & $\begin{array}{c}\text { Melosiren, Synedren, } \\
\text { Naviculaceen, } \\
\text { Pleurosigma }\end{array}$ & 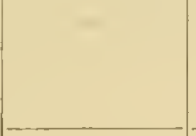 & $\begin{array}{l}\text { Pedi- } \\
\text { astruIs }\end{array}$ & $\begin{array}{l}\text { Pollenkörner; } \\
\text { kleinere und } \\
\text { J grosses } \\
\text { Pflanzenstück }\end{array}$ & $\begin{array}{l}\text { Balanidemnatuplien } \\
\text { und -metanatsplien } \\
\text { ziemlich viel }\end{array}$ & $\begin{array}{c}\text { Anuraea in he- } \\
\text { träclitlicher } \\
\text { Menge } \\
\text { Spongiennadeln }\end{array}$ & $\begin{array}{l}\text { sehr } \\
\text { viel }\end{array}$ & viel \\
\hline 12. & 6 & n & . & $\begin{array}{c}\text { Melosiren, Synedren } \\
\text { u. S. w. } \\
\text { wie } 10 \text { etc. }\end{array}$ & - & ? & $--?$ & $\begin{array}{c}\text { Balanidennamplien } \\
\text { viel }\end{array}$ & Anuraca wenig & $\begin{array}{l}\text { schir } \\
\text { riel }\end{array}$ & viel \\
\hline 13. & 5 & ? & $"$ & $\begin{array}{c}\text { Melosiren, Synedren } \\
\text { u. s. w. } \\
\text { wie } 10 \text { etc. }\end{array}$ & - & - ? & ? & $\begin{array}{c}\text { Balanidennauplien } \\
\text { vicl }\end{array}$ & $\begin{array}{l}\text { Amuraea selir } \\
\text { zalilreich }\end{array}$ & $\begin{array}{l}\text { selır } \\
\text { viel }\end{array}$ & viel \\
\hline 14 & 4 & . & 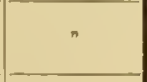 & $?$ & - & $-?$ & - ? & $\begin{array}{c}\text { Balanidennauplien } \\
\text { spärlich }\end{array}$ & $\begin{array}{l}\text { Anuraca ver- } \\
\text { einzelt }\end{array}$ & $\begin{array}{l}\text { sehr } \\
\text { viel }\end{array}$ & liel \\
\hline 15. & 10 & . & " & $?$ & - & 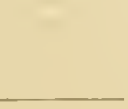 & ? & kleine Reste & $\begin{array}{c}\text { Anuracal ver- } \\
\text { einzelt, } \\
\text { Sclowamnameln }\end{array}$ & $\begin{array}{l}\text { selur } \\
\text { vicl }\end{array}$ & viel \\
\hline 16 & $?$ & $\begin{array}{r}21.9 \\
1899 \\
\end{array}$ & : & $\begin{array}{l}\text { Claictoceros, } \\
\text { Naviculaceen }\end{array}$ & $\rightarrow$ & & $\begin{array}{c}\text { selur viel kleine } \\
\text { Stucke }\end{array}$ & & - & $\begin{array}{l}\text { Selur } \\
\text { vicl }\end{array}$ & bicl \\
\hline 17 & $?$ & " & " & $\begin{array}{c}\text { Chaetoceros, Rlizo- } \\
\text { solenia, Navicula- } \\
\text { cecn, Cocconeis } \\
\end{array}$ & $\begin{array}{l}\text { Ceratiun!- } \\
\text { reste }\end{array}$ & & $\begin{array}{c}\text { sehr viel Algen- } \\
\text { und Seegras- } \\
\text { stiicken } \\
\end{array}$ & $\begin{array}{l}\text { Copepodeu, z. T. } \\
\text { gut erlalten }\end{array}$ & & $\begin{array}{l}\text { selit } \\
\text { viel }\end{array}$ & viel \\
\hline 38. & $?$ & . & 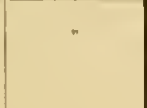 & $\begin{array}{l}\text { Chaetoceros, Rhizo- } \\
\text { solenia, Naviculat- } \\
\text { ceen, Cocconeis }\end{array}$ & $\begin{array}{l}\text { Ceratiun } \\
\text { reste }\end{array}$ & & $\begin{array}{c}\text { sehr viel Algen- } \\
\text { und Seegras- } \\
\text { stifcken }\end{array}$ & Copepodentleile & & $\begin{array}{l}\text { Selir } \\
\text { viel }\end{array}$ & viel \\
\hline
\end{tabular}




\begin{tabular}{|c|c|c|c|c|c|c|c|c|c|c|c|c|c|}
\hline $\bar{v}$ & $\vec{a}$ & $\overrightarrow{~ \vec{r}}$ & $\mp$ & $\bar{\omega}$ & $\bar{N}$ & $=$ & $\bar{\rho}$ & $=$ & $\infty$ & $\sim$ & $\rho$ & $\bar{j}$ & $z$ \\
\hline 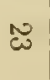 & N & $\tilde{E}$ & $\widetilde{\mathscr{C}}$ & $\widetilde{\Xi}$ & $\vec{\infty}$ & $\bar{\infty}$ & $\bar{\infty}$ & $\bar{\infty}$ & $\vec{v}$ & $\bar{v}$ & $\bar{v}$ & $\nu$ & 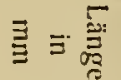 \\
\hline : & : & : & : & = & : & : & $=$ & $=$ & : & : & $\bar{\delta}^{\infty}$ & $\overrightarrow{\underline{\alpha}}=$ & 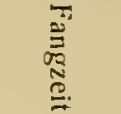 \\
\hline : & $=$ & : & $=$ & $=$ & : & $=$ & $=$ & $=$ & : & $=$ & 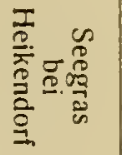 & 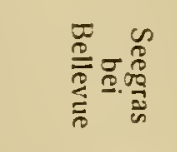 & 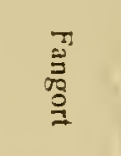 \\
\hline & $v$ & $\sim$ & $v$ & 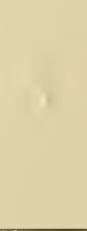 & & & 1 & 1 & 1 & 1 & & 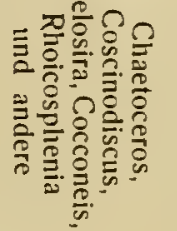 & 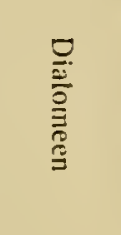 \\
\hline & 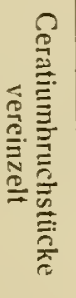 & 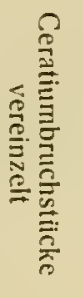 & 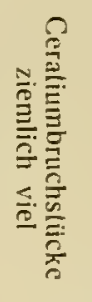 & 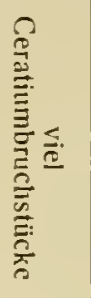 & 1 & 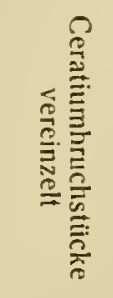 & 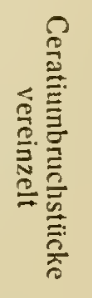 & 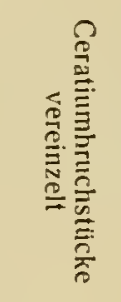 & 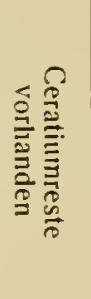 & 1 & 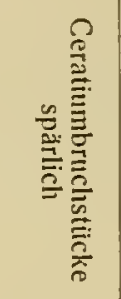 & 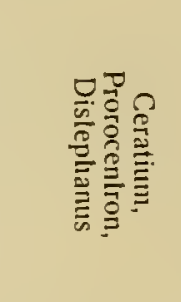 & 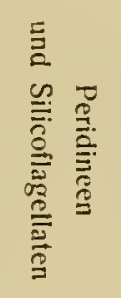 \\
\hline 1 & 1 & 1 & & & & & 1 & 1 & & 1 & 1 & 总产鸹 & $\overrightarrow{\underline{\underline{E}}}$ \\
\hline 1 & 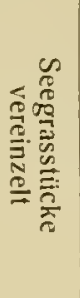 & 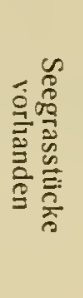 & 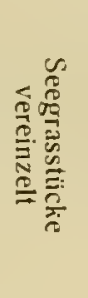 & 1 & 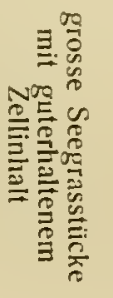 & 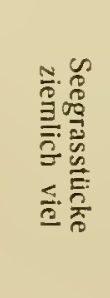 & 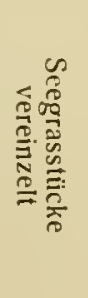 & 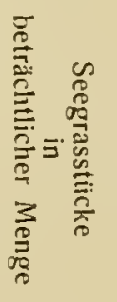 & 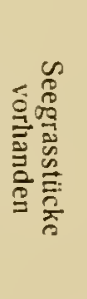 & 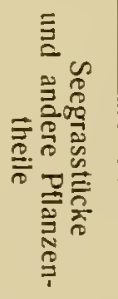 & 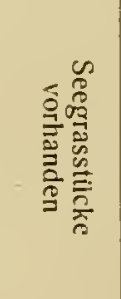 & 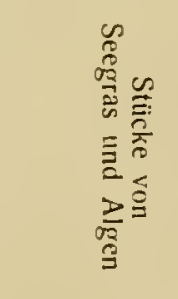 & 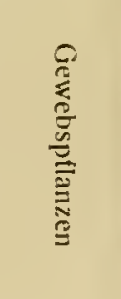 \\
\hline & 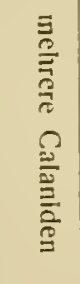 & 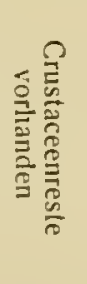 & 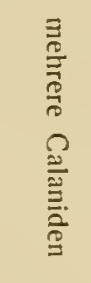 & 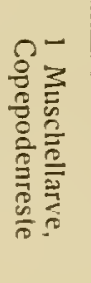 & 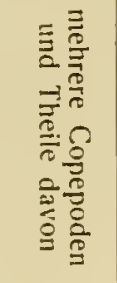 & 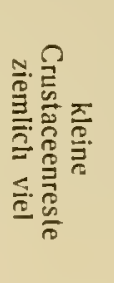 & 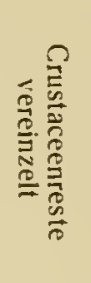 & 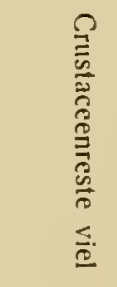 & 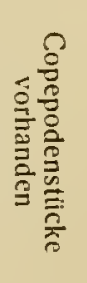 & 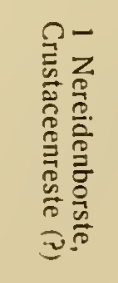 & 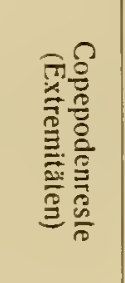 & 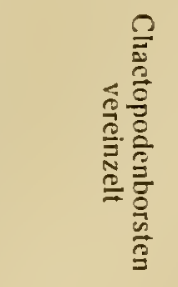 & 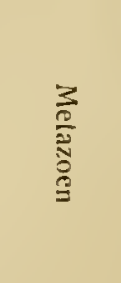 \\
\hline$v$ & $\omega$ & $v$ & $v$ & $v$ & $\nu$ & $\nu$ & $v$ & $v$ & $\nu$ & $v$ & $\nu$ & 总. & 崖 \\
\hline 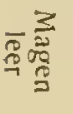 & 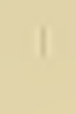 & ! & 1 & t & 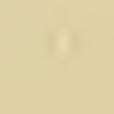 & 1 & I & 1 & 1 & 1 & 1 & 1 & 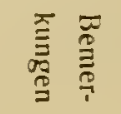 \\
\hline
\end{tabular}


Mytilus edulis ist eine der gemeinsten Muscheln der Kieler Föhrde. Man findet sie an Pfählen und anderen im Wasser befindlichen Gegenständen, in den sandigen Küstenzonen und spärlicher auch ani Mudgrund. In Betreff der Zusammensetzung des Darminhaltes ${ }^{1}$ ) kamen für die dreissig von mir untersuchten Exemplare in Betracht: Diatomeen, Peridineen, Tintinnen und Pflanzenstücke. Tierische Reste habe ich nur vereinzelt und spärlich gefunden, sodass ich ihnen keine Bedeutung beimesse, ebenso lasse ich dic Sandkörnchen ausser Acht. Die unkenntliche Masse kann ich ans dem oben angegebenen Grunde auch nicht berücksichtigen, obgleich sie verschiedentlich vorherrschend war. (Tabelle siehe S. 54 ॥. 55.) Im Darminhalt der Exemplare von verschiedenen Fundorten habe ich kcine wesentlichen Unterschiede wahrgenommen. Den reinsten Planktonfrass habe ich bei den Exemplaren Nr. 6 und 7 gefunden. Der Inhalt der untersuchten Darmparthieen bestand aus einer Unmenge kleiner Peridineen. Es waren kleinc Ellipsoide mit einer medianen Einschuürung - vermuthlich junge Peridoneen. Daneben waren Prorocentren in grosser Menge vorhanden. Diatomeen und kleine Pflanzenstücke standen in keinem Verhältniss zu deı Peridineen. Viel Planktonorganismen habe ich auch im Darm von Nr. 8, 13-15 und 17 gefunden, und zwar auch hier wieder vorwiegend Peridineen (Ceratien und Prorocentren), ferner Dinophysis und Silicoflagellaten (Distephanus). Während die Verschiedenartigkeit der Fundstellen, wie gesagt, für die Beschaffenheit des Darminhaltes von Mytilus nicht von Bedeutung war, machten sich bei den zu verschiedencn Zeiten gefangenen Exemplaren diesbezügliche Unterschiede geltend. Die oben erwähnten Exemplare (Nr. 6, 7, 8, 13, 14, 15, 17) sind im Sommer oder Herbst gefangen worden, also in der Zeit, in der die Peridineen im Plankton besonders entwickelt sind. Zwei Individuen aus dem Januar (Nr. 1 u. 17) hatten noch ziemlich viel Peridineen im Darm, dagegen fehlten sie im Darm der im Februar, März und April gefangenen Miesmuscheln fast gänzlich. Dafür hatten diese, besonders diejenigen, welche im März und April gefangen worden waren (Nr. 18, 19, 20, 23, 25), sehr viel Diatomeen aufgenommen. Im Frühling sind die Diatomeen die vorherrschenden Organismen im Plankton. Leider habe ich nicht ermitteln können, ob diejenigen Diatomeen, die am häufigsten waren, typische Planktondiatomeen sind. Es waren kleine, gestreckte Formen, die am meisten Aehnlichkeit mit Synedra Holsatiae zeigten, und kleine kreisrunde Formen, die ich in der Tabelle als "kleine Coscinodiscen" bezeichnet habe; vielleicht waren es aber auch Melosiren. Typische Planktondiatomeen, wie Chactoceros und Rhizosolenia, waren immer nur spärlich anzutreffen; möglicherweise werden die langen, sperrigen Formen schwerer von den Muscheln aufgenommen als die kleinen, runden $\left.{ }^{\circ}\right)$. Auf das Vorkommen der übrigen Bestandtheile waren die verschiedenen Fundzeiten ohne Einfluss. Tintinnen habe ich immer nur vereinzelt im Darm von Mytilus gefunden; kleine Pflanzenstücke waren fast immer, mehr oder minder zahlreich vorhanden. Abgeseheı von leeren Chitinhüllen und zerbrochenen Spongiennadeln, habe ich keine Theile von höheren Thieren gefunden. Das Fehlen von kleinen Planktonkrebsen erklärt sich vielleicht, wie schon erwähnt, damit, dass diese den von der Muschel erregten Saugstrom überwinden können. - Aus den Darmuntersuchungen habe ich nicht entnehmen können, dass, wie Lotsy") behauptet, Mytilus die Fähigkeit besitzt, unter verschiedenen Nahrungsstoffen auszuwählen. Vielmehr scheint mir das fast inmer beobachtete Vorhandensein von Schwammnadeln und Sand für das Gegentheil zu sprechen. Lotsy bot Austern und Miesmuschelı Diatomeen und zerstückelte Teile von Fischen und Krabben an. Erstere wurden aufgenommen, letztere dagegen nicht, oder wenn doch einmal, sofort wieder ausgestossen. Ich vermuthe, dass dic Fisch- und Krabbenstückchen den Muscheln zur Aunnahme zu gross waren, denn in Bestandtheile von so geringer Grösse, wie die Diatomeen besitzen, lässt sich das Fleisch schwerlich zertheilen. Ferner schrcibt Lotsy: "The food of the adult oyster (wic Lotsy ausdrücklich betont, gilt dies auch für Mya und Mytilus) consists practically of diatoms". Für Mytilus und, wie wir sehen werden auch für Mya, trifft dies wohl zu, jedoch nur mit der Einschränkung "theilweise“. Deby ${ }^{4}$ ) fand 37 Arten Diatomcen, zahlreiche Spongienspicula, feine Sandkörnchen und Detritus von marinen Algen im Darm von Mytilus.

1) Bei Mytilus und mehreren andern Muscheln habe ich nicht den ganzen Darm, sondern nur kleinere Parthieen des Vorderund Hinterdarmes untersucht, olne Unterschiede in der Zusammensetzung des Inhaltes zu finden.

2) Lohmann: [1. c. p. 134] vermuthet als Grund für das spärliche Vorhandensein von Rhizosolenia und Chactoceros im Darm von Appendikularien die geringe Grösse der Aufnahmeơffnung und die starke Krümmung der Speiseröhre.

) I. $c$.

4) 1. c. 


\section{Mytilus edulis L.}

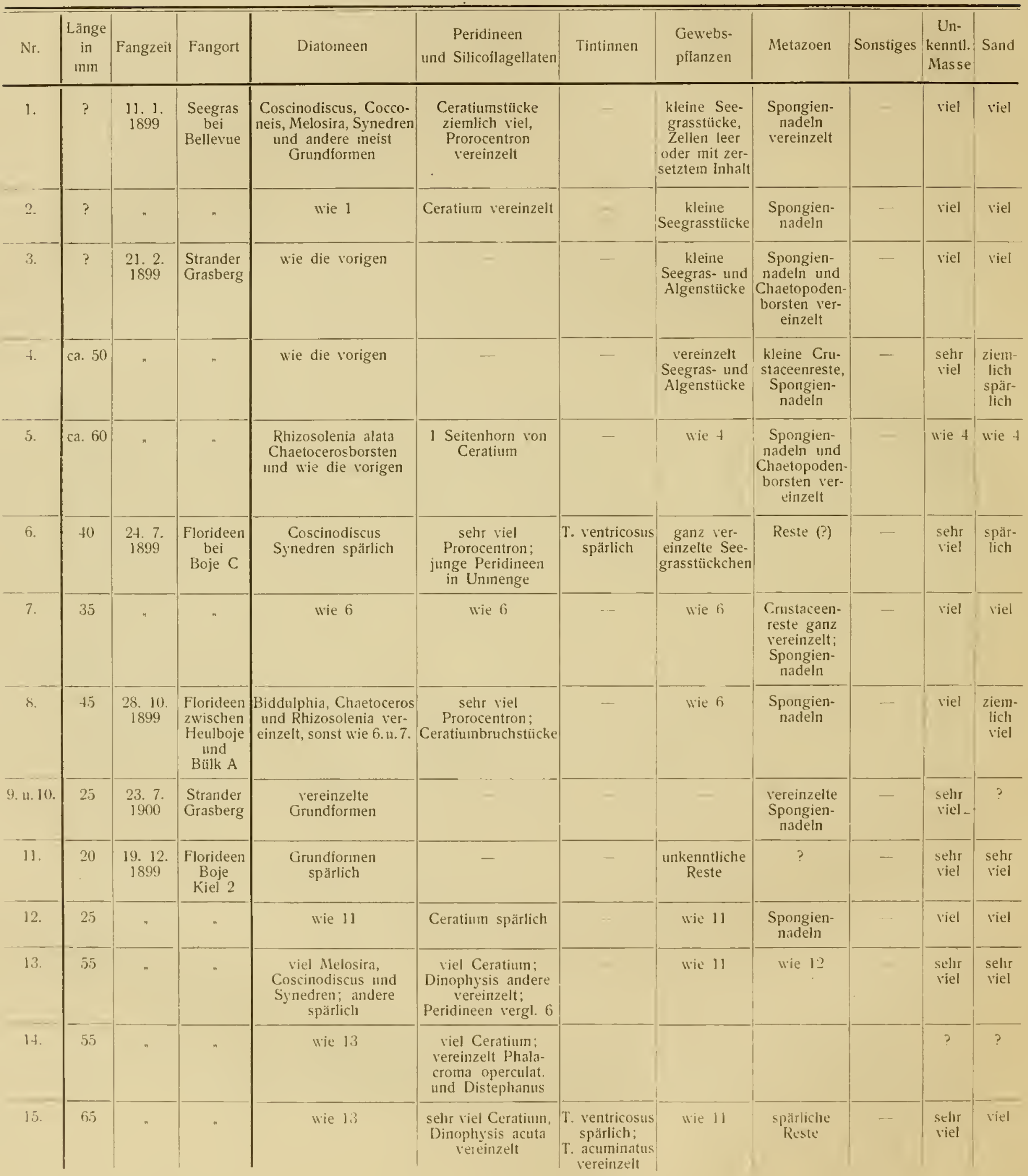


Mytilus edulis L. (Fortsetzung.)

\begin{tabular}{|c|c|c|c|c|c|c|c|c|c|c|c|}
\hline Nr. & $\left|\begin{array}{c}\text { Länge } \\
\text { in } \\
\text { mm }\end{array}\right|$ & Fangzeit & Fangorl & Diatomeen & $\begin{array}{l}\text { Peridineen } \\
\text { und } \\
\text { Silicoflagellaten }\end{array}$ & Tintinnen & $\begin{array}{l}\text { Gewebs- } \\
\text { pflanzen }\end{array}$ & Metazoen & Sonstiges & $\left|\begin{array}{c}\text { Un- } \\
\text { kenntl. } \\
\text { Masse }\end{array}\right|$ & Sand \\
\hline 16. & 70 & $\begin{array}{l}19.12 . \\
1899\end{array}$ & $\begin{array}{c}\text { Florideen, } \\
\text { Boje } \\
\text { Kiel } 2\end{array}$ & wie 13 & $\begin{array}{l}\text { Ceratium und } \\
\text { l'rorocentron } \\
\text { spärliclı; Dinophysis } \\
\text { und Distephanus } \\
\text { vereinzelt }\end{array}$ & wie 15 & $\begin{array}{l}\text { viel Pflanzen- } \\
\text { slïcke }\end{array}$ & $\begin{array}{c}\text { vereinzelte } \\
\text { Eizellen: } \\
\text { kleine } \\
\text { Crustaceen- } \\
\text { resle. } \\
\text { Spongien- } \\
\text { nadeln } \\
\end{array}$ & $\begin{array}{l}\text { I braune } \\
\text { dornige } \\
\text { Cyiste }\end{array}$ & viel & rel \\
\hline 17. & SO & . & . & wie 13 & $\begin{array}{c}\text { viel Ceratium, } \\
\text { Dinophysis acuta } \\
\text { spärlich }\end{array}$ & $\begin{array}{c}\text { T. ventri- } \\
\text { cosus spärlich }\end{array}$ & $\begin{array}{l}\text { unkenntlich } \\
\text { kleine Reste }\end{array}$ & wie 16 & - & $\begin{array}{l}\text { sehr } \\
\text { riel }\end{array}$ & $\begin{array}{l}\text { stelir } \\
\text { viel }\end{array}$ \\
\hline 18. & 35 & $\begin{array}{l}27.3 . \\
1900\end{array}$ & $\begin{array}{c}\text { Florideen } \\
\text { zwischen } \\
\text { Stoller } \\
\text { Grund und } \\
\text { Glocken- } \\
\text { boje }\end{array}$ & $\begin{array}{l}\text { kleine Coscinodiscus (?) } \\
\text { sehr viel, grosse ziem- } \\
\text { lich viele Rhizosolenia, } \\
\text { ganz vereinzelte Grund- } \\
\text { jormen spärlich }\end{array}$ & - & & wie 17 & $?$ & - & viel & viel \\
\hline 19. & 60 & $" 1$ & $"$ & $\begin{array}{c}\text { wie 18; keine Rhizo- } \\
\text { solenia, aber äusserst } \\
\text { riel Synedren }\end{array}$ & - & - & $\begin{array}{c}\text { vereinzelte } \\
\text { kleine Algen- } \\
\text { stücke }\end{array}$ & $\begin{array}{l}\text { Spongien- } \\
\text { nadeln }\end{array}$ & - & viel & viel \\
\hline 20. & 60 & " & $"$ & wie 19 & - & - & $\begin{array}{l}\text { unkenntlich } \\
\text { kleine Resle }\end{array}$ & - & $\begin{array}{c}1 \text { kleine } \\
\text { slachelige } \\
\text { Cyste }\end{array}$ & viel & $\begin{array}{l}\text { zicml. } \\
\text { spïrl. }\end{array}$ \\
\hline 21. & 90 & $"$ & ", & $\begin{array}{l}\text { Coscinodiscus, Mela- } \\
\text { sira und Synedren }\end{array}$ & - & $\rightarrow$ & wie 20 & $\begin{array}{l}\text { Spongien- } \\
\text { nadeln }\end{array}$ & - & viel & $?$ \\
\hline 22. & 7 & $\begin{array}{l}\text { 2. } 6 . \\
1900\end{array}$ & $\begin{array}{l}\text { Sand am } \\
\text { Stoller } \\
\text { Grund }\end{array}$ & 1 Melosira & - & $\cdots$ & - & - & - & v'iel & viel \\
\hline 23. & 30 & $\begin{array}{l}22.4 \\
1899\end{array}$ & $\begin{array}{l}\text { Mud ror } \\
\text { der } \\
\text { Hansa- } \\
\text { briicke }\end{array}$ & $\begin{array}{l}\text { Rhizosolenia alata und } \\
\text { Chaetoceros vereinzelt; } \\
\text { Synedren sehr viel; } \\
\text { andere Grundformen } \\
\text { sparlich }\end{array}$ & & $\begin{array}{l}\text { T. ventri- } \\
\text { cosus ziemliclı } \\
\text { spärliclı }\end{array}$ & $\begin{array}{c}1 \text { kleines } \\
\text { Seegrasstiick }\end{array}$ & - & - & viel & viel \\
\hline 24. & 17 & " & $"$ & $\begin{array}{c}\text { Synedren spärlich } \\
\text { Rhizosolenia, Chaeto- } \\
\text { ceros und Coscinodiscus } \\
\text { rereinzelt }\end{array}$ & - & $\begin{array}{l}\text { T. ventri- } \\
\text { cosus } \\
\text { vereinzelt }\end{array}$ & $\begin{array}{c}1 \text { kleines } \\
\text { Seegrasstïck }\end{array}$ & $\begin{array}{l}\text { Crustaceen- } \\
\text { bruchsticke }\end{array}$ & $=$ & viel & viel \\
\hline 25. & 35 & " & . & $\begin{array}{l}\text { sehr viel Synedren; } \\
\text { typische Grundformen } \\
\text { sowie Rhizosolenia } \\
\text { alata spärlich }\end{array}$ & - & wie 24 & $\begin{array}{c}\text { melırere } \\
\text { kleine } \\
\text { Seegrasstijcke }\end{array}$ & $\begin{array}{l}\text { Spongien- } \\
\text { nadeln }\end{array}$ & - & siel & viel \\
\hline 26. & $?$ & $\begin{array}{l}21.2 . \\
1899\end{array}$ & $\begin{array}{c}\text { Mud } \\
\text { zwischen } \\
\text { Fried- } \\
\text { richsort u. } \\
\text { Möltenort }\end{array}$ & $\begin{array}{c}\text { zerbrochent Cocconeis, } \\
\text { Coscinodiscus und } \\
\text { Synedren }\end{array}$ & - & - & wie 25 & wie 25 & - & viel & viel \\
\hline 27. & $?$ & $\begin{array}{l}18.1 \\
1899\end{array}$ & $\begin{array}{l}\text { Langes } \\
\text { Briicke }\end{array}$ & Synedren und andere & $\begin{array}{l}\text { Ceratium vereinzelt; } \\
\text { ziemlicls viel } \\
\text { Promcentron }\end{array}$ & - & $\begin{array}{l}\text { kleine } \\
\text { Pflanzen- } \\
\text { sliicke }\end{array}$ & $\begin{array}{l}\text { kleine } \\
\text { Crustaceen- } \\
\text { reste; } \\
\text { Spongien- } \\
\text { nadeln } \\
\end{array}$ & - & viel & vitel \\
\hline 28. & $?$ & , & " & spärlich & - & - & wie 27 & $\begin{array}{l}\text { Spongien- } \\
\text { nadeln }\end{array}$ & 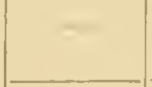 & viel & viel \\
\hline 29. & $?$ & $\begin{array}{l}11.2 . \\
1899\end{array}$ & $\begin{array}{l}\text { Piahl bei } \\
\text { Bellev'ue }\end{array}$ & $\begin{array}{c}\text { zerbrocliene Cocconeis } \\
\text { und Coscinodiscus }\end{array}$ & & - & wie 27 & wic 28 & & viel & $\begin{array}{l}\text { selur } \\
\text { viel }\end{array}$ \\
\hline 30. & $?$ & " & " & $\begin{array}{c}\text { Synedren, Melosira, } \\
\text { Naviculaceen }\end{array}$ & 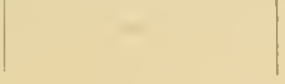 & $=$ & - & wie 28 & - & viel & viel \\
\hline
\end{tabular}




\section{Cyprina islandica $\mathrm{L}$.}

\begin{tabular}{|c|c|c|c|c|c|c|c|c|c|c|c|c|c|}
\hline Nr. & $\begin{array}{c}\text { Länge } \\
\text { in } \\
\text { mun }\end{array}$ & Fangzeit & Fangort & Diatomeen & $\begin{array}{l}\text { Peridineen } \\
\text { und andere } \\
\text { chlorophyll- } \\
\text { führende } \\
\text { Flagellaten }\end{array}$ & $\begin{array}{l}\text { Andere } \\
\text { ein- } \\
\text { zellige } \\
\text { Algen }\end{array}$ & $\begin{array}{l}\text { Tin- } \\
\text { tinnen }\end{array}$ & $\begin{array}{l}\text { Gewebs- } \\
\text { pilanzen }\end{array}$ & $\begin{array}{l}\text { Meta- } \\
\text { zoen }\end{array}$ & \begin{tabular}{|c|} 
Un- \\
kennt- \\
liche \\
Masse
\end{tabular} & Sand & Sonstiges & $\begin{array}{l}\text { Bemer- } \\
\text { kungen }\end{array}$ \\
\hline 1. & ? & $\begin{array}{l}21.2 . \\
1899\end{array}$ & Muschelbank & $\begin{array}{c}\text { Sceletonema, } \\
\text { Melosira, } \\
\text { Cocconeis, } \\
\text { Naviculaceen }\end{array}$ & . & - & & - & $\begin{array}{l}\text { kleine } \\
\text { Reste }\end{array}$ & viel & viel & & - \\
\hline 2. & 20 & $\begin{array}{l}24.7 . \\
1899\end{array}$ & $\begin{array}{c}\text { Mud } \\
\text { zwischen } \\
\text { Friedrichsort } \\
\text { und Boje D }\end{array}$ & $?$ & $\begin{array}{c}\text { mehrere } \\
\text { Prorocentron }\end{array}$ & 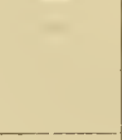 & $=$ & $=$ & - & $\begin{array}{l}\text { sehr } \\
\text { viel }\end{array}$ & $\begin{array}{c}\text { sehr } \\
\text { viel }\end{array}$ & 1 dornige & $=$ \\
\hline 3. & 23 & $\begin{array}{l}18.6 . \\
1900\end{array}$ & $\begin{array}{c}\text { Mud auf der } \\
\text { Höhe der } \\
\text { Wiker Bucht }\end{array}$ & - & - & $=$ & - & - & - & $\begin{array}{l}\text { sehr } \\
\text { viel }\end{array}$ & $\begin{array}{l}\text { sehr } \\
\text { viel }\end{array}$ & $=$ & - \\
\hline 4. & 20 & $\begin{array}{l}20.1 . \\
1900\end{array}$ & $\begin{array}{l}\quad \text { Mud } \\
\text { zwischen } \\
\text { Bülk und } \\
\text { Heulboje } \\
\end{array}$ & $\begin{array}{l}\text { Synedra } \\
\text { Holsatiae viel. } \\
\text { Cocconeis. }\end{array}$ & ] Distephanus & - & - & - & $\begin{array}{c}\text { kleine } \\
\text { Crusta- } \\
\text { ceen- } \\
\text { reste } \\
\end{array}$ & $\begin{array}{l}\text { sehr } \\
\text { viel }\end{array}$ & $\begin{array}{l}\text { sehr } \\
\text { viel }\end{array}$ & - & \\
\hline 5. & 22 & $\begin{array}{l}17.7 . \\
1899\end{array}$ & $\begin{array}{c}\text { Mud beim } \\
\text { Stoller Grund }\end{array}$ & $\begin{array}{c}\text { Grunddiatomeen } \\
\text { wenig }\end{array}$ & $\begin{array}{c}\text { Prorocentron } \\
\text { viel }\end{array}$ & $\begin{array}{l}\text { Rhizo- } \\
\text { clonium } \\
\text { (?) viel }\end{array}$ & $\begin{array}{l}\text { T. ven- } \\
\text { tricosus } \\
\text { spärliclı }\end{array}$ & $\begin{array}{l}\text { kleine } \\
\text { pllanz- } \\
\text { liche } \\
\text { Reste } \\
\end{array}$ & $\begin{array}{l}\text { kleine } \\
\text { Reste }\end{array}$ & viel & $?$ & $1 \begin{array}{l}\text { dornige } \\
\text { Cyste }\end{array}$ & \\
\hline 6. & $?$ & $\begin{array}{l}8.11 . \\
1899\end{array}$ & $\begin{array}{c}\text { Mud vor } \\
\text { dem Stolter } \\
\text { Grund } \\
\text { (ca. } 16 \mathrm{~m} \text { ) }\end{array}$ & $\begin{array}{l}\text { Coscinodiscus, } \\
\text { Melosira und } \\
\text { andere }\end{array}$ & $\begin{array}{l}\text { Prorocentron und } \\
\text { Ceratim tripos } \\
\text { sehr viel }\end{array}$ & - & - & - & - & $?$ & wenig & $\begin{array}{c}\text { Eizellen } \\
\text { vereinzelt }\end{array}$ & - \\
\hline 7. 9 & $\begin{array}{c}28 \\
? \\
? \\
\end{array}$ & $"$ & $"$ & $\begin{array}{c}\text { Coscinodiscus } \\
\text { vorherrschend, } \\
\text { viel } \\
\end{array}$ & $\begin{array}{l}\text { Prorocentron } \\
\text { und Ceratium } \\
\text { spärlich }\end{array}$ & - & 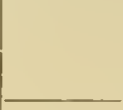 & - & - & $?$ & viel & - & - \\
\hline 10 . & $?$ & $"$ & $"$ & $\begin{array}{l}\text { Coscinodiscus } \\
\text { und andere } \\
\text { vorhanden }\end{array}$ & $\begin{array}{l}\text { Prorocentron } \\
\text { relativ viel }\end{array}$ & - & - & - & $\begin{array}{c}\text { Spon- } \\
\text { gien- } \\
\text { nadeln } \\
\text { und and. }\end{array}$ & $?$ & $\begin{array}{l}\text { sehr } \\
\text { viel }\end{array}$ & - & - \\
\hline 11. & $?$ & , & $"$ & $?$ & $\begin{array}{l}\text { Prorocentron } \\
\text { vorherrschend }\end{array}$ & - & - & - & - & ? & $?$ & - & $\begin{array}{c}\text { Darm } \\
\text { spärlichlı } \\
\text { gefüllt }\end{array}$ \\
\hline 12. & $?$ & $\begin{array}{l}\text { 2. } 11 . \\
1899\end{array}$ & $\begin{array}{c}\text { Mud } \\
\text { Zwischen } \\
\text { Feuerschiff } \\
\text { und } \\
\text { Glockenboje } \\
\end{array}$ & $\begin{array}{l}\text { Coscinodiscus, } \\
\text { Melosira und } \\
\text { andere }\end{array}$ & $\begin{array}{l}\text { Prorocentron } \\
\text { und Ceratium } \\
\text { sehr viel }\end{array}$ & - & - & - & $\begin{array}{l}1 \text { Hala- } \\
\text { carus }\end{array}$ & viel & viel & - & - \\
\hline 13. 17. & $?$ & $"$ & $"$ & $\begin{array}{l}\text { Coscinodiscus, } \\
\text { Melosira und } \\
\text { andere } \\
\end{array}$ & $\begin{array}{c}\text { Prorocentron } \\
\text { und Ceratium } \\
\text { sehr viel }\end{array}$ & - & - & - & - & viel & viel & - & - \\
\hline 18. & $?$ & $"$ & " & $\begin{array}{l}\text { Coscinodiscus, } \\
\text { Melosira und } \\
\text { andere }\end{array}$ & $\begin{array}{c}\text { Prorocentron } \\
\text { und Ceratium } \\
\text { viel }\end{array}$ & - & - & - & - & viel & $\begin{array}{l}\text { sehr } \\
\text { viel }\end{array}$ & - & - \\
\hline 19. & $?$ & $"$ & $"$ & $\begin{array}{l}\text { Coscinodiscus, } \\
\text { Melosira und } \\
\text { andere }\end{array}$ & $\begin{array}{l}\text { Prorocentron } \\
\text { und Ceratium } \\
\text { spärlich }\end{array}$ & - & - & - & - & $\begin{array}{l}\text { sehr } \\
\text { liel }\end{array}$ & $\begin{array}{l}\text { sehr } \\
\text { viel }\end{array}$ & - & - \\
\hline 20. & $?$ & $\begin{array}{l}\text { 5. } 11 \\
1899\end{array}$ & $\begin{array}{c}\text { Mud } \\
\text { 2wischen } \\
\text { Boje Kiel } 5 \\
\text { und Fried- } \\
\text { richsorler } \\
\text { Leuchthum } \\
\end{array}$ & \multicolumn{10}{|c|}{ Im Protokoll steht nur die Angabe: verunreinigtes Plankton. } \\
\hline 21. & ? &.. & . & \multicolumn{10}{|c|}{ Planktonorganismen fehlen fast gänzlicl. } \\
\hline 22. & 40 & $\begin{array}{l}21,2 . \\
1900\end{array}$ & $\begin{array}{c}\text { Mud bei } \\
\text { Boje Kiel } 2\end{array}$ & \multicolumn{10}{|c|}{ Der untersuchte Darmabsclınitt war leer; das Thier zwar gleich gelötet, aber trotzdem stark macerirt. } \\
\hline
\end{tabular}


Auch im Darn der von mir untersuchten Exemplare von Cyprina islandica, der grössten auf Mudgrund lebenden Muschel der Kieler Bucht, bildeten Peridineen und Diatomeen den Hanptbestandtheil des erkenubaren Inhaltes. (Tabelle siehe S. 56). Unter den Diatomeen kamen besonders Coscinodiscus, Melosira und Synedra in Betracht, unter den Peridineen Prorocentron und Ceratium. Einen Unterschied in der Beschaffenheit des Darminhaltes nach der Jahreszeit, wie bei Mytilus, habe ich bei Cyprina uicht nachweisen können, weil die meisten untersuchten Exemplare in der Zeit gefangen worden sind, in der die Peridineen im Plankton prävaliren. Immerhin ist zu beachten, dass, abgesehen von Nr. 3, deren Darm nur mit unkenntlicher Masse gefüllt war, und von Nr. 20 und 21, über die ich nur ungenaue Protokollangaben gemacht habe, das in Februar gefangene Exemplar Nr. 1 das einzige ist, in dessen Darm keine Peridineen nachzuweisen waren. Im Darm einer Cyprina habe ich kleine in Ketten angeordnete, cylindrische Algen bemerkt, die ich nicht bestimmen komnte. Viellcicht handelte es sich, wie Herr Geheimrath Professor Dr. Reinke vermuthete, um Rhizoclonium. Kleine Pilanzenstücke habe ich nur in einem Falle verzeichnet. Thierische Reste waren nur vereinzelt und in spärlicher Menge vorhanden. Ein Halacarls, den ich in einem Darm gesehen habe, wird wohl in todtem Zustand aufgenommen worden sein, weil die Halacariden nur in den Pflanzenregionen leben. Nach Bronn ${ }^{1}$ ) soll Cyprina auch Fiscls. köder verschlingen. In Magen einer Muschel dieser Art soll eine halbverdaute Nercis pelagica gefunden worden sein.

Von der ebenfalls auf Mudgrund lebenden Astarte borealis habe icls zwölf Exemplare untersucht, die zum grössten Theil auch während der Herbstmonate gefangen worden sind. Die Nahrung dieser Muschel scheint mit der von Cyprina übereinzustimmen; leider habe ich über die letzten fünf Exemplare nur ungenaue Protokolle über die Befunde im Darm aufgenommen.

Astarte borealis Chemnitz.

\begin{tabular}{|c|c|c|c|c|c|c|c|c|c|c|c|c|}
\hline Nr. & $\begin{array}{c}\text { Länge } \\
\text { in } \\
\text { mm }\end{array}$ & $\begin{array}{c}\text { Fang- } \\
\text { zeil }\end{array}$ & Fangort & Diatomeen & $\begin{array}{l}\text { Peridineen } \\
\text { und Silico- } \\
\text { flagellaten }\end{array}$ & Tintinnen & $\begin{array}{l}\text { Gewebs- } \\
\text { pilanzen }\end{array}$ & Metazoen & $\mid \begin{array}{c}\text { Un- } \\
\text { kennt- } \\
\text { liclse } \\
\text { Mlasse }\end{array}$ & Sind & $\begin{array}{c}\text { Son- } \\
\text { stiges }\end{array}$ & $\begin{array}{l}\text { Bemer- } \\
\text { kungen }\end{array}$ \\
\hline 1. & $?$ & $\begin{array}{l}21.2 . \\
1899\end{array}$ & $\begin{array}{l}\text { Schlick } \\
\text { zwischen } \\
\text { Friedriclus- } \\
\text { ort lund } \\
\text { Möltenorl }\end{array}$ & $\begin{array}{c}\text { Coscinodiscus } \\
\text { Melosira }\end{array}$ & $\begin{array}{l}\text { Ceratium- } \\
\text { hörner }\end{array}$ & - & $\begin{array}{l}\text { kleine } \\
\text { Seegras- } \\
\text { stiicke }\end{array}$ & $\begin{array}{c}\text { Spongien: } \\
\text { nadeln }\end{array}$ & liel & viel & - & - \\
\hline 2. แ. 3 . & $?$ & " & $"$ & $\begin{array}{c}\text { Coscinodiscus, } \\
\text { Rhabdonema, } \\
\text { Cyclotella, } \\
\text { Cocconeis, } \\
\text { meist zerbrochen } \\
\end{array}$ & - & - & - & - & $\begin{array}{l}\text { selir } \\
\text { vie] }\end{array}$ & viel & - & - \\
\hline 4. 11.5. & $?$ & $\begin{array}{l}\text { 2. } 11 . \\
1899\end{array}$ & $\begin{array}{c}\text { Sclolick } \\
\text { beim } \\
\text { Feuerschilf }\end{array}$ & $\begin{array}{c}\text { Coscinodiscus, } \\
\text { Melosira } \\
\text { und andere }\end{array}$ & $\begin{array}{l}\text { Prorocentron, } \\
\text { Ceratien und } \\
\text { Dislephanus } \\
\end{array}$ & $\begin{array}{l}\text { Tint. } \\
\text { ventri- } \\
\text { cosus }\end{array}$ & - & - & wenig & Wenig & $\begin{array}{c}\text { Ei- } \\
\text { zellen }\end{array}$ & - \\
\hline 6. & 26 & $\begin{array}{l}21.2 . \\
1900\end{array}$ & $\begin{array}{c}\text { Mud bei } \\
\text { Boje Kiel } 2\end{array}$ & $\begin{array}{l}\text { Synedren und } \\
\text { Coscinodiscus }\end{array}$ & - & - & - & - & $\begin{array}{l}\text { selir } \\
\text { viel }\end{array}$ & $\begin{array}{l}\text { selis } \\
\text { viel }\end{array}$ & $\ldots$ & $\begin{array}{l}\text { mur ein } \\
\text { Kleiner } \\
\text { Dirnu- } \\
\text { abschnilt } \\
\text { unter- } \\
\text { sucht }\end{array}$ \\
\hline 7. & 10 & $\begin{array}{l}27.3 . \\
1900\end{array}$ & $\begin{array}{l}\text { Florideen } \\
\text { und Seegras } \\
\text { bei der } \\
\text { Glockentoje }\end{array}$ & $\begin{array}{c}\text { Coscinodiscus } \\
\text { und } \\
\text { verscliedene } \\
\text { Grunddiatomeen }\end{array}$ & - & - & $\begin{array}{l}\text { kleine } \\
\text { Pilanzen- } \\
\text { slijctie }\end{array}$ & $\begin{array}{c}\text { kleine } \\
\text { Crusti- } \\
\text { ceenreste }\end{array}$ & $\begin{array}{l}\text { selir } \\
\text { viel }\end{array}$ & $\begin{array}{l}\text { selur } \\
\text { viel }\end{array}$ & & \\
\hline 8. -12 . & $?$ & $\begin{array}{l}8.11 . \\
1899\end{array}$ & $\begin{array}{l}\text { sclalickiger } \\
\text { Florideen- } \\
\text { grund bei } \\
\text { der Heulboje }\end{array}$ & lin Proto & kisll stellt nur & dic Angal & be: reines & Plankton, & vorwiege & end $\mathrm{Pr}$ & mosentr & \\
\hline
\end{tabular}

1) H. S. Bronn: Die Klassen und Ordnungen der Weichthiere (.Malacaroa). Leipzig u. Heidelberg 1862 p. 417. 
Auch für Mya arenaria, wenigstens für die in der Kieler Bucht lebenden, kommen Diatomeen und Peridineen in erster Linie als Nahrung in Betracht. Mya arenaria bewohnt den Sand und auch den Mud. Die Muschel gräbt sich bekanntlich ein und streckt ihren Doppelsipho in das Wasser.

Mya arenaria $\mathrm{L}$.

\begin{tabular}{|c|c|c|c|c|c|c|c|c|c|c|c|c|}
\hline Nr. & $\begin{array}{c}\text { Länge } \\
\text { in } \\
\mathrm{mm}\end{array}$ & Fangzeit & Fangort & Dialomeen & Peridineen & $\begin{array}{c}\text { Cyano- } \\
\text { phyceen }\end{array}$ & Tintinnen & $\begin{array}{l}\text { Gewebs- } \\
\text { pilanzen }\end{array}$ & Melazoen & $\begin{array}{c}\text { Un- } \\
\text { kennt- } \\
\text { liche } \\
\text { Masse }\end{array}$ & Sand & Sonstiges \\
\hline 1. & са. 50 & $\begin{array}{l}10.7 \\
1899\end{array}$ & $\begin{array}{c}\text { Sand } \\
\text { bei } \\
\text { Bellevue }\end{array}$ & \begin{tabular}{|c|} 
Grunddialomeen, \\
Cocconeis und \\
andere in \\
beträchtlicher \\
Menge
\end{tabular} & $\begin{array}{l}\text { sehr viel } \\
\text { Prorocentron; } \\
\text { Ceraliumtheile } \\
\text { nicht so } \\
\text { zahlreich }\end{array}$ & $\begin{array}{c}\text { Merismo- } \\
\text { pedia } \\
\text { ziemlich } \\
\text { viel }\end{array}$ & - & $\begin{array}{c}\text { kleine } \\
\text { Algen- } \\
\text { und } \\
\text { Seegras- } \\
\text { stücke }\end{array}$ & $\begin{array}{c}\text { kleine } \\
\text { Crusta- } \\
\text { ceenreste, } \\
\text { Chaeto- } \\
\text { poden- } \\
\text { borsten } \\
\end{array}$ & viel & viel & - \\
\hline 2. & ca. 35 & ", & , & $\begin{array}{l}\text { Grunddiatomeen } \\
\text { wenig zahlreich }\end{array}$ & $\begin{array}{l}\text { Prorocentron } \\
\text { und Ceratium } \\
\text { spärlich }\end{array}$ & - & - & $\begin{array}{c}\text { kleine } \\
\text { Stücke } \\
\text { ganz } \\
\text { vereinzelt }\end{array}$ & $\begin{array}{c}\text { Borsten } \\
\text { und Kiefer } \\
\text { yon } \\
\text { Chaeto- } \\
\text { poden } \\
\end{array}$ & $\begin{array}{l}\text { sehr } \\
\text { viel }\end{array}$ & viel & 1 Eizelle \\
\hline 3. & ca. 40 & $"$ & " & $\begin{array}{c}\text { wenig } \\
\text { Diatomeen }\end{array}$ & $\begin{array}{l}\text { Prorocentron } \\
\text { spärlich }\end{array}$ & $\begin{array}{c}\text { Merismo- } \\
\text { pedia in } \\
\text { beträcht- } \\
\text { licher } \\
\text { Menge }\end{array}$ & - & $\begin{array}{c}\text { Pollen- } \\
\text { körner } \\
\text { ziemlich } \\
\text { viel; } \\
\text { vereinzelt } \\
\text { Seegras- } \\
\text { stiicke } \\
\end{array}$ & $\begin{array}{c}1 \\
\text { Nauplius, } \\
\text { ver- } \\
\text { schiedene } \\
\text { kleine } \\
\text { Resle }\end{array}$ & $\begin{array}{l}\text { sehr } \\
\text { viel }\end{array}$ & viel & - \\
\hline 4. & 25 & $\begin{array}{l}22.4 . \\
1899\end{array}$ & $\begin{array}{l}\text { Mud bei } \\
\text { Bellevue }\end{array}$ & \begin{tabular}{|} 
Coscinodiscus, \\
Grunddiatomeen, \\
Synedra und \\
Naviculaceen; \\
Chaetoceros- \\
borsten sehr viel \\
\end{tabular} & - & $=$ & $\begin{array}{l}\text { T. ven- } \\
\text { tricosus } \\
\text { ver- } \\
\text { einzelt }\end{array}$ & $\begin{array}{l}\text { kleine } \\
\text { Slückchen } \\
\text { vereinzelt }\end{array}$ & $\begin{array}{c}\text { ver- } \\
\text { schiedene } \\
\text { kleine } \\
\text { Reste }\end{array}$ & $\begin{array}{c}\text { sehr } \\
\text { viel }\end{array}$ & viel & - \\
\hline 5. & 22 & $\begin{array}{l}18.6 \\
1900\end{array}$ & \begin{tabular}{|c|} 
Mud \\
zwischen \\
Bellevue \\
und \\
Holtenau \\
\end{tabular} & - ? & $\begin{array}{l}\text { Dinophysis } \\
\text { acula }\end{array}$ & - & - & $-?$ & -? & $\begin{array}{l}\text { sehr } \\
\text { viel }\end{array}$ & $\begin{array}{l}\text { sehr } \\
\text { viel }\end{array}$ & $\begin{array}{l}\text { mehrere } \\
\text { Eihuillen }\end{array}$ \\
\hline 6. & $?$ & $\begin{array}{l}24.7 . \\
1899\end{array}$ & $\begin{array}{c}\text { schwarzes } \\
\text { Seegras } \\
\text { bei der } \\
\text { Muschel- } \\
\text { bank } \\
\end{array}$ & ? & $\begin{array}{c}\text { Prorocentron } \\
\text { in heträchtlicher } \\
\text { Menge }\end{array}$ & - & - & - & - & viel & viel & $\begin{array}{l}\text { mehrere } \\
\text { dornige } \\
\text { Cysten }\end{array}$ \\
\hline 7. -12 . & $\begin{array}{l}11 \\
\text { bis } \\
13\end{array}$ & $"$ & \begin{tabular}{|c|} 
Mud \\
2wischen \\
Friedrichs. \\
ort und \\
Boje D \\
\end{tabular} & - & $\begin{array}{l}\text { Prorocenlron } \\
\text { und junge } \\
\text { Peridineen viel }\end{array}$ & - & - & - & - & viel & wenig & - \\
\hline 13. & 20 & $\begin{array}{l}9.6 . \\
1900\end{array}$ & $\begin{array}{l}\text { K. W.-K. } \\
\text { kin } 97,5, \\
\text { Ufer }\end{array}$ & $\begin{array}{l}\text { Melosiren und } \\
\text { Naviculaceen } \\
\text { ziemlicl viel; } \\
\text { Pleurosigma }\end{array}$ & - & - & $=$ & - & $\begin{array}{l}1 \text { Chaelo- } \\
\text { poden- } \\
\text { borste }\end{array}$ & $\begin{array}{c}\text { sehr } \\
\text { viel }\end{array}$ & $?$ & $\begin{array}{l}1 \text { volle } \\
\text { und } \\
1 \text { leere } \\
\text { Eihiille }\end{array}$ \\
\hline 14. แ. 15. & $\begin{array}{l}37 \\
32\end{array}$ & $"$ & $\begin{array}{l}\text { K. W. } \mathrm{K} . \\
\text { him } 95 \\
\text { Dredge }\end{array}$ & $\begin{array}{l}\text { Melosiren und } \\
\text { andere spärlicli }\end{array}$ & - & - & - & - & $\begin{array}{c}\text { Spongien- } \\
\text { nadeln, } \\
1 \text { Chaelo- } \\
\text { poden- } \\
\text { borste } \\
\end{array}$ & $\begin{array}{l}\text { sehr } \\
\text { viel }\end{array}$ & $\begin{array}{l}\text { sehr } \\
\text { viel }\end{array}$ & - \\
\hline 16. & 27 & $"$ & $"$ & $\begin{array}{l}\text { Melosiren und } \\
\text { andere spärlich }\end{array}$ & - & - & - & - & $\begin{array}{l}\text { Spongien- } \\
\text { nadeln }\end{array}$ & $\begin{array}{l}\text { selır } \\
\text { viel }\end{array}$ & $\begin{array}{l}\text { selur } \\
\text { viel }\end{array}$ & $\begin{array}{l}1 \text { leere } \\
\text { Eihüllle }\end{array}$ \\
\hline
\end{tabular}

Was die im Sand lebenden Exemplare anbelangt, so habe ich von ihnen drei untersucht, die ich bei Bellevue gefangen habe. Grunddiatomeen, besonders Cocconeis, waren von allen dreien auf- 
genommen worden; ein Exemplar hatte sehr viel Prorocentren und viel Ceratien gefressen, im Darm der andern beiden waren Peridineen spärlich. Zwei der drei Individuen hatten kleine Cyanophyceen (Merismopedia) gefressen. Kleine Seegras- und Algenstücke habe ich nur in geringem Masse gefunden; von thierischen Bestandtheilen ist ein Nauplius zu nennen. Unkenntliche Masse war immer in Menge anwesend. Die folgenden Exemplare Nr. 4-12 habe ich an verschiedenen Stellen auf Mudgrund gedredget. Nr. 6-12 enthielten an organischen Stoffen fast ansschliesslich Prorocentren und die sclon bei Mytilus erwähnten "jungen Peridineen". Dazı kam freilich stets viel nnkenntliche Masse und zum Theil auch viel Sand. Nr. 4, die im April gefangen war, hatte keine Peridineen, daüur viel Diatomeen, besonders Chaetoceros aufgenommen; auch fanden sich vereinzelt Tintinnen ( $T$. ventricosus). Der Darminhalt von Nr. 5 bestand ausschliesslich aus unkenntlicher Masse und Sand, worin sich nur eine Dinophysis und mehrere Eihüllen erkennen liessen. Die Jetzten vier Exemplare stammten aus dem Kaiser WilhelmKanal. Ihr Darm enthielt, abgesehen von vereinzelten Eihüllen und Melosiren, deren Lebensweise mir zweifelhaft ist, keine planktonischen Bestandtheile; dafür waren unkenntliche Masse und Sand in grosser Menge vorhanden. Vielleicht ist der Grund dafür darin zu suchen, dass der Boden des schmalen Kanals durch den lebhaften Dampfscliffverkehr in stärkerem Masse aufgewülılt wird, als in der Föhrde.

Mya truncata ist in ihrem Vorkommen auf Mudgrund beschränkt. Die Untersuchung der neun gefangenen Exemplare hat kein klares Ergebniss gehabt. Der Darm war fast stets hauptsächlich mit 11!kenntlicher Masse gefüllt, in der nur vereinzelt Planktonorganismen eingeschlossen waren. Bemerkenswerth ist das Exemplar Nr. 5, weil es das einzige von sämmtlichen untersuchten Thieren der Kieler Bucht ist, in dessen Darm ich eine Anuraea gefunden habe.

Mya truncata L.

\begin{tabular}{|c|c|c|c|c|c|c|c|c|c|c|c|}
\hline Nr. & $\left|\begin{array}{c}\text { Länge } \\
\text { in } \\
\text { mm }\end{array}\right|$ & Fangzeit & Fangort & Diatomeen & Peridineen & Tintinnen & $\begin{array}{c}\text { Andere } \\
\text { Protozoen }\end{array}$ & $\begin{array}{l}\text { Gewebs- } \\
\text { pflanzen }\end{array}$ & Metazoen & $\left|\begin{array}{c}\text { Un- } \\
\text { kennt- } \\
\text { liclee } \\
\text { Masse }\end{array}\right|$ & Sand \\
\hline 1. & 15 & $\begin{array}{l}18.6 \\
1900\end{array}$ & $\begin{array}{c}\text { Mud auf der } \\
\text { Höhe der } \\
\text { Wiker Bucht }\end{array}$ & $\begin{array}{l}\text { vereinzelte } \\
\text { Grund- } \\
\text { diatomeen }\end{array}$ & & $\begin{array}{l}1 \text { Tin- } \\
\text { tinnus } \\
\text { ventri- } \\
\text { cosus }\end{array}$ & - & $\begin{array}{l}1 \text { Coniferen- } \\
\text { pollenkorn }\end{array}$ & $\begin{array}{c}\text { zerbrochente } \\
\text { Spongien- } \\
\text { nadeln } \\
\text { vereinzelt }\end{array}$ & viel & $?$ \\
\hline 2. & 14 & $"$ & , & $-?$ & - & $\ldots$ & $\begin{array}{l}1 \text { Fora- } \\
\text { minifere }\end{array}$ & & - & $\begin{array}{l}\text { sehr } \\
\text { viel }\end{array}$ & $?$ \\
\hline 3. & 15 & " & " & $-?$ & - & - & & & $\begin{array}{c}\text { kleine } \\
\text { Cruslaceen- } \\
\text { resle } \\
\text { vereinzelt } \\
\end{array}$ & $\begin{array}{l}\text { sehr } \\
\text { viel }\end{array}$ & ? \\
\hline 4. & 16 & ". & ., & $-?$ & - & - & - & $\begin{array}{l}\text { vereinzelte } \\
\text { kleine } \\
\text { Pflanzen- } \\
\text { stücke } \\
\end{array}$ & - & $\begin{array}{l}\text { sehr } \\
\text { viel }\end{array}$ & $?$ \\
\hline 5. & 20 & " & " & $\begin{array}{c}\text { Melosira } \\
\text { vereinzelt }\end{array}$ & - & - & - & - & $\begin{array}{c}1 \text { Anuraea } \\
\text { lecta, kleine } \\
\text { Cruslaceen- } \\
\text { stitcke }\end{array}$ & $\begin{array}{l}\text { sehr } \\
\text { viel }\end{array}$ & ? \\
\hline 6. & $?$ & $\begin{array}{c}15.11 \\
1899\end{array}$ & $\begin{array}{c}\text { Mud } \\
\text { zwischen } \\
\text { Boje Kiel } 5 \\
\text { und Fried- } \\
\text { richsorter } \\
\text { 1.euchithurm } \\
\end{array}$ & Coscinodiscus & Prorocentron & - & - & ? & $?$ & $\begin{array}{l}\text { sehr } \\
\text { viel }\end{array}$ & viel \\
\hline 7. & $?$ & , & $"$ & $\begin{array}{c}\text { kleine } \\
\text { Melosiraketten, } \\
\text { Coscinodiscus }\end{array}$ & $\begin{array}{l}1 \text { Prorocenlrom, } \\
\text { I Peridlinimun }\end{array}$ & - & - & ? & ? & $\begin{array}{l}\text { sehr } \\
\text { viel }\end{array}$ & $\begin{array}{l}\text { selir } \\
\text { viel }\end{array}$ \\
\hline ห.1. 9. & $?$ & $\begin{array}{l}24.7 . \\
1899\end{array}$ & $\begin{array}{l}\text { Alud zwischen } \\
\text { Friedrichsort } \\
\text { und Boje D }\end{array}$ & $\ln 1$ & Protokoll stehit & Ir, dass & lankton & Darm & den worden & t. & \\
\hline
\end{tabular}


Auch bei Cardium edule haben die Darmuntersuchungen nicht ergeben, ob die Hauptnahrung dieser Muschel aus Plankton besteht. Thre Einrichtungen zur Nahrungsaufnahme stimmen mit denen der besprochenen Muschel überein und aus diesem Grunde glaube ich Cardium edule hier erwähnen zu dürfen.

Cardium edule L.

\begin{tabular}{|c|c|c|c|c|c|c|c|c|c|c|c|}
\hline Nr. & $\begin{array}{l}\text { Länge } \\
\text { int } \\
\text { min }\end{array}$ & Fangzeit & Fangort & Diatomeen & Peridineen & $\begin{array}{l}\text { Cyano- } \\
\text { phyceen }\end{array}$ & $\begin{array}{c}\text { Tin- } \\
\text { tinnen }\end{array}$ & $\begin{array}{l}\text { Gewebs- } \\
\text { pilanzen }\end{array}$ & Metazoen & \begin{tabular}{|} 
Un- \\
kennt- \\
liche \\
Masse
\end{tabular} & Sand \\
\hline 1. & 15 & $\begin{array}{l}10.7 . \\
1899\end{array}$ & $\begin{array}{l}\text { Sand am } \\
\text { Slrande } \\
\text { bej } \\
\text { Bellevue }\end{array}$ & $\begin{array}{l}\text { Grunddiatomeen, } \\
\text { vorwiegend } \\
\text { Cocconeis }\end{array}$ & $\begin{array}{l}\text { Prorocentron } \\
\text { spärlich }\end{array}$ & $\begin{array}{c}\text { Merismopedia } \\
\text { viel }\end{array}$ & - & $\begin{array}{l}\text { Pollen- } \\
\text { körner } \\
\text { viel }\end{array}$ & $\begin{array}{c}\text { Spongien- } \\
\text { nadeln, } \\
\text { Chaetopoden- } \\
\text { borsten und } \\
\text { kleine Cru- } \\
\text { staceenreste }\end{array}$ & viel & - viel \\
\hline 2. & 12 & " & . & $\begin{array}{l}\text { Grunddiatomeen } \\
\text { ziemlich viel }\end{array}$ & - & $\begin{array}{l}\text { Merismopedia } \\
\text { ziemlich viel }\end{array}$ & - & 一 & $\begin{array}{c}\text { Spongien- } \\
\text { nadeln, } \\
\text { Chaetopoden- } \\
\text { borsten }\end{array}$ & $\begin{array}{l}\text { sehr } \\
\text { viel }\end{array}$ & viel \\
\hline 3. u. 4. & $\begin{array}{l}15 \\
13\end{array}$ & " & . & $\begin{array}{c}\text { Grunddiatomeen } \\
\text { wenig }\end{array}$ & - & $\begin{array}{c}\text { Merismopedia } \\
\text { vereinzelt }\end{array}$ & $\longrightarrow$ & - & $\begin{array}{c}\text { Chaetopoden- } \\
\text { borsten }\end{array}$ & $\begin{array}{l}\text { sehr } \\
\text { viel }\end{array}$ & viel \\
\hline 5. 7. & ca. 20 & $\begin{array}{l}24.7 . \\
1899\end{array}$ & $\begin{array}{l}\text { Strand } \\
\text { bei } \\
\text { Stein }\end{array}$ & & Protokoll stel & nur die Anga & abe: $v$ & Plankto & nenig Sand & & \\
\hline 8. & 13 & $\begin{array}{l}9.6 \\
1900\end{array}$ & $\begin{array}{l}\text { K. W.-K. } \\
k m \\
97,5 \\
\text { (Ufer) }\end{array}$ & & einzelte Diat & een, sonst nur & is Sand & und unke & ntliche Masse & & \\
\hline 9. -12. & $\begin{array}{r}15 \\
14 \\
14 \\
7\end{array}$ & , & $n$ & & & Sand und unt & kenntli & e Masse & & & \\
\hline
\end{tabular}

Bei der nahe verwandten Art - Cardium fasciatum - habe ich Planktonfrass mit Sicherheit nachweisen können, und zwar bildeten Peridineen den Hauptbestandtheil des erkennbaren Darminhaltes der fünf untersuchten Exemplare.

Cardium fasciatum Mont.

\begin{tabular}{|c|c|c|c|c|c|c|c|c|}
\hline Nr. & $\begin{array}{l}\text { Länge } \\
\text { in } \\
\text { min }\end{array}$ & Fangzeit & Fangort & Diatomeen & Peridineen & Tintinnen & $\begin{array}{c}\text { Unkennt- } \\
\text { liche } \\
\text { Masse }\end{array}$ & Sand \\
\hline 1. & 8 & $\begin{array}{l}24.7 . \\
1899\end{array}$ & $\begin{array}{c}\text { Mud zwischen } \\
\text { Friedrichs- } \\
\text { ort und } \\
\text { Boje D } \\
\end{array}$ & - & $\begin{array}{l}\text { Prorocentron in beträcht- } \\
\text { licher Menge }\end{array}$ & $\cdots$ & sehr viel & Wenig \\
\hline 2. & 10 & " & $\begin{array}{c}\text { Schwarzes } \\
\text { Seegras } \\
\text { bei der } \\
\text { Muschelbank }\end{array}$ & 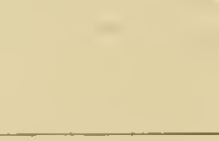 & $\begin{array}{c}\text { Prorocentron und junge } \\
\text { Peridineen }\end{array}$ & - & - & - \\
\hline 3. -5 . & $?$ & 15. 11. & $\begin{array}{l}\text { Mud bei } \\
\text { Friedriclis- } \\
\text { ort }\end{array}$ & $\begin{array}{l}\text { Coscinodiscus, } \\
\text { Melosira }\end{array}$ & $\begin{array}{l}\text { Prorocentron, } \\
\text { Ceratimun tripos }\end{array}$ & $\begin{array}{c}\text { Tintinnus } \\
\text { ventricosus }\end{array}$ & viel & viel \\
\hline
\end{tabular}

Von Scrobicularia piperata habe ich sechs Exemplare untersucht. Zwei von ihnen hatten Peridineen - Prorocentren und junge Peridineen - in beträchtlicher Menge aufgenommen; bei den übrigen fehlten sie; kleine pflanzliche und thierische Reste sowie Diatoneen waren spärlich, unkenntliche Masse 
dagegeı stets viel vorhanden. Ueber ilıre Ernährungsweise schreiben Meyer und Möbius ${ }^{1}$ ): ${ }_{\text {nDas Ende }}$ (der Mantelhöhle) krümmt sich nnd tastet hin und her; es greift in den Schlanm und löst Theilchen desselben los, welche dann schnell in den Körper hineinfahren." Danach wäre Scrobicularia besser zı den Detritusfressern zu stellen.

Scrobicularia piperata Gmel.

\begin{tabular}{|c|c|c|c|c|c|c|c|c|c|c|}
\hline $\mathrm{Nr}$. & $\begin{array}{c}\text { Länge } \\
\text { in } \\
\text { ImIn }\end{array}$ & Fangzeit & Fangort & Diatomeen & Peridineen & $\begin{array}{c}\text { Gellebs- } \\
\text { piflanzen }\end{array}$ & $\begin{array}{l}\text { Meta- } \\
\text { zoen }\end{array}$ & $\left|\begin{array}{c}\text { Unkennt- } \\
\text { liche } \\
\text { Masse }\end{array}\right|$ & Sand & $\begin{array}{l}\text { Son- } \\
\text { sliges }\end{array}$ \\
\hline 1. & $?$ & $\begin{array}{l}24.7 . \\
1899\end{array}$ & $\begin{array}{c}\text { schwarzes } \\
\text { Seegras } \\
\text { bei der } \\
\text { Muschelbank } \\
\end{array}$ & $\begin{array}{l}\text { Naviculaceen } \\
\text { und andere } \\
\text { (leer) }\end{array}$ & & $\begin{array}{l}\text { kleine } \\
\text { Reste }\end{array}$ & $\begin{array}{l}\text { kleine } \\
\text { Reste }\end{array}$ & viel & viel & \\
\hline 2. & $?$ & " & $n$ & $\begin{array}{l}\text { leere Schalen von } \\
\text { Naviculaceen } \\
\text { und anderen }\end{array}$ & $\begin{array}{l}\text { Prorocentron und } \\
\text { junge Peridineen } \\
\text { in beträchllicher } \\
\text { Anzahl }\end{array}$ & $\begin{array}{l}\text { kleine } \\
\text { Reste }\end{array}$ & $\begin{array}{l}\text { kleine } \\
\text { Reste }\end{array}$ & viel & viel & \\
\hline 3. & 15 & $"$ & $\begin{array}{l}\text { Mudzwischen } \\
\text { Friedrichs- } \\
\text { ort und } \\
\text { Boje D } \\
\end{array}$ & ? & $\begin{array}{l}\text { Prorocentron } \\
\text { in beträchtlicher } \\
\text { Anzahl }\end{array}$ & - & - & selır viel & viel & \\
\hline 4. 6. & $?$ & $\begin{array}{l}27.11 . \\
1899\end{array}$ & \begin{tabular}{|} 
Mud zwischen \\
Strander \\
Grasberg und \\
Gasboje
\end{tabular} & $\begin{array}{l}\text { einige leere } \\
\text { Coscinodiscus- } \\
\text { schalen }\end{array}$ & $\ldots$ & $?$ & $?$ & sehr viel & sehr viel & \\
\hline
\end{tabular}

Dasselbe gilt von Tellina baltica. In Aquarium habe ich diese Muschel oft in gleicher Weise ihre Nahrung suchen sehen, wie es oben von Scrobicularia gesagt wird. Im Darm der 25 untersuchten Exemplare habe ich ausserdem nur ganz vereinzelt Planktonorganismen gefunden. (Tabelle siehe S. 62). Ich habe die beiden letzten Muschelarten trotzdem bei den Planktonzehrern erwähnt, weil ich die untersuchten Muscheln im Zusammenhang besprechen wollte.

Ascidia canina findet sich in der Kieler Buclut in den Pflanzenregionen, meist an Seegras und Algen, seltener an Steinen und anderen Gegenständen sitzend. Im Darm der 22 untersuchten Exemplare habe ich als wesentliche Nahrungsbestandtheile Diatomeen, Peridineen und Pflanzenstücke gefunden. Dazu kamen in vereinzelten Fällen Copepoden, kleine thierische Reste und die schon oben erwähnte Alge (Rhizoclonium.) (Tabelle siehe S. 63). Unter den Diatomeen spielten die typischen Planktonformen, Chaetoceros und Rhizosolenia eine bedeutendere Rolle, als es bei irgend einer der bisher besprochenen planktonfressenden Thierarten der Fall war; jedoch überwogen auch hier meist die Grundformen. Die im Darm von Ascidia gefundenen Peridineen waren die gleichen wie diejenigen im Darm der Muschelı. In wechselnder Menge waren sie fast immer vorhanden. Nur im Darm der im Februar gefangenen Exemplare Nr. 15-17 fehiten sie; dagegen machten sich in dem Darın von Nr. 1-7, die ebenfalls in Februar gedredget waren, Reste von Ceratien bemerkbar. Seegras- und Algenstücke fehiten sehr selten; verschiedentlich habe ich auch Florideentriebe und dünne, verzweigte, einzellreihige niedere Algen bemerkt. Bei Brom²) findet sich die Angabe, dass die Nahrung der Tunikaten ganz vegetabilisch sein und aus Algenstücken, Diatomeen und Desmidiaceen bestehen soll; jedoch zweifelt Bronn schon selbst, ob die kleinen Krebschen und andere Thiere nicht auch aufgenommen werden und nur schueller der Verdaunng anheimfallen. Die Annahuse, dass keine Thiere gefressen werden, gründet sich anf eise Beobachtung von Lister (in Bronn erwähnt). Lister sah im Kiemendarm von Ascidien kleine Krebse monatelang leben. Wie schon Bronn vermuthet, und wie sicher nachgewiesen ist, handelt es sich um Parasiten; es sind Copepoden (Notonelphys). Ich habe sie verschiedentlich im Kiemendarm von Ascidia canina gefunden. Mehrere Ascidien, die am

1) H. A. Meyer und K. Möbius: Die Lamellibranchiata etc. I. c. p. 107.

4) H. G. Bronn: Die Klassen und Ordnungen der Weichthiere (Malacazoa). I. c. p. 170. 
Tellina baltica L.

\begin{tabular}{|c|c|c|c|c|c|c|c|c|c|c|c|c|}
\hline Nr. & $\begin{array}{c}\text { Länge } \\
\text { in } \\
\mathrm{mm}\end{array} \mid$ & Fangzeit & Fangort & Diatomeen & Peridineen & $\begin{array}{c}\text { Tin- } \\
\text { tinnen }\end{array}$ & $\begin{array}{l}\text { Gewebs- } \\
\text { pflanzen }\end{array}$ & Metazoen & $\begin{array}{c}\text { Un- } \\
\text { kennt- } \\
\text { liche } \\
\text { Masse }\end{array}$ & Sand & Sonstiges & $\begin{array}{l}\text { Bemer- } \\
\text { kungen }\end{array}$ \\
\hline 1. & $?$ & $\begin{array}{c}22.4 \\
1899\end{array}$ & $\begin{array}{c}\text { Mud auf } \\
\text { der Höhe } \\
\text { von Bellevue }\end{array}$ & & - & -. & $\begin{array}{l}\text { spärliche } \\
\text { Reste }\end{array}$ & $\begin{array}{l}\text { spärliche } \\
\text { Reste }\end{array}$ & viel & $\begin{array}{l}\text { sehr } \\
\text { viel }\end{array}$ & - & - \\
\hline 2. & $?$ & $\begin{array}{l}15.11 . \\
1899\end{array}$ & $\begin{array}{l}\text { Mud zwischen } \\
\text { Kjel } 5 \text { und } \\
\text { Friedrichsort }\end{array}$ & $?$ & - & - & $\begin{array}{l}\text { spärliche } \\
\text { Reste }\end{array}$ & $\begin{array}{l}\text { spärliche } \\
\text { Reste }\end{array}$ & $\begin{array}{l}\text { sehr } \\
\text { viel }\end{array}$ & $\begin{array}{l}\text { sehr } \\
\text { viel }\end{array}$ & $\begin{array}{l}1 \text { "um- } \\
\text { rindete } \\
\text { Cyste" }\end{array}$ & - . \\
\hline 3. & $?$ & ", & " & $\begin{array}{c}\text { zerbrochene } \\
\text { Coscinodiscus } \\
\text { Melosira }\end{array}$ & $\begin{array}{c}\text { Ceratium- } \\
\text { bruch- } \\
\text { stücke } \\
\end{array}$ & - & $\begin{array}{l}\text { Spärliche } \\
\text { Reste }\end{array}$ & $\begin{array}{l}\text { spärliche } \\
\text { Reste }\end{array}$ & viel & viel & $\begin{array}{l}1 \text { dornige } \\
\text { Cyste }\end{array}$ & - \\
\hline $4 .-7$ & ? & $\begin{array}{l}24.7 . \\
1899\end{array}$ & $\begin{array}{l}\text { Mud zwischen } \\
\text { Friedrichsort } \\
\text { und Boje D }\end{array}$ & ? & - & 一 & ? & ? & $\begin{array}{l}\text { sehr } \\
\text { viel }\end{array}$ & viel & - & - \\
\hline 8. แ1. 9. & ? & $\begin{array}{l}\text { 15. } 11 . \\
1899\end{array}$ & $\begin{array}{c}\text { Mud bei } \\
\text { Friedrichsort }\end{array}$ & $?$ & - & - & $?$ & $?$ & $\begin{array}{l}\text { äus- } \\
\text { serst } \\
\text { viel }\end{array}$ & $\begin{array}{l}\text { sehr } \\
\text { viel }\end{array}$ & - & - \\
\hline 10. & ? & $\begin{array}{l}\text { 8. } 11 . \\
1899\end{array}$ & $\begin{array}{c}\text { sandiger } \\
\text { Schlick beim } \\
\text { Stoller Grund }\end{array}$ & $?$ & - & - & $?$ & $?$ & $\begin{array}{l}\text { äus- } \\
\text { serst } \\
\text { viel }\end{array}$ & $\begin{array}{l}\text { sehr } \\
\text { vie] }\end{array}$ & - & - \\
\hline 11. - 14. & $?$ & $\begin{array}{l}17.7 \\
1899\end{array}$ & $\begin{array}{c}\text { Mud beim } \\
\text { Stoller Grund }\end{array}$ & - & - & - & - & $?$ & $\begin{array}{l}\text { sehr } \\
\text { viel }\end{array}$ & $\begin{array}{l}\text { sehr } \\
\text { viel }\end{array}$ & - & - \\
\hline 15 & 11 & $\begin{array}{c}27.3 . \\
1900\end{array}$ & $\begin{array}{c}\text { Florideen und } \\
\text { Seegras hei } \\
\text { der Glocken- } \\
\text { boje }\end{array}$ & $\begin{array}{c}\text { zerbrochene } \\
\text { Schalen in } \\
\text { geringer Menge }\end{array}$ & - & - & - & $\begin{array}{c}\text { Spongien- } \\
\text { nadeln }\end{array}$ & $\begin{array}{l}\text { sehr } \\
\text { viel }\end{array}$ & $\begin{array}{l}\text { sehr } \\
\text { viel }\end{array}$ & & - \\
\hline 16. & 9 & $"$ & " & $\begin{array}{l}\text { leere Coscino- } \\
\text { discus vereinzelt }\end{array}$ & - & - & $\begin{array}{c}\text { kleine } \\
\text { Reste } \\
\text { vereinzelt }\end{array}$ & - & $\begin{array}{l}\text { sehr } \\
\text { viel }\end{array}$ & $\begin{array}{l}\text { sehr } \\
\text { viel }\end{array}$ & & - \\
\hline 17. & 10 & ", & $"$ & $\begin{array}{l}\text { Cocconeis } \\
\text { vereinzelt, } \\
\text { Coscinodiscus } \\
\text { vereinzelt, } \\
\text { Grammatophora } \\
\text { vereinzelt, } \\
\text { Naviculaceen } \\
\text { vereinzelt } \\
\text { (zum Theil } \\
\text { zerbrochen) }\end{array}$ & - & - & $\begin{array}{c}\text { kleine } \\
\text { Reste } \\
\text { vereinzelt }\end{array}$ & $\begin{array}{c}\text { Spongien- } \\
\text { nadeln }\end{array}$ & $\begin{array}{c}\text { sehr } \\
\text { viel } \\
\text { (vor- } \\
\text { herr- } \\
\text { schend) }\end{array}$ & $\begin{array}{l}\text { sehr } \\
\text { viel }\end{array}$ & - & - \\
\hline 18. & 13 & $\begin{array}{l}9.6 . \\
1900\end{array}$ & $\begin{array}{l}\text { K. W.-K. } \\
\text { Nobiskrug, } \\
\text { Dredge }\end{array}$ & $\begin{array}{l}\text { leere Schalen } \\
\text { (zum Theil } \\
\text { zerbrochen) }\end{array}$ & - & - & - & ? & $\begin{array}{l}\text { sehr } \\
\text { viel }\end{array}$ & $\begin{array}{l}\text { sehr } \\
\text { viel }\end{array}$ & - & - \\
\hline 19. & 13 & $\begin{array}{l}9.6 . \\
1900\end{array}$ & $\begin{array}{l}\text { K. W.-K. } \\
\text { km } 97,5\end{array}$ & - & - & - & - & - & $\begin{array}{l}\text { spär- } \\
\text { liclı }\end{array}$ & $?$ & - & $\begin{array}{c}\text { Darm } \\
\text { nahezu } \\
\text { leer }\end{array}$ \\
\hline 20. & 11 & $"$ & " & - & - & - & - & - & - & - & 一 & $\begin{array}{c}\text { Darm } \\
\text { leer }\end{array}$ \\
\hline 21. 24 & $\begin{array}{l}13 \\
13 \\
12 \\
13 \\
\end{array}$ & $"$ & $"$ & $\begin{array}{l}\text { leere Schalen } \\
\text { spärliclı }\end{array}$ & - & - & $\begin{array}{l}\text { kleine } \\
\text { Reste }\end{array}$ & $\begin{array}{l}\text { kleine } \\
\text { Reste }\end{array}$ & $\begin{array}{l}\text { sehr } \\
\text { viel }\end{array}$ & $\begin{array}{l}\text { sehr } \\
\text { viel }\end{array}$ & - & - \\
\hline 25. & 12 & " & " & $\begin{array}{l}\text { leere Schalen } \\
\text { Synedren, } \\
\text { Naviculaceen } \\
\text { äusserst viel } \\
\text { Pleurosigma }\end{array}$ & - & 一 & - & - & wenig & viel & - & - \\
\hline
\end{tabular}


E. Rauschenplat, Ueber die Nahrung von Thieren aus der K̈ieler Bucht.

$6 i 3$

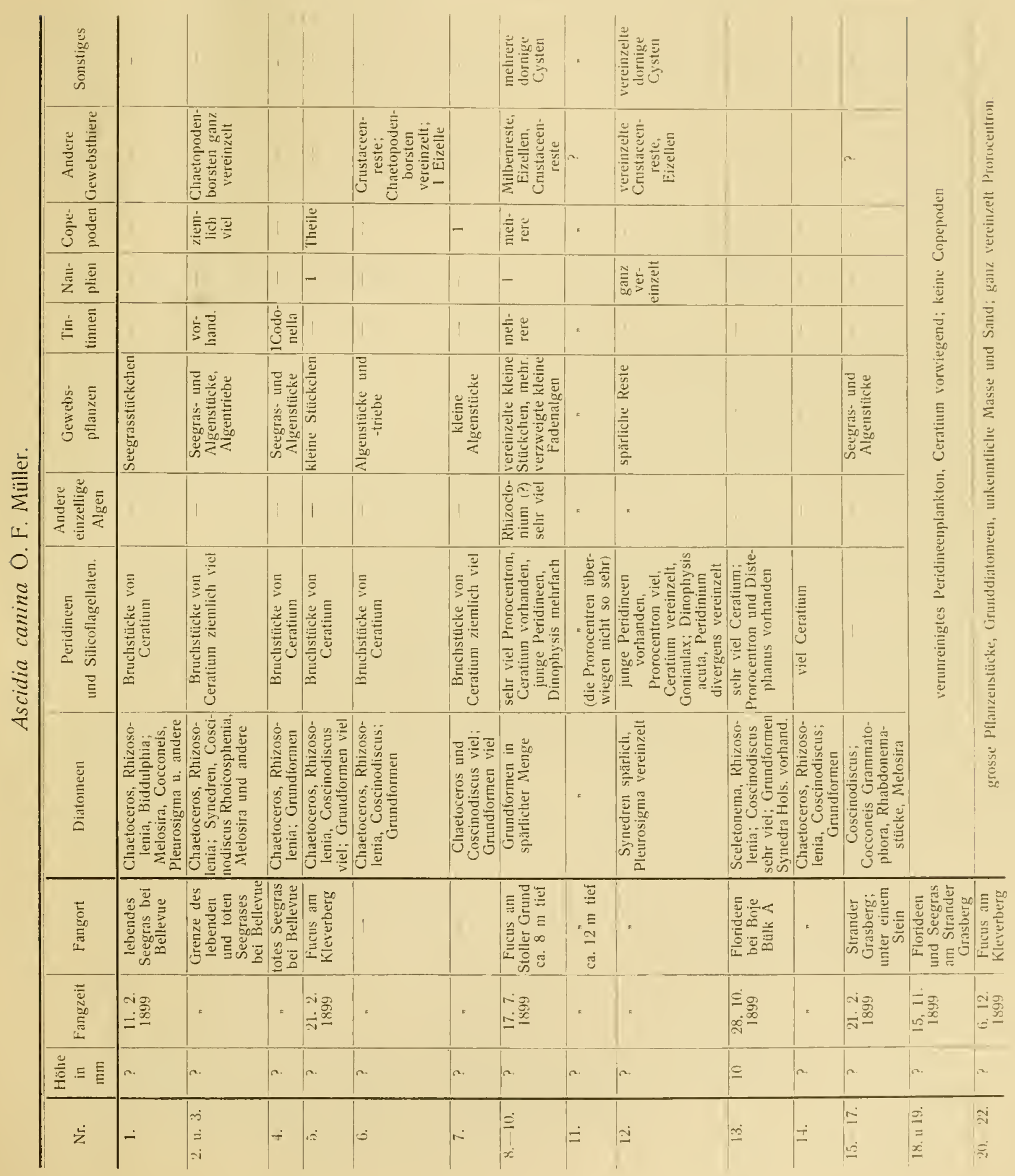


21. 2. 1899 am Kleverberg gefangen waren, habe ich in lebendem Plankton gehalten, das, um Bodensatz zu vermeiden, durch einen Apparat beständig in schwebendem Zustand erhalten wurde. Ein Exemplar nahm ich nach etwa 40 Stunden heraus, um es zu untersuchen. $1 \mathrm{~m}$ Darm fand ich meist Chaetoceros, Rhizosolenia, Sceletonema und Coscinodiscus, daneben auch Grundformen und vereinzelte Bruchstücke; thierische Reste fehlten gänzlich. Im Darm eines zweiten Exemplares, das nach vier Tagen 'untersucht wurde, fand ich bei weitem vorwiegend Chactoceros, Rhizosolenia und Synedra ziemlich viel, Dinophysis und Peridinium nicht selten; bemerkenswerth ist, dass Copepoden und Nauplien, die im vorigen Exemplar fehlten, in diesem ziemlich viel vorhanden waren. Ein drittes Exemplar, das ich nach zwei weiteren Tagen untersuchte, stimmte bezüglich seines Darminhaltes mit dem eben besprochenen überein. Vereinzelt fand ich kleine Seegras- und Algenstücke und Grunddiatomeen.

Von den beiden hier vorkommenden Cynthien, lebt die eine Art, Cynthia grossularia, vorzugsweise im Gebiet der Algen, an diesen meist dicht und zusammengewachsen sitzend. Cynthia rustica

Cynthia rustica L.

\begin{tabular}{|c|c|c|c|}
\hline Nr. & Fundzeit & Fundort & Darminhalt \\
\hline 1. & $\begin{array}{l}28.10 . \\
1899\end{array}$ & $\begin{array}{c}\text { Mud zwischen Heul- } \\
\text { boje und Büllk A }\end{array}$ & Stark verunreinigtes Plankton, Ceratium vorwiegend \\
\hline 2. -5 . & $\begin{array}{r}8.11 . \\
1899\end{array}$ & $\begin{array}{l}\text { Mud vor dem } \\
\text { Stoller Grund }\end{array}$ & Sehr reines Plankton, Ceratium vorwiegend \\
\hline 6. แ. 7. & $"$ & " & $\begin{array}{l}\text { Wie die vorigen; Tintinnus acuminatus, Distephanus, Rhizosolenia vereinzelt; } \\
\text { Synedra ziemlich viel. }\end{array}$ \\
\hline 8. แ. 9. & " & $\begin{array}{l}\text { Florideen bei der } \\
\text { Heulboje }\end{array}$ & Reines Plankton, Ceratium rorwiegend. \\
\hline
\end{tabular}

dagegen findet man vorwiegend auf Mudgrund, an Steinen, Muschelschalen und anderen festen Gegenständen festgewachsen. Doch kommen Vertreter der letzteren Art auch auf sandigem Grund zwischen Florideen vor, und $C$. grossularia habe ich andererseits auch auf Mudboden angetroffen. Was die Beschaffenheit des Darminhaites anbetrifft, so ist diese bei beiden Arten gleich. Von C. rustica habe ich 9 Exemplare untersucht. Sämmtliche Exemplare sind im Herbst und Winter gefangen worden, und dementsprechend bestand der Darminhalt auch vorzugsweise aus Peridineenplankton.

Cynthia grossularia van Beneden.

\begin{tabular}{|c|c|c|c|}
\hline Nr. & Fundzeit & Fundort & Darminhalt \\
\hline 1. & $\begin{array}{l}21.2 . \\
1899\end{array}$ & Fucus bei Bülk & $\begin{array}{c}\text { Coscinodiscus, Cocconeis, Naviculaceen; Stücke von Seegras und Algen; viel unkenntliche } \\
\text { Masse; Sand }\end{array}$ \\
\hline 2. & $\begin{array}{l}23.7 . \\
1900\end{array}$ & $\begin{array}{c}\text { Florideen u. Seegras } \\
\text { am } \\
\text { Strander Grasberg }\end{array}$ & Coscinodiscus, Synedra; mehrese Tintinnus ventricosus; unkenntliche Masse und Sand \\
\hline 3. & 10 & $"$ & $\begin{array}{c}\text { Chaetoceros, Coscinodiscus, Synedra; melurere Tintinnen; } 1 \text { dornige Cyste; unkenntliche } \\
\text { Masse und Sand }\end{array}$ \\
\hline $4 .-7$ & $\begin{array}{c}13.12 . \\
1899\end{array}$ & $\begin{array}{l}\text { Mud mit Florideen } \\
\text { hinter der Gasboje }\end{array}$ & Plankton, vorwiegend Ceratium \\
\hline 8. -10 & 6. 12. & $\begin{array}{l}\text { Mud bei der } \\
\text { Gasboje }\end{array}$ & Stark verunreinigtes Plankton, Ceratium vorwiegend \\
\hline 11.11 .12 . & $\begin{array}{l}13.12 . \\
1899\end{array}$ & $\begin{array}{c}\text { Mud zwischen } \\
\text { Gas- u. Glockenboje }\end{array}$ & Stark verunreinigtes Plankion, Ceratiun vorwiegend \\
\hline 13. -20. & $\begin{array}{c}8.11 . \\
1899\end{array}$ & $\begin{array}{l}\text { Florideen an } \\
\text { Stoller Grumd }\end{array}$ & Reines Peridineenplankton, vorwiegend Ceratium, Prorocentron spärliclı \\
\hline $21 .-24$. & 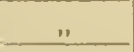 & . & Ziemlich viel Sand und unkenntlicle Masse, sonsı wie bei den vorigen \\
\hline 25.-29. & $\begin{array}{c}25.5 . \\
1900\end{array}$ & " & $\begin{array}{l}\text { Chaetoceros, Sceletonema; sehr viel Synedren; Peridinium und Dinophysis vereinzelt; } \\
\text { Sand und unkenntliche Masse spärlich }\end{array}$ \\
\hline 30. & " & " & fast nur Synedren \\
\hline
\end{tabular}


Das Gleiche war bei den im Herbst und Winter gefangenen Exemplaren der anderen Art der Fall, wenngleich der Darm manchmal auch zum grossen Theil mit Sand und unkenntlicher Masse gefüllt war. Im Darm der sieben im Februar und Mai gefangenen Exemplare fehlten dagegen Peridinecn gänzlich und ihre Stelle vertraten Diatomeen, wie es der nach den Jahreszeiten verschiedenen Zusammensetzung des Planktons entspricht.

\section{Detritusfresser.}

Die von mir untersuchten Detritusfresser sind:

Halicryptus spinulosus v. Sieb.,
Priapulus caudatus Lamarck,
Arenicola marina L.,
Terebellides Stroemii Sars,
Pectinaria belgica Pallas,
Polydora cillata Müller,

Spirorbis nantiloides Lamarck, Amphitrite Johnstonii Malmgren, Flabelligera affinis M. Sars, Nereis diversicolor Müller, Cuma Rathkei Kröyer.

$\mathrm{Zu}$ den Detritusfressern rechne ich diejenigen Thiere, die sich von toten, zu Boden sinkenden oder gesunkenen Stoffen vegetabilischen oder animalischen Ursprungs nähren. Kleine Pflanzenstücke, die zweifellos auch zum Detritus gerechnet werden müssen, habe ich auch im Darm der Muscheln und Ascidicn gefunden; manchmal waren sie sogar in so reichem Masse vorhanden, dass ihnen eine wesentliche Bedeutung als Nahrung für planktonzelırende Thiere nicht abgesprochen werden kanı. Aber während im Darminhalt der von mir als Planktonzehrer bezeichneten Thiere Planktonorganismen prävalirten oder doch wenigstens fast immer in grösserer Menge vorhanden waren, fehlten sie im Darm der hier als Detrituszehrer aufgeführten Thiere gänzlich oder waren nur vereinzelt anzutreffen.

Zunächst seien die beiden in der Kieler Bucht nicht gerade häufig vorkommenden Gephyreen erwähnt').

Von Halicryptus habe ich zehn Excmplare untersucht, von denen vier jedoch keinen Darminhait hatten. Bei den übrigen bestand er aus Sand und unkenntlicher Masse; im Darm eines Exemplars habc ich einige zerbrochene Diatomeen und Spongiennadeln bemerkt.

Halicryptus spinulosus v. Sieb.

\begin{tabular}{|c|c|c|c|c|c|}
\hline Nr. & $\begin{array}{l}\text { Länge } \\
\text { in } \\
\mathrm{mm}\end{array}$ & Fangzeit & Fangort & Darminltalt & Bemerkungen \\
\hline 1. แ. 2. & ? & 22.4. & $\begin{array}{l}\text { Mud im } \\
\text { inneren } \\
\text { Hafen }\end{array}$ & unkenntlicle Masse und Sand & - \\
\hline 3. & 16 & $\begin{array}{l}18.6 . \\
1900\end{array}$ & $\begin{array}{c}\text { Mud } \\
\text { zwischen } \\
\text { Bellevue und } \\
\text { Holtenau } \\
\end{array}$ & $\begin{array}{c}\text { unkentstiche Masse und Sand; einige zerbrochene Diatomeen } \\
\text { und Spongiennadeln }\end{array}$ & - \\
\hline $4 .-7$ & $\begin{array}{l}18 \\
17 \\
11 \\
10\end{array}$ & $"$ & $"$ & Dann leer & $\begin{array}{l}\text { Die Exemplare waren } \\
\text { nicht gleicl getölel } \\
\text { und hatten ilıren Darm- } \\
\text { inlıalt ausgestossen }\end{array}$ \\
\hline 8. -10. & ? & $\begin{array}{l}24.7 \\
1899\end{array}$ & $\begin{array}{c}\text { Mud } \\
\text { bei der } \\
\text { Muschelbank }\end{array}$ & unkenntliclie Masse und Sand; lileine Seegrasstïckchen & - \\
\hline
\end{tabular}

Auch im Darm der sechzehn untersuchten Exemplare von Priapulus waren Sand und unkenutliche Masse vorwiegend. Daneben warcn auch kleine Pflanzenstücke ziemlich zahlteich vorhanden. Von thierischen Resten kamen vor Allem Spongiennadeln und Clsaetopodenborsten in Betracht: in cincm Darm lrahe ich des Störs.

1) In der östlichen Ostsee tritt Haticryptus häufiger auf und bildet dort zusammen mit Idotho'a crutomon die Hauptnalırung 
von letzteren 50 von einer Art gesehen. Bemerkenswerth ist das Fehlen von kleinen Crustaceenresten. Diatomeen und Coniferenpollenkörner habe ich vereinzelt und in spärlicher Menge angetroffen. Frey und Leuckart ${ }^{1}$ ) fanden im Darm von Priapulus "Sandkörnchen und Stücke von Molluskengehäusen“.

Priapulus caudatus Lam.

\begin{tabular}{|c|c|c|c|c|c|}
\hline Nr. & $\begin{array}{c}\text { Länge } \\
\text { in } \\
\text { mm }\end{array}$ & Fangzeit & Fangort & Darminhalt & Bemerkungen \\
\hline 1. & 10 & $\begin{array}{l}18.6 . \\
1900\end{array}$ & $\begin{array}{c}\text { Mud zwischen } \\
\text { Bellevue } \\
\text { und } \\
\text { Holtenau } \\
\end{array}$ & $\begin{array}{l}\text { Sand und unkenntliche Masse vorherrschend; einige grössere } \\
\text { Pflanzenstücke; leere Diatomeenschalen (Grundformen) Spongien- } \\
\text { nadeln; ca. } 50 \text { gleiche Chaetopodenborsten }\end{array}$ & $\begin{array}{l}\text { Der Darm war nur an den } \\
\text { beiden Enden gfilllt }\end{array}$ \\
\hline 2. & 10 & " & " & $\begin{array}{l}\text { Sand und unkenntliche Masse vorherrschend; leere Grund- } \\
\text { diatomeen und Spongiennadeln; grössere Pflanzenstücke fehlen }\end{array}$ & n \\
\hline 3. & 9 & , & $\because$ & wie 2. grössere Pflanzenstücke aber vorhanden & - \\
\hline 4. & 8 & , & " & $\begin{array}{l}\text { Sand, unkenntliche Masse, Spongiennadeln und leere } \\
\text { Diatomeen; vereinzelte Coniferenpollenkörner }\end{array}$ & - \\
\hline 5. u. 6. & 10 & " & $\begin{array}{l}\text { Ulven zw. } \\
\text { Möltenort } \\
\text { und } \\
\text { Heikendorf }\end{array}$ & $\begin{array}{c}\text { Sand und unkenntliche Masse mit vereinzelten organischen } \\
\text { Resten; Ellipsoide massenhaft }\end{array}$ & - \\
\hline 7. & ? & $\begin{array}{l}15.11 \\
1899\end{array}$ & $\begin{array}{c}\text { Mud bei } \\
\text { Friedrichsort }\end{array}$ & $\begin{array}{c}\text { Sand und unkenntliche Masse; grosse Seegrasstücke; } \\
\text { Ellipsoide vorhanden }\end{array}$ & - \\
\hline 8.-13. & ? & 24. 7. & $\begin{array}{c}\text { Mud bei } \\
\text { der } \\
\text { Muschelbank }\end{array}$ & $\begin{array}{c}\text { Sand und unkenntliche Masse; im Darm einiger Exemplare } \\
\text { kleine Seegrasstuickchen }\end{array}$ & - \\
\hline 14. & ? & 11.2. & $\begin{array}{c}\text { Grenze des } \\
\text { lebenden und } \\
\text { toten See- } \\
\text { grases bei } \\
\text { Bellevue } \\
\end{array}$ & $\begin{array}{l}\text { viel Sand und unkenntliche Masse; Grunduiatomeen; Seegrasstücke; } \\
\text { I Pollenkorn. Der Sand zum Theil in recht grossen Körnern }\end{array}$ & - \\
\hline 15. & ? & $\begin{array}{l}15.11 \\
1899\end{array}$ & $\begin{array}{l}\text { Mudzwischen } \\
\text { Friedrichsort } \\
\text { und Boje D } \\
\end{array}$ & $\begin{array}{c}\text { Sand und unkenntliche Masse; kleine Seegrasstücke mit } \\
\text { braunem Zellinhalt }\end{array}$ & - \\
\hline 16. & ? & , & $\begin{array}{c}\text { Seegras und } \\
\text { Florideen } \\
\text { am Strander } \\
\text { Grasberg }\end{array}$ & Sand und unkenntliche Masse; 1 Seegrasstuick & - \\
\hline
\end{tabular}

Obgleich ich im Darm fast aller untersuchten Exemplare kleine Pflanzenstücke gefunden habe, kann ich mich der Ansicht von Ehlers ${ }^{2}$ ), "dass Priapulus Pflanzenfresser ist", nicht anschliessen, denn erstens überwiegen, wie schon oben gesagt, im Detritus pflanzliche Bestandtheile stets, und zweitens darf der Befund von 50 gleichen Chaetopodenborsten in einem Darm nicht übersehen werden; drittens endlich war der Gesammthabitus des Darminhaltes bei Priapulus ein ganz anderer als bei denjenigen Thieren, die ich unter den Pflanzenfressern besprochen habe. Die Zellen der Pflanzenstücke aus dem Darm von Priapulus waren immer entweder leer oder mit stark deformirtem lnlıalt gefüllt, während der Zellinhalt derjenigen Pflanzentheile, die ich im Darm von Pflanzenfressern gefunden habe, oft noch gut erhalten war; auch habe ich im Darm von Pflanzenfressern niemals derartige Mengen von Sand und unkenntlicher Masse gesehen, wie es bei Priapulus der Fall war. Ehlers giebt selbst an, den Mitthcilungen von Rathke und Fabricius folgend, dass der Wurm „sich auf dem sandigen oder thonigen Boden des Meeres Gänge gräbt. In diesen lebt er ruhig, während der Schwanz frei ins Wasser hineinragt". Ueberdies citirt Ehlers die Worte von Phillips, der einen Priapulus drei Wochen

1) H. Frey u. R. Leuckart: Beiträge zur Kenntniss wirbelloser Thiere. Braunschweig 1847.

$\Rightarrow$ Ehlers: Ueber Priapulus. Zeitschr. wiss. Zoologie. Band XI. 
im Aquarium beobachtet hat. "Es wurde nie beobachtet, dass das Thier irgend cinen besonderen Versuch machte, Futter zu sich zu nehmen, obwohl bei der Zufuhr von frischem Seewasser Fäkalmassen aus der an der Basis des Schwanzes licgenden Afteröffnung ausgestossen wurden." Gefressen hat das Thier sicherlich, sonst hätte es keine Fäkalmassen ausstossen können. Das es keinen Versuch gemacht bat, Nahrung zu sich zn nehmen - was doch wohl so zn verstehen ist, dass das Thier die Röhre nicht verlassen hat --, so bleibt nichts übrig, als dass der Wurm die im nungebenden Boden enthaltene organische Substanz gefressen hat. Im Darm einiger Exemplare habe ich die auch von Frey und Leuckart ${ }^{1}$ ), Ehlers ${ }^{3}$ ) und Apel ${ }^{3}$ ) crwähnten Ellipsoide gefunden. Ehlers beschreibt sie als „plattovale, an dem einen Ende meist elwas zugespitzte Körper mit dicker starker Wand; an der einen zugespitzten Stelle scheint die Wand oft durchbrochen zu sein und cinen Eintritt in das Inncre zu gewähren; in diesem lagen, meist zu einem Haufen zusammengeballt, runde, gelbliche, das Liclıt stark brechende Kügelchen, die nur in seltenen Fällen fehlten. Die Grösse des ganzen Körpers betrug 0,0222-0,0296 mm, die Dicke der Wand 0,0018 mm. Die einzelnen Kügelchen hatten cinen Durchmesser von $0,0037 \mathrm{~mm}$.... A Auf Behandlung mit Jod und Schivefelsäure erschieı die für Cellulose charaktcristische dunkelviolette Farbe in ihnen." Ehlers hält diese Ellipsoide für "Sporenzellen von Algen, dic deın Thiere als Nahrung gedient haben". Ich möchte sie mit Rücksicht darauf, dass ich sie, wie auch Apel, auch zwischen den Epithelzellen der Darmwand bemerkt habe, mit Apel für Parasiten ansehen.

Von Arenicola marina habe ich etwa 10 Exemplare aus der Kieler Bucht (Strand bei Bellevuc) und ebensoviel aus dem Wattenmeer an der Elbmündung untersucht. Immer bestand der Darminhalt vorwiegend aus Sandkörnchen, unkenntlicher Masse, kleinen und kleinsten Pflanzenstückchen, zerbrochenen und leeren Diatomeenschalen und kleinen thierischen Resten, wie Crustaceentheilchen, Chaetopodenborsten und Schwammnadeln; hin und wieder habe ich auch kleine Stückchen von Muschel- und Schneckenschalen bemerkt. Marshall schreibt in Brehms Thierleben ${ }^{4}$ ): Gleich den Regenwürmern verschlingt der Sandwurm grosse Mengen des Bodens, in dem er lebt, um damit die zu seiner Ernährung dienende organische Materie in den Magen zu bekommen". Im gleichen Sime spricht sich auch Hcincke ") aus.

Die übrigen von mir untersuchten sedentären Polychaeten Icben zum Theil in oder auf Mudgrund (Terebellides Stroemii, Pectinaria belgica, Polydora ciliata), zum Theil auf oder zwischen Pflanzen (Spirorbis nalliloides. Amphitrite Johnstonii, Flabelligera affinis). Die meisten von ihnen sind durch den Besitz langer Tentakeln ausgezeichnet. Lang ${ }^{6}$ ) schreibt über diese: "Sic sind ... sehr ausdehnbar, selır kontraktil und werden als feine Fäden nach allen Seiten weit ausgestreckt, wo sie die Ungebung sondiren, um Nahrungstheile aufzuspïren, welche erfasst und zum Munde gefülırt werden." Im Aquarium ist die Ernährungsweise besonders gut an Polydora und an den von mir nicht untersuchten Siphonostomum multisetosum zu beobachten.

Was den Darminhalt der von mir untersuchten Arten anbelangt, so bestand dersclbe stets aus unkenntlicher Masse, Sand und kleinsten vegetabilischen und animalischen Resten. Ich habe deswegen von einer tabellarischen Uebersicht Abstand genommen. Vereinzelt habe ich Planktonorganismen, wie Rhizosolenia und Ceratium bemerkt, doch sind dieselben zweifellos in todtem Zustande, also als Bestandtheile des Detritus aufgenommen worden. Polydora ciliata schädigt nach Carazzi ) die Austern in hohem Maasse, indem sie in das lnnere der Schale dringt, wenn diese halb geöffnct ist, 11 sich dort in der Nälse des Randes festzusetzen und viel Schlamm un sich anzuhäıfen.

„Eine rechte Kernfanilie ist die der Nereiden (Nereidea), in welcher der räuberische Charakter, verbunden mit ununterbrochencr Agiliä̆t, Geschwindigkeit und Sichcrheit der Bewegnnngen den höchsten

1) I. c. p. 43 .

2) 1. c. p. 238 .

3) W. Apel: Beiträge zur Anatomie und Histologie von Priapulus caudatus Lan. Inaug.-Diss. Göttingen 1885 , p. 45.

t) I. c. p. 122 .

5) Niedere Thiere I. c. p. 398

b) 1. c. p. 44.

¡) D. Carazzi: Revisione del genere Polydora Bose e cenui su due specie clie vivono sulle oslricle in: Mitt. zool. Stat. Neapel. 11. Band. Referat von H. Eisig. 
Ausdruck gefunden hat." 1) Von dieser Charakteristik möchte ich Nereis diversicolor wenigstens bezüglich der Ernährungsweise ausnehmen. Im Darm der zwanzig untersuchten Exemplare habe ich grössere animalische Bestandtheile nur vereinzelt gefunden, in einem Falle einen Copepoden und einen Nauplius, in einem andern eine kleine Muschel. Im Uebrigen wies die Beschaffenheit des Darminhaltes diesem Wurm einen Platz unter den Detritusfressern an. Im Aquarium lebt Nereis diversicolor meist im

Nereis diversicolor Müller.

\begin{tabular}{|c|c|c|c|c|c|c|c|c|c|c|}
\hline Nr. & $\begin{array}{l}\text { Länge } \\
\text { in } \\
\text { mm }\end{array}$ & $\begin{array}{c}\text { Fang- } \\
\text { zeit }\end{array}$ & Fangort & Diatomeen & $\begin{array}{l}\text { Cyano- } \\
\text { phyceen }\end{array}$ & Gewebspflanzen & Metazoen & \begin{tabular}{|c|} 
Un- \\
kennt- \\
liche \\
Masse
\end{tabular} & Sand & $\begin{array}{l}\text { Bemer- } \\
\text { kungen }\end{array}$ \\
\hline 1. -8 & $\begin{array}{l}\text { durch- } \\
\text { schnittl. } \\
55\end{array}$ & $\begin{array}{l}4.1 . \\
1900\end{array}$ & $\begin{array}{c}\text { Strand } \\
\text { bei } \\
\text { Bellevue }\end{array}$ & $\begin{array}{l}\text { Grundformen } \\
\text { spärlich }\end{array}$ & - & $\begin{array}{c}\text { Seegrasstiicke; } \\
\text { Zellen leer oder mit } \\
\text { braunem Inhalt }\end{array}$ & $\begin{array}{l}\text { vereinzelte Crusta- } \\
\text { ceenreste und Chae- } \\
\text { topodenborsten }\end{array}$ & viel & viel & - \\
\hline 9. & 60 & n & , & - & _. & - & - & viel & - & $\begin{array}{l}\text { Darm } \\
\text { spärlich } \\
\text { gefuillt }\end{array}$ \\
\hline 10. & 60 & $n$ & " & - & - & - & - & - & - & - \\
\hline 11. & 50 & $\begin{array}{l}\text { 10. } 7 . \\
1899\end{array}$ & " & $\begin{array}{c}\text { Grundformen bilden } \\
\text { den grössten Theil } \\
\text { des erkennbaren } \\
\text { Darminhaltes }\end{array}$ & $\begin{array}{l}\text { Merismo- } \\
\text { pedia } \\
\text { ziemlich } \\
\text { viel }\end{array}$ & $\begin{array}{c}\text { Seegrasstücke } \\
\text { ziemlich viel in } \\
\text { verschiedener } \\
\text { Grösse; Algentriebe } \\
\text { ziemlich viel }\end{array}$ & $\begin{array}{l}1 \text { Copepode und } \\
1 \text { Nauplius }\end{array}$ & viel & viel & - \\
\hline 12. น. 13. & ? & " & $n$ & - & - & - & - & - & - & - \\
\hline 14. & ? & n & " & $\begin{array}{l}\text { sehr viel Grund- } \\
\text { formen }\end{array}$ & - & einige Algenfäden & - & viel & wenig & - \\
\hline 15. & 54 & $\begin{array}{l}17.9 . \\
1900\end{array}$ & $\begin{array}{l}\text { Strand } \\
\text { bei } \\
\text { Heiken- } \\
\text { dorf }\end{array}$ & viel Synedren & - & $\begin{array}{c}\text { Pflanzenstïcke } \\
\text { mit braunem Zell- } \\
\text { inhalt }\end{array}$ & 1 kleine Muschel & viel & wenig & - \\
\hline 16. & 35 & n & $n$ & viel Synedren & - & , & $\begin{array}{l}\text { kleine Mytilus- } \\
\text { stückchen }\end{array}$ & viel & viel & - \\
\hline 17. น. 18. & $\begin{array}{l}27 \\
25\end{array}$ & n & $n$ & Synedren vorlı. & - & $\begin{array}{l}\text { kleinste vegeta- } \\
\text { bilische' Reste }\end{array}$ & - & wenig & wenig & $\begin{array}{l}\text { Darm } \\
\text { spärlich } \\
\text { gefüillt }\end{array}$ \\
\hline 19. แ. 20. & $\begin{array}{l}32 \\
24\end{array}$ & " & , & - & 一 & - & - & - & - & - \\
\hline
\end{tabular}

Sande verborgen. Sie besitzt ein gutes Witterungsvermögen: wenn kleine Miesmuschelstückchen in den Behälter geworfen werden, in dem sich Nereiden im Sande vergraben aufhalten, so kommen die Würmer nach kurzer Zeit zum Vorschein, um die Fleischstückchen zu ergreifen und sich mit ihnen in den Sand zurückzuziehen.

Unter den von mir untersuchten Krebsen verdient nur Cuma Rathkei hier der Erwähnung. (Tabelle siehe S. 69). Abgesehen von vereinzelten Planktonorganismen, die wohl unbeabsichtigt aufgenommen worden sein dürften, war auch bei diesem Thier Detritusfrass sicher nachzuweisen.

Ferner seien an dieser Stelle die schon früher besprochenen beiden Muscheln Tellina baltica und Scrobicularia piperata erwähnt.

1) Brehms Thierleben. I. c. p. 118 . 
Cuma Rathkei Kröy.

\begin{tabular}{|c|c|c|c|c|c|}
\hline Nr. & $\begin{array}{l}\text { Länge } \\
\text { in } \\
\text { min }\end{array}$ & Fangzeit & Fangort & Magenintialt & Bemerkungen \\
\hline 1. & ? & $\begin{array}{l}5.6 . \\
1899\end{array}$ & $\begin{array}{c}\text { Mud auf der } \\
\text { Höhe der } \\
\text { Universität }\end{array}$ & $\begin{array}{c}\text { einige Diatomeen, fast alle leer; wenige Crustaceenreste; } \\
\text { Bruchstücke von Scliwammnadeln; viel Sand und unkenntliche } \\
\text { Masse }\end{array}$ & $\begin{array}{l}\text { der umgebende } \\
\text { Mud zeigte die } \\
\text { gleiclie } \\
\text { Zusammensetzung }\end{array}$ \\
\hline $2 .-4$ & ? & $\begin{array}{l}24.7 . \\
1899\end{array}$ & $\begin{array}{c}\text { Mud } \\
\text { zwischen } \\
\text { Friedrichsort } \\
\text { und } \\
\text { Boje D }\end{array}$ & unkenntliche Masse und Sand & - \\
\hline 5. -14 & $\begin{array}{l}\text { durch- } \\
\text { schnitt- } \\
\text { lich } \\
13\end{array}$ & $\begin{array}{c}18.6 . \\
1900\end{array}$ & $\begin{array}{c}\text { Mud auf der } \\
\text { Höhe der } \\
\text { Wiker Bucht }\end{array}$ & $\begin{array}{l}\text { unkenntliche Masse und Sand vorherrschend; Diatomeenschalen, } \\
\text { kleine Crustaceenreste und Spongiennadeln; in einem Darm } \\
\text { Bruchstijcke von Chaetopodenborsten, in einem andern I Coni- } \\
\text { ferenpolienkorn und 1 Tintinnengehäuse, in einem dritten } \\
\text { 1 dornige Cy'ste }\end{array}$ &. \\
\hline $15 .-20$ & ? & $\begin{array}{c}15.11 \\
1899\end{array}$ & $\begin{array}{c}\text { Mud } \\
\text { zwischen } \\
\text { Boje Kiel } 5 \\
\text { und } \\
\text { Friedrichs- } \\
\text { orter } \\
\text { Leuchtthurm }\end{array}$ & unkenntliche Masse und Sand & - \\
\hline 21.--23. & ? & 28. 10 & $\begin{array}{l}\text { Mud bei der } \\
\text { Heulboje }\end{array}$ & $\begin{array}{c}\text { unkenntliche Masse und Sand; vereinzelte Crustaceenreste und } \\
\text { Spongiennadein }\end{array}$ & - \\
\hline $24 .-30$ & ? & $\begin{array}{l}28.10 \\
1899\end{array}$ & $\begin{array}{c}\text { Mud } \\
\text { zwischen } \\
\text { Heulboje } \\
\text { und } \\
\text { Boje Biilk } 1\end{array}$ & $\begin{array}{c}\text { unkenntliche Masse und Sand; im Darm einiger Exemplare } \\
\text { vereinzeit Ceratium tripos }\end{array}$ & - \\
\hline
\end{tabular}

Zum Schluss will ich noch ein Thier, die Ophioglypha albida, (Tabelle siehe S. 70 u. 71) erörtern, über dessen Nahrungsweise ich, obgleich ich 42 Exemplare untersucht labe, im Unklaren bin. Das reichliche Vorkommen von Sand und unkenntlicher Masse, sowie das Auftreten von kleinen pflanzlichen Resten und thierischen Bestandtheilen sprechen dafür, dass Ophoglypha zu den Detritusfressern zu stelleı ist. Auffallend ist aber das häufige Vorhandensein von Planktonorganismen, die zum Theil noch mit lnhalt versehen waren. Ich glaube nicht, dass Ophioglypha zur direkten Aufnalme von Plankton befähigt ist wenigstens gaben Aquariumbcobachtungen keinen Anhalt dafür. Eher möchte ich, in Anbetracht dessen, dass ich im Darm eines Exemplares ein Polychaetenstück und in dem eines andern viele Borsten von Pectinaria gefunden habe, vermuthen, dass der Schlangenstern Planktonzehrer, wie ctwa Cynthia, frisst. 
E. Rauschenplat, Ueber die Nahrung von Thieren aus der Kieler Bucht.

Ophioglypha albida Forb.

\begin{tabular}{|c|c|c|c|c|c|c|c|c|c|c|c|}
\hline Nr. & Fangzeit & Fangort & Diatomees & Peridineen & $\begin{array}{c}\text { Andere } \\
\text { einzellige } \\
\text { Pflanzen }\end{array}$ & Tintinnen & $\begin{array}{l}\text { Gewebs- } \\
\text { pflanzen }\end{array}$ & Metazoen & $\begin{array}{l}\text { Son- } \\
\text { stiges }\end{array}$ & $\begin{array}{l}\text { Un- } \\
\text { kennt- } \\
\text { liche } \\
\text { Masse }\end{array}$ & Sand \\
\hline 1. & $\begin{array}{l}27.11 \\
1899\end{array}$ & $\begin{array}{c}\text { Mud } \\
\text { 2wischen } \\
\text { Strander } \\
\text { Grasberg } \\
\text { und Gasboje }\end{array}$ & - & - & - & - & $\begin{array}{l}\text { Seegras- } \\
\text { stïcke }\end{array}$ & $\begin{array}{l}\text { sehr viel } \\
\text { Borsten von } \\
\text { Terebellides } \\
\text { Stroemii }\end{array}$ & 一 & viel & viel \\
\hline 2. & $"$ & $"$ & mehrere & - & - & - & - & $\begin{array}{c}\text { sehr viel } \\
\text { Crustaceenreste }\end{array}$ & - & vorh. & vorh. \\
\hline 3. & $"$ & ," & $\begin{array}{l}\text { Coscinodiscus und } \\
\text { andere }\end{array}$ & $\begin{array}{l}\text { sehr viel } \\
\text { Ceratien, } \\
\text { Prorocentron; } \\
\text { Dinophysis }\end{array}$ & - & $\begin{array}{l}1 \text { Tin- } \\
\text { tinnus } \\
\text { acumi- } \\
\text { natus }\end{array}$ & $\begin{array}{l}\text { Seegras- } \\
\text { stuicke }\end{array}$ & $\begin{array}{l}\text { Spongien- } \\
\text { nadeln }\end{array}$ & - & viel & viel \\
\hline 4. -9 . & $\begin{array}{l}\text { 6. } 12 . \\
1899\end{array}$ & $\begin{array}{c}\text { Mud bei } \\
\text { der Gasboje }\end{array}$ & - & $\begin{array}{l}\text { Ceratium- } \\
\text { bruchstïcke }\end{array}$ & - & - & - & - & - & $\begin{array}{l}\text { seht } \\
\text { viel }\end{array}$ & viel \\
\hline 10.- -12 & $"$ & ", & - & - & - & - & - & 一 & - & - & - \\
\hline 13. -17 & $\begin{array}{l}\text { 2. } 11 . \\
1899\end{array}$ & $\begin{array}{l}\text { Mud mit } \\
\text { Florideen } \\
\text { zwischen } \\
\text { Heul- und } \\
\text { Glockenboje }\end{array}$ & - & 一 & - & - & 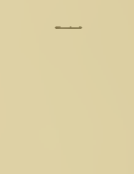 & - & - & - & - \\
\hline 18. & $\begin{array}{l}8.11 . \\
1899\end{array}$ & $\begin{array}{l}\text { Mud vor } \\
\text { dem Stoller } \\
\text { Grund }\end{array}$ & vorhanden & $\begin{array}{l}\text { Ceratium- } \\
\text { bruchstücke }\end{array}$ & - & - & - & $\begin{array}{l}\text { Crustaceen- } \\
\text { reste. } \\
\text { Spongien- } \\
\text { nadeln }\end{array}$ & - & viel & viel \\
\hline 19. & " & " & vorhanden & $"$ & - & $\begin{array}{l}1 \text { Tin- } \\
\text { tinnus } \\
\text { ventri- } \\
\text { cosus }\end{array}$ & - & $"$ & - & " & " \\
\hline 20. & $\begin{array}{l}17.7 . \\
1899\end{array}$ & , & $\begin{array}{l}\text { Grundformen } \\
\text { in geringer Menge }\end{array}$ & - & $\begin{array}{l}\text { Rhizo- } \\
\text { clonium } \\
\text { viel }\end{array}$ & - & - & $\begin{array}{c}1 \text { Copepode; } \\
\text { Crustaceenreste } \\
\text { in grösseren } \\
\text { Stücken }\end{array}$ & - & $\begin{array}{l}\text { sehr } \\
\text { viel }\end{array}$ & $\begin{array}{l}\text { sehr } \\
\text { viel }\end{array}$ \\
\hline 21. & $"$ & $"$ & " & 一 & " & - & - & $\begin{array}{c}1 \text { Halacaride; } \\
\text { Crustaceenreste }\end{array}$ & - & " & , \\
\hline 22. & $"$ & " & $"$ & - & $"$ & - & $\begin{array}{l}\text { Seegras- } \\
\text { stuicke } \\
\text { ohne } \\
\text { Zellinhalt }\end{array}$ & Crustaceenreste & - & " & $"$ \\
\hline 23. & $"$ & , & " & - & - & - & - & $\begin{array}{c}1 \text { Balaniden- } \\
\text { larve. } \\
\text { (cyprisstad.) } \\
1 \text { Ostracode; } \\
\text { grössere } \\
\text { Crustaceenreste }\end{array}$ & - & ; & ", \\
\hline 24. & $"$ & ", & " & - & $\ldots$ & - & $\begin{array}{l}\text { grosse } \\
\text { Seegras- } \\
\text { stïcke }\end{array}$ & $\begin{array}{c}1 \text { Stïck } \\
\text { von einem } \\
\text { Polychaeten }\end{array}$ & - & $"$ & ", \\
\hline 25. & $"$ & " & ", & $\begin{array}{l}\text { Ceratium- } \\
\text { bruchstücke } \\
\text { ziemlich viel }\end{array}$ & - & $\begin{array}{c}\text { mehrere } \\
\text { Tintinnus } \\
\text { ventri- } \\
\text { cosus }\end{array}$ & - & Crustaceenreste & $\begin{array}{l}1 \text { dor- } \\
\text { nige } \\
\text { Cyste }\end{array}$ & " & " \\
\hline
\end{tabular}




\section{Ophioglypha albida Forb. (Fortsetzung.)}

\begin{tabular}{|c|c|c|c|c|c|c|c|c|c|c|c|}
\hline Nr. & Fangzeit & Fangort & Diatomeen & Peridineen & $\begin{array}{c}\text { Andere } \\
\text { einzellige } \\
\text { Pllanzen }\end{array}$ & Tintinnen & $\begin{array}{l}\text { Gewebs- } \\
\text { pflanzen }\end{array}$ & Metazoen & $\begin{array}{l}\text { Son- } \\
\text { stiges }\end{array}$ & $\begin{array}{l}\text { Un- } \\
\text { kennl- } \\
\text { liche } \\
\text { Masse }\end{array}$ & Sand \\
\hline 26. & $\begin{array}{c}28.10 . \\
1899\end{array}$ & $\begin{array}{l}\text { Mud } \\
\text { zwisclien } \\
\text { Heulboje und } \\
\text { Boje Bülk A }\end{array}$ & $\begin{array}{c}\text { sehr viel; } \\
\text { Rhizosolenia, } \\
\text { Sceletonema, Melo- } \\
\text { sira, Coscinodiscus; } \\
\text { Rhoícosphenia, } \\
\text { Grammatophora } \\
\text { und andere }\end{array}$ & - & - & - & $\begin{array}{l}\text { cinige } \\
\text { Seegras- } \\
\text { stiickclien }\end{array}$ & $\begin{array}{l}\text { einige } \\
\text { Spongien- } \\
\text { nadeln }\end{array}$ & - & viel & viel \\
\hline 27. & $"$ & $"$ & $\begin{array}{l}\text { Melosira, Navicula- } \\
\text { ceen, Synedren, } \\
\text { Coscinodiscus und } \\
\text { andere; alle leer }\end{array}$ & $\begin{array}{l}\text { einige Proso- } \\
\text { centron und } \\
\text { Dinophysis } \\
\text { z. Th. gefiillt }\end{array}$ & - & $\begin{array}{l}1 \text { Tin- } \\
\text { tinnus } \\
\text { ventri- } \\
\text { costis }\end{array}$ & $\begin{array}{l}1 \text { Algen- } \\
\text { faden }\end{array}$ & . & - & ", & $"$ \\
\hline 28. & $"$ & $"$ & $"$ & - & - & - & - & 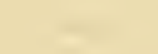 & - & ", & $"$ \\
\hline 29. & $"$ & " & $\begin{array}{c}\text { ziemlich viel } \\
\text { Rhizosolenia, sonst } \\
\text { wie die vorigen. } \\
\text { Sceletonema } \\
\text { vereinzelt }\end{array}$ & $\begin{array}{l}\text { I Ceratiun } \\
\text { furca }\end{array}$ & - & - & - & - & - & " & " \\
\hline 30. & $"$ & " & $\begin{array}{l}\text { Chaetoceros und } \\
\text { Rlizosolenia } \\
\text { vereinzelt. } \\
\text { Coscinodiscus und } \\
\text { Melosira. }\end{array}$ & $\begin{array}{c}\text { Dinophysis } \\
\text { vereinzelt }\end{array}$ & - & - & $\begin{array}{l}\text { grosse } \\
\text { Seegras- } \\
\text { und } \\
\text { Algen- } \\
\text { stücke }\end{array}$ & - & - & ", & " \\
\hline 31. & ", & ., & - & - & - & - & - & - & - & $\begin{array}{l}\text { selir } \\
\text { viel }\end{array}$ & $\begin{array}{l}\text { sehr } \\
\text { viel }\end{array}$ \\
\hline $32-37$ & $\begin{array}{l}21.2 . \\
1900\end{array}$ & Boje Kiel 2 & - & - & - & - & $=$ & - & - & - & - \\
\hline $38 .-42$. & , & ", & $\begin{array}{c}\text { vereinzelt. } \\
\text { Coscinodiscus, } \\
\text { Melosira, Synedren } \\
\text { und andere }\end{array}$ & - & - & - & $\begin{array}{c}\text { vereinzelt } \\
\text { kleine } \\
\text { Stiicke }\end{array}$ & $\begin{array}{c}\text { Spongien- } \\
\text { nadeln }\end{array}$ & - & viel & viel \\
\hline
\end{tabular}





\section{Thesen.}

Die Diatoneen besitzen grosse Bedeutung als Thiernahrung.

Das Plankton des Meeres ist in Gebieten mit gleichartigen Lebensbedingungen recht gleichmässig vertheilt.

Von den Methoden zur Bestimmung der Nahrung von Meeresthieren ist die der Darmuntersuchungen die exakteste. 



\section{Lebenslauf.}

Ich Ernst August Ranschenplat bin am 2. August 1877 als Sohn des Buchdruckereibesitzers Georg Rauschenplat und seiner Ehefrau Marie geb. Fitter in Cuxhaven geboren. Nachdem ich die staatliche Realschule daselbst besucht und an dieser Anstait mein Einjährigen-Examen bestanden hatte, irat ich in das Realgymnasium des Johanneums zu Hamburg ein, und absolvirte Michaelis 1896 die Maturitätsprüfung. Darauf studirte ich vier Semester in Jena und fünf Semester in Kiel Naturwissenschaften und speciell Zoologie.

Meine Lehrer waren die Herren Professoren und Privatdozenten Auerbach, Brandt, Detmer, Deussen, Haeckel, Knorr, Kükenthal, Lehmann, Lohmann, Martius, Reinke, Schaefier, Vauhöfen, Walther, Winkelmann. Allen meineu Lehrern sage ich an dieser Stelle aufrichtigen Dank.

Ein besonders lebhaftes Bedürtniss ist es mir, Herrn Professor Brandt für die Hülfe bei meiner Arbeit und für das rege Interesse an meinen Untersuchungen verbindlichst zu danken. Zu grossem Danke bin ich ferner den Herren Drs. Apstein, Lohmann und Vanhöffen verpflichtet, die mir werthrolle Anregungen und Fingerzeige in Betreff meiner Arbeit gegeben haben. 


